\title{
Assessment and Recommendations for Fissile-Material Packaging Exemptions and General Licenses Within 10 CFR Part 71
}

Manuscript Completed: June 1998

Date Published: July 1998

Prepared by

C.V. Parks, C. M. Hopper, J. L. Lichtenwalter

Oak Ridge National Laboratory

Managed by Lockheed Martin Energy Research Corp.

Oak Ridge, TN 37831-6370

P.G. Brochman, NRC Project Manager

Spent Fuel Project Office

Office of Nuclear Material Safety and Safeguards U.S. Nuclear Regulatory Commission DISTRIBUTION OF THS DOCUMENT IS UMLIMTED Washington, DC 20555-0001.

NRC Job Code B0009

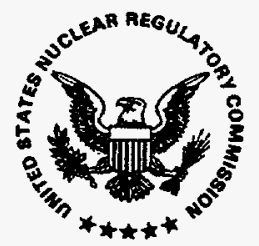




\section{DISCLAMMER}

This report was prepared as an account of work sponsored by an agency of the United States Government. Neither the United States Government nor any agency thereof, nor any of their employees, makes any warranty, express or implied, or assumes any legal liability or responsibility for the accuracy, completeness, or usefulness of any information, apparatus, product, or process disclosed, or represents that its use would not infringe privately owned rights. Reference herein to any specific commercial product, process, or service by trade name, trademark, manufacturer, or otherwise does not necessarily constitute or imply its endorsement, recommendation, or favoring by the United States Government or any agency thereof. The views and opinions of authors expressed herein do not necessarily state or reflect those of the United States Government or any agency thereof. 


\section{DISCLAIMER}

Portions of this document may be illegible in electronic image products. Images are produced from the best available original document. 


\begin{abstract}
This report provides a technical and regulatory assessment of the fissile-material general licenses and fissile-material exemptions within Title 10 of the Code of Federal Regulations Part 71. This assessment included literature studies and calculational analyses to evaluate the technical criteria; review of current industry practice and concerns; and a detailed evaluation of the regulatory text for clarity, consistency and relevance. Recommendations for potential consideration by the Nuclear Regulatory Commission staff are provided. The recommendations call for a simplification and consolidation of the general licenses and a change in the technical criteria for the fissile-material exemptions.
\end{abstract}




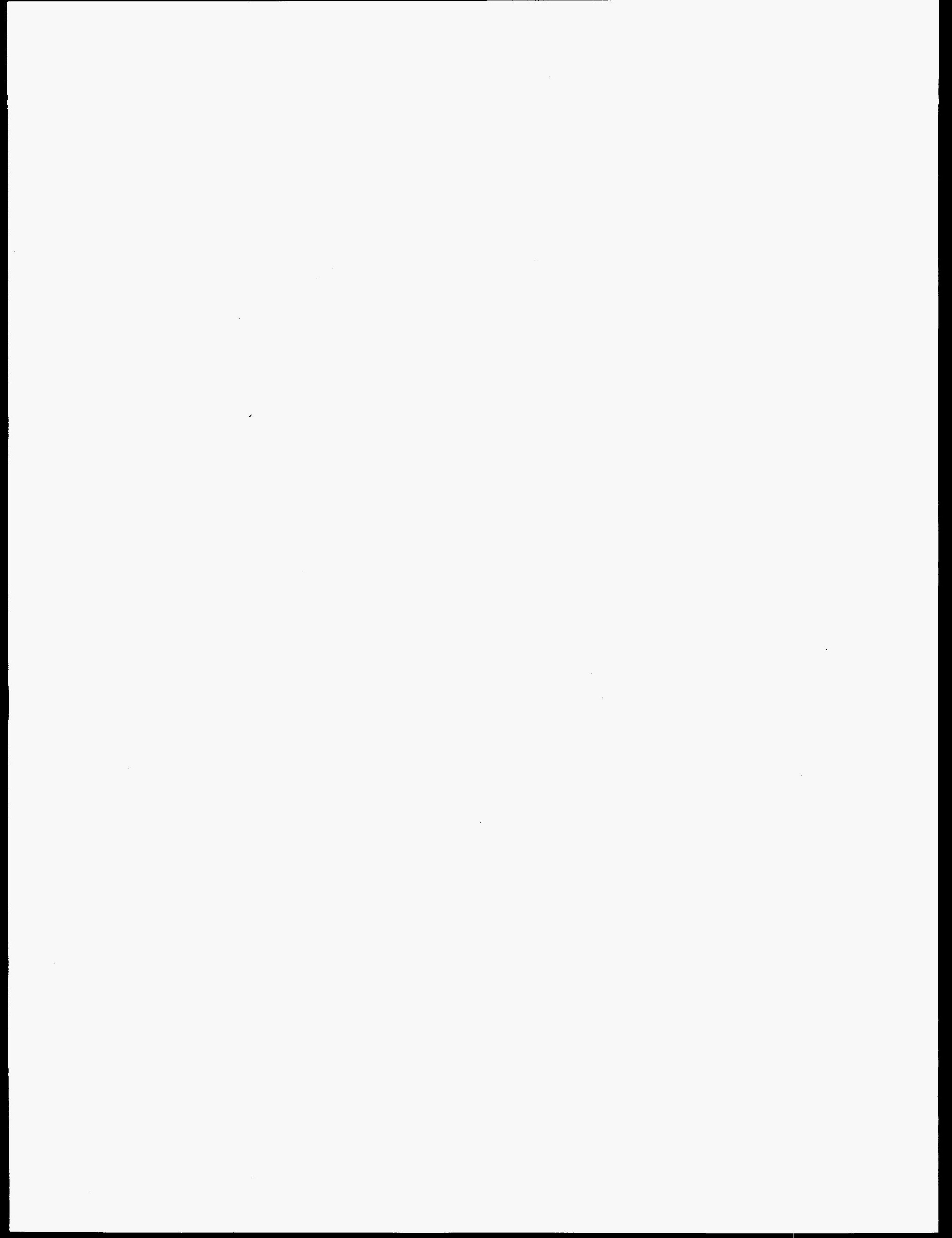




\section{CONTENTS}

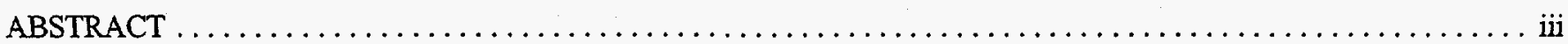

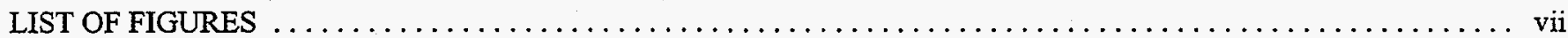

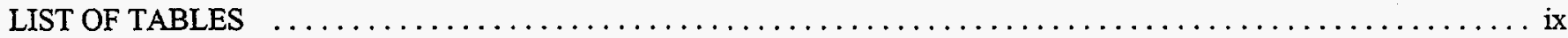

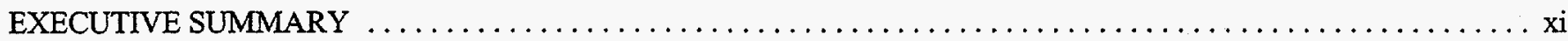

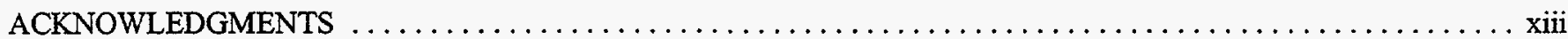

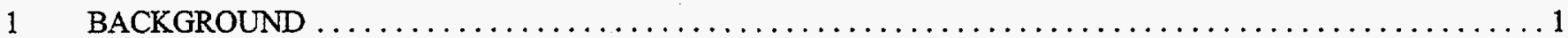

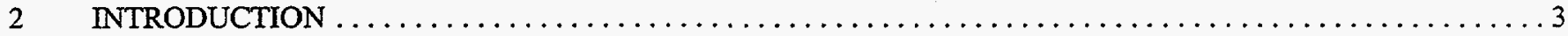

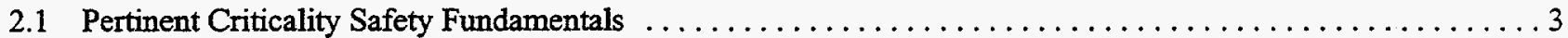

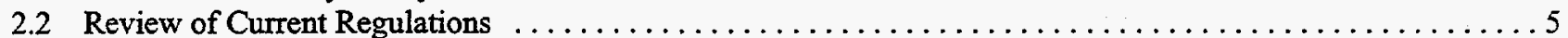

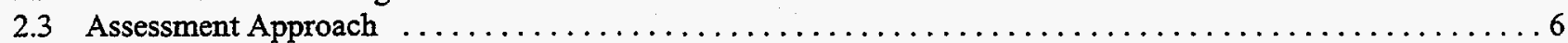

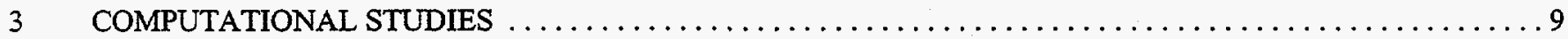

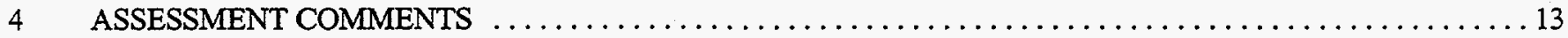

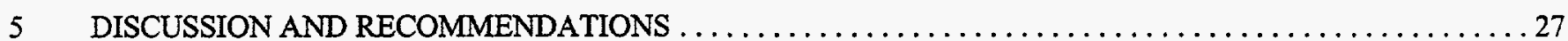

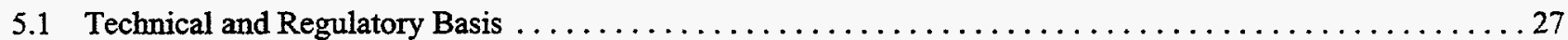

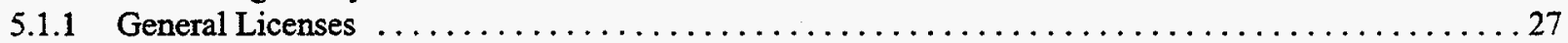

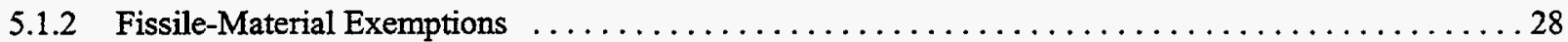

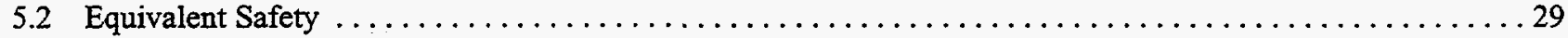

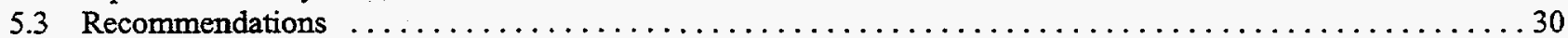

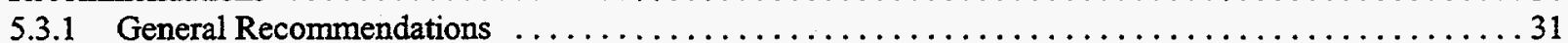

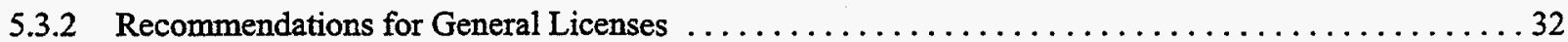

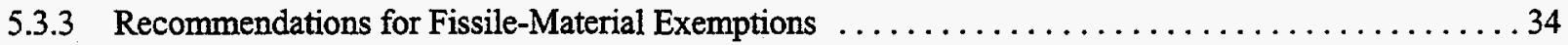

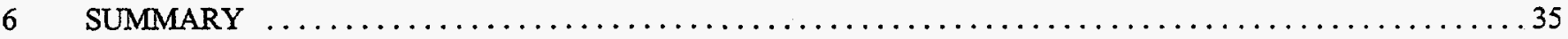

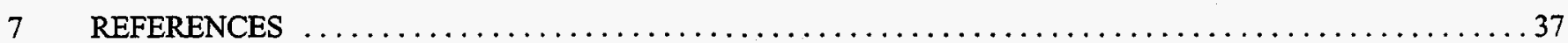

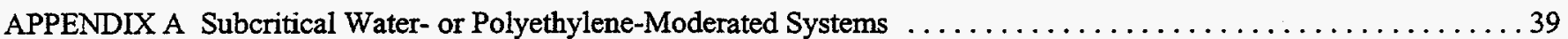

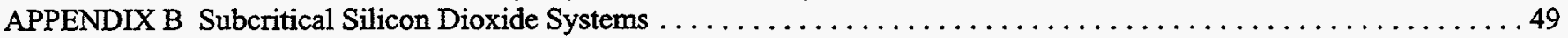

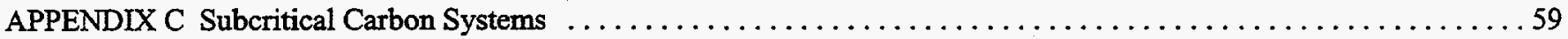

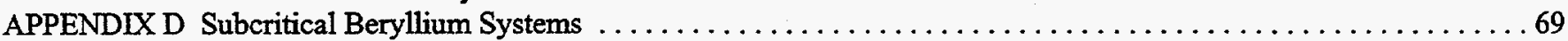

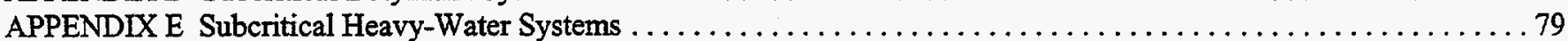

APPENDIX F Discussion of Radioactivity Exemption Limit of $70 \mathrm{~Bq} / \mathrm{g}(0.002 \mu \mathrm{Ci} / \mathrm{g})$

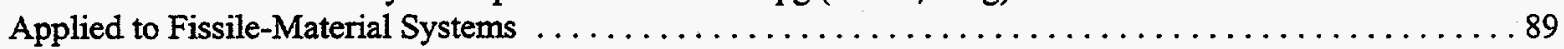

APPENDIX G Recommended New Criteria for Fissile-Material Exemptions $\ldots \ldots \ldots \ldots \ldots \ldots \ldots \ldots \ldots \ldots \ldots . \ldots \ldots$

G.1 Exemption for Packages with Small Fissile-Material Mass $\ldots \ldots \ldots \ldots \ldots \ldots \ldots \ldots \ldots \ldots \ldots 97$

G.2 Exemption for Packages not Meeting Standards for NCT $\ldots \ldots \ldots \ldots \ldots \ldots \ldots \ldots \ldots \ldots \ldots$

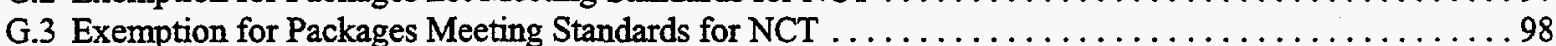




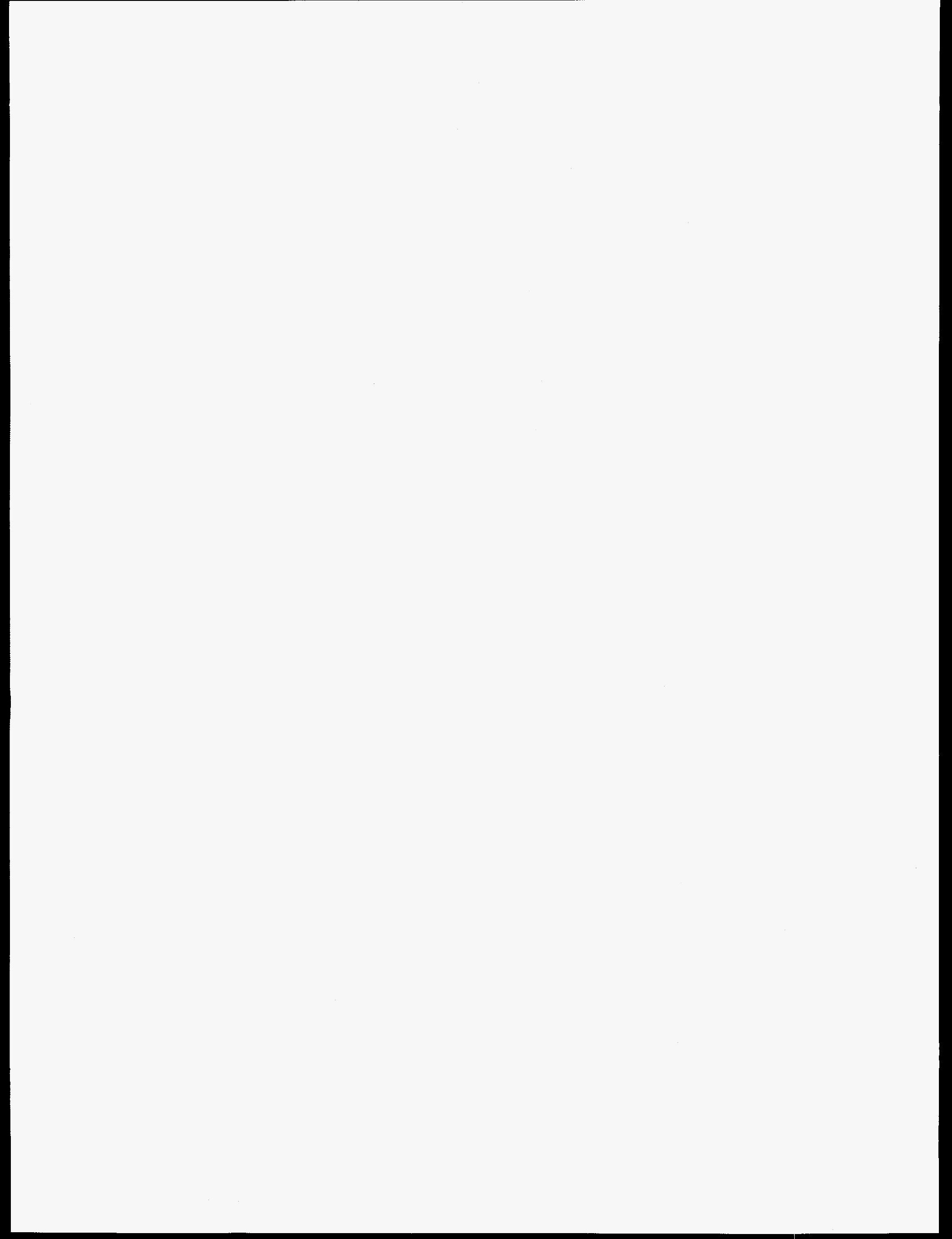




\section{LIST OF FIGURES}

Figure

Page

4-1 Minimum spherical critical masses (from Figure 22 of Ref. 17) as functions of ${ }^{235} \mathrm{U}$ enrichment

in homogeneous and heterogeneous hydrogen-moderated systems.

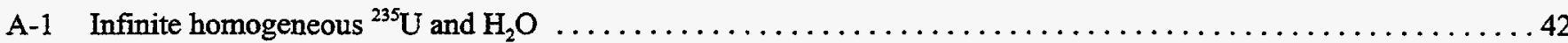

A-2 Water-reflected, five-vehicle volume of homogeneous ${ }^{235} \mathrm{U}$ and $\mathrm{H}_{2} \mathrm{O} \ldots \ldots \ldots \ldots \ldots \ldots \ldots \ldots \ldots \ldots \ldots \ldots$

A-3 Water-reflected, five-vehicle volume of homogeneous ${ }^{235} \mathrm{U}$ and $\mathrm{H}_{2} \mathrm{O} ; \mathrm{k}_{\text {eff }} \sim 0.93 \ldots \ldots \ldots \ldots \ldots \ldots \ldots \ldots$

A-4 Water-reflected, five-vehicle volume of homogeneous ${ }^{235} \mathrm{U}$ and $\mathrm{H}_{2} \mathrm{O} ;{ }^{235} \mathrm{U}$ concentration

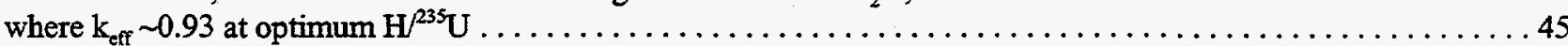

A-5 Critical masses of water-reflected, homogeneous ${ }^{235} \mathrm{U}$ and $\mathrm{H}_{2} \mathrm{O}$ spheres; $\mathrm{k}_{\text {eff }} \sim 0.95 \ldots \ldots \ldots \ldots \ldots \ldots \ldots \ldots$

A-6 Fissile masses and densities of water-reflected ${ }^{239} \mathrm{Pu}$ and $\mathrm{H}_{2} \mathrm{O}$ spheres; $\mathrm{k}_{\text {eff }} \approx 0.95 \ldots \ldots \ldots \ldots \ldots \ldots \ldots$

A-7 Fissile masses and densities of water-reflected ${ }^{233} \mathrm{U}$ and $\mathrm{H}_{2} \mathrm{O}$ spheres; $\mathrm{k}_{\mathrm{eff}} \approx 0.95 \ldots \ldots \ldots \ldots \ldots \ldots \ldots$

A-8 Critical masses of water-reflected, homogeneous ${ }^{235} \mathrm{U}$ and polyethylene spheres; $\mathrm{k}_{\text {eff }} \sim 1.00 \ldots \ldots \ldots \ldots \ldots 48$

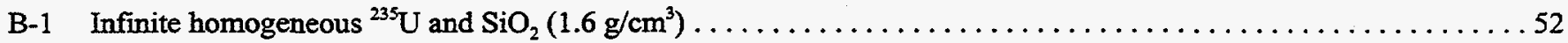

B-2 Water-reflected, five-vehicle volume of homogeneous ${ }^{235} \mathrm{U}, \mathrm{SiO}_{2}\left(1.6 \mathrm{~g} / \mathrm{cm}^{3}\right)$, and $\mathrm{H}_{2} \mathrm{O} \ldots \ldots \ldots \ldots \ldots \ldots 53$

B-3 Water-reflected, five-vehicle volume of homogeneous ${ }^{235} \mathrm{U}, \mathrm{SiO}_{2}\left(1.6 \mathrm{~g} / \mathrm{cm}^{3}\right)$, and $\mathrm{H}_{2} \mathrm{O} ; \mathrm{k}_{\text {eff }} \sim 0.93 \ldots \ldots \ldots 5$

B-4 Water-reflected, five-vehicle volume of homogeneous ${ }^{235} \mathrm{U}$, $\mathrm{SiO}_{2}$, and $\mathrm{H}_{2} \mathrm{O}$;

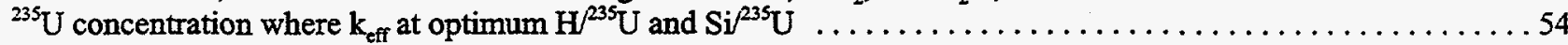

B-5 Critical masses of water-reflected, homogeneous ${ }^{235} \mathrm{U}$ and $\mathrm{SiO}_{2}\left(1.6 \mathrm{~g} / \mathrm{cm}^{3}\right)$ spheres; $\mathrm{k}_{\text {eff }} \sim 0.95 \ldots \ldots \ldots \ldots$

B-6 Fissile masses and densities of water-reflected ${ }^{239} \mathrm{Pu}$ and $\mathrm{Si}$ spheres; $\mathrm{k}_{\mathrm{eff}} \approx 0.95 \ldots \ldots \ldots \ldots \ldots \ldots \ldots \ldots$

B-7 Fissile masses and densities of water-reflected ${ }^{233} \mathrm{U}$ and $\mathrm{Si}$ spheres; $\mathrm{k}_{\mathrm{eff}} \approx 0.95 \ldots \ldots \ldots \ldots \ldots \ldots \ldots \ldots$

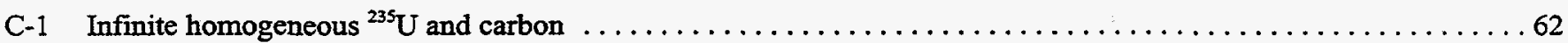

C-2 Water-reflected, five-vehicle volume of homogeneous ${ }^{235} \mathrm{U}$, carbon $\left(1.26 \mathrm{~g} / \mathrm{cm}^{3}\right)$, and $\mathrm{H}_{2} \mathrm{O} \ldots \ldots \ldots \ldots \ldots$

C-3 Water-reflected, five-vehicle volume of homogeneous ${ }^{235} \mathrm{U}$, carbon $\left(1.26 \mathrm{~g} / \mathrm{cm}^{3}\right)$,

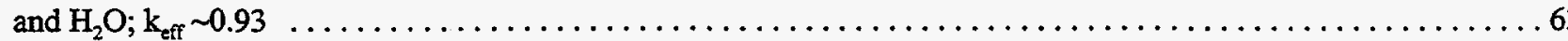

C-4 Water-reflected, five-vehicle volume of homogeneous ${ }^{235} \mathrm{U}$, carbon, and $\mathrm{H}_{2} \mathrm{O}$;

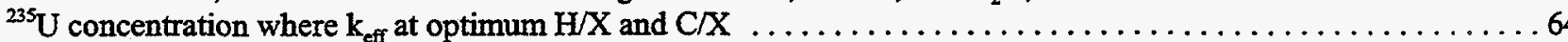

C-5 Critical masses of water-reflected, homogeneous ${ }^{235} \mathrm{U}$ and carbon $\left(1.26 \mathrm{~g} / \mathrm{cm}^{3}\right)$ spheres;

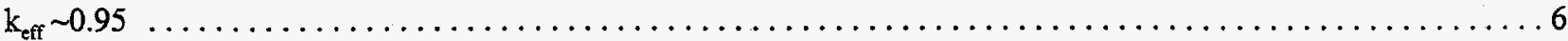


C-6 Fissile masses and densities of water-reflected ${ }^{239} \mathrm{Pu}$ and $\mathrm{C}$ spheres; $\mathrm{k}_{\mathrm{eff}} \approx 0.95 \ldots \ldots \ldots \ldots \ldots \ldots \ldots \ldots \ldots \ldots$

C-7 Fissile masses and densities of water-reflected ${ }^{233} \mathrm{U}$ and $\mathrm{C}$ spheres; $\mathrm{k}_{\mathrm{eff}} \approx 0.95 \ldots \ldots \ldots \ldots \ldots \ldots \ldots \ldots \ldots \ldots \ldots \ldots \ldots$

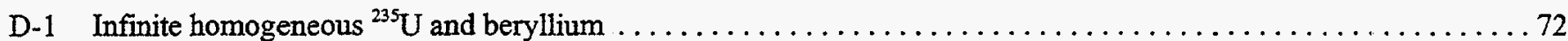

D-2 Water-reflected, five-vehicle volume of homogeneous ${ }^{235} \mathrm{U}$, beryllium $\left(1.11 \mathrm{~g} / \mathrm{cm}^{3}\right)$, and $\mathrm{H}_{2} \mathrm{O} \ldots \ldots \ldots \ldots 73$

D-3 Water-reflected, five-vehicle volume of homogeneous ${ }^{235} \mathrm{U}$, beryllium $\left(1.11 \mathrm{~g} / \mathrm{cm}^{3}\right)$, and $\mathrm{H}_{2} \mathrm{O}$;

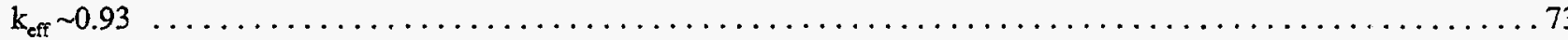

D-4 Water-reflected, five-vehicle volume of homogeneous ${ }^{235} \mathrm{U}$, beryllium, and $\mathrm{H}_{2} \mathrm{O}$;

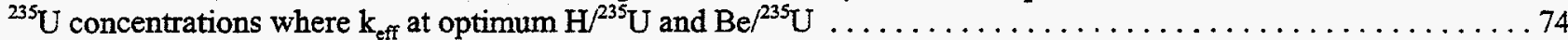

D-5 Critical masses of water-reflected, homogeneous ${ }^{235} \mathrm{U}$ and beryllium $\left(1.11 \mathrm{~g} / \mathrm{cm}^{3}\right)$ spheres;

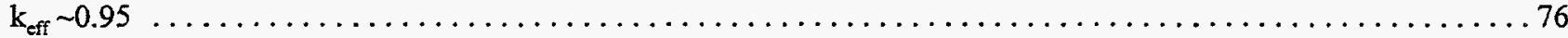

D-6 Fissile masses and densities of water-reflected ${ }^{239} \mathrm{Pu}$ and $\mathrm{Be}$ spheres; $\mathrm{k}_{\mathrm{eff}} \approx 0.95 \ldots \ldots \ldots \ldots \ldots \ldots \ldots 77$

D-7 Fissile masses and densities of water-reflected ${ }^{233} \mathrm{U}$ and Be spheres; $\mathrm{k}_{\mathrm{eff}} \approx 0.95 \ldots \ldots \ldots \ldots \ldots \ldots \ldots \ldots 77$

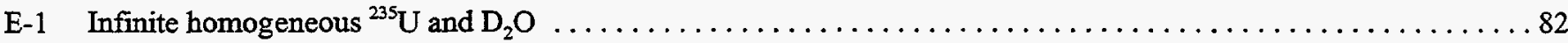

E-2 Water-reflected, five-vehicle volume of homogeneous ${ }^{235} \mathrm{U}, \mathrm{D}_{2} \mathrm{O}\left(0.6632 \mathrm{~g} / \mathrm{cm}^{3}\right)$, and $\mathrm{H}_{2} \mathrm{O} \ldots \ldots \ldots \ldots . \ldots 3$

E-3 Water-reflected, five-vehicle volume of homogeneous ${ }^{235} \mathrm{U}, \mathrm{D}_{2} \mathrm{O}\left(0.6632 \mathrm{~g} / \mathrm{cm}^{3}\right)$, and $\mathrm{H}_{2} \mathrm{O}$;

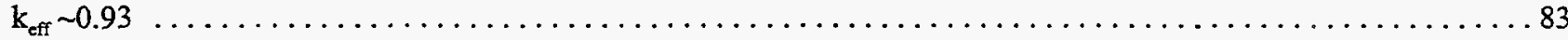

E-4 Water-reflected, five-vehicle volume of homogeneous ${ }^{235} \mathrm{U}, \mathrm{D}_{2} \mathrm{O}$, and $\mathrm{H}_{2} \mathrm{O}$;

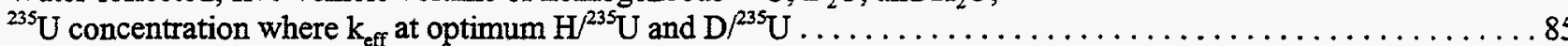

E-5 Critical masses of water-reflected, homogeneous ${ }^{235} \mathrm{U}$ and $\mathrm{D}_{2} \mathrm{O}\left(0.6632 \mathrm{~g} / \mathrm{cm}^{3}\right)$ spheres;

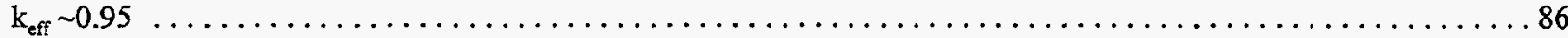

E-6 Fissile masses and densities of water-reflected ${ }^{239} \mathrm{Pu}$ and $\mathrm{D}_{2} \mathrm{O}$ spheres; $\mathrm{k}_{\text {eff }} \approx 0.95 \ldots \ldots \ldots \ldots \ldots \ldots \ldots$

E-7 Fissile masses and densities of water-reflected ${ }^{233} \mathrm{U}$ and $\mathrm{D}_{2} \mathrm{O}$ spheres; $\mathrm{k}_{\text {eff }} \approx 0.95 \ldots \ldots \ldots \ldots \ldots \ldots \ldots$

F-1 Critical masses of unreflected spheres of $\mathrm{U}(93)$ diluted with various moderators $\ldots \ldots \ldots \ldots \ldots \ldots \ldots . \ldots 9$ 


\section{LIST OF TABLES}

Table

3-1 Critical and subcritical minimum mass values calculated for selected moderators

5-1 Comparison of allowable limits and requirements for shipment of ${ }^{235} U$ under the general

licenses or fissile exemptions

5-2 Mass limits for general-license packages containing mixed quantities of fissile material

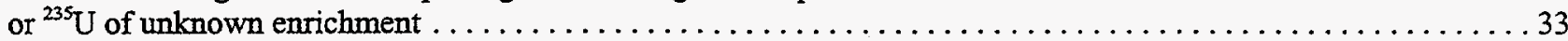

5-3 Mass limits for general-license packages containing ${ }^{235} \mathrm{U}$ of known enrichment $\ldots \ldots \ldots \ldots \ldots \ldots \ldots \ldots \ldots \ldots \ldots$

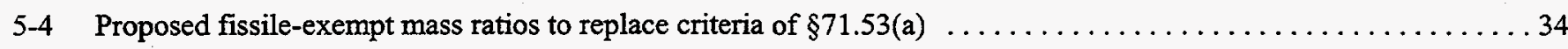

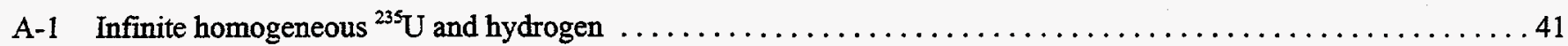

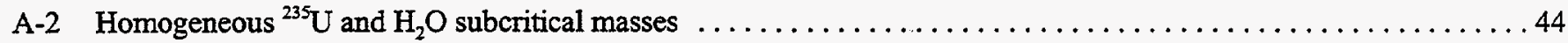

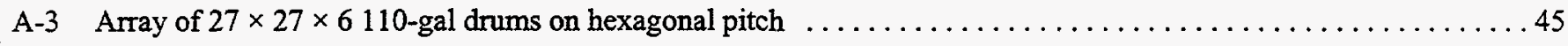

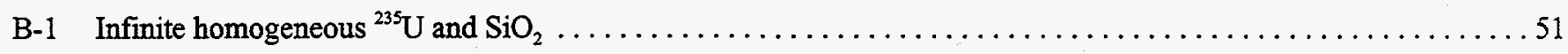

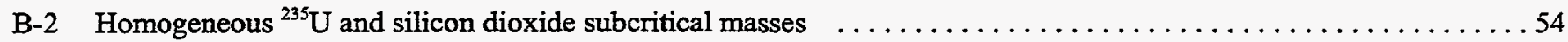

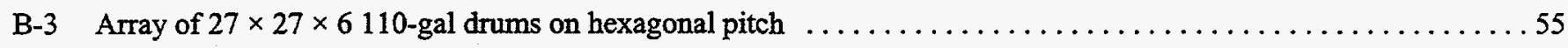

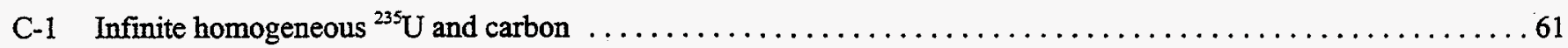

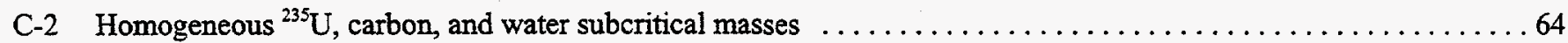

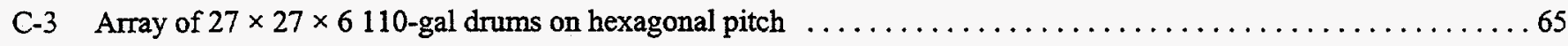

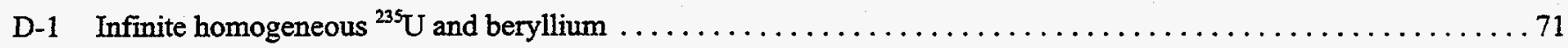

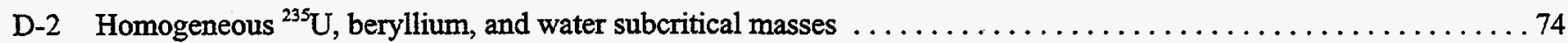

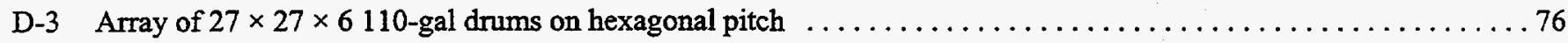

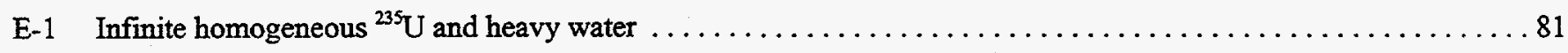

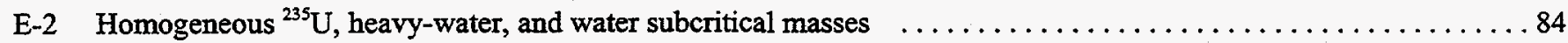

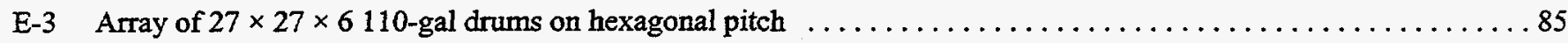

F-1 Critical data for $U(93)$ in various materials, assuming limit of $70 \mathrm{~Bq} / \mathrm{g}$ radioactivity

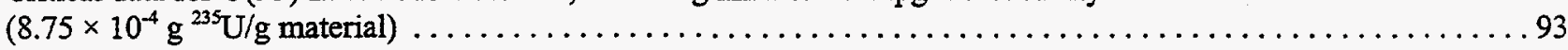




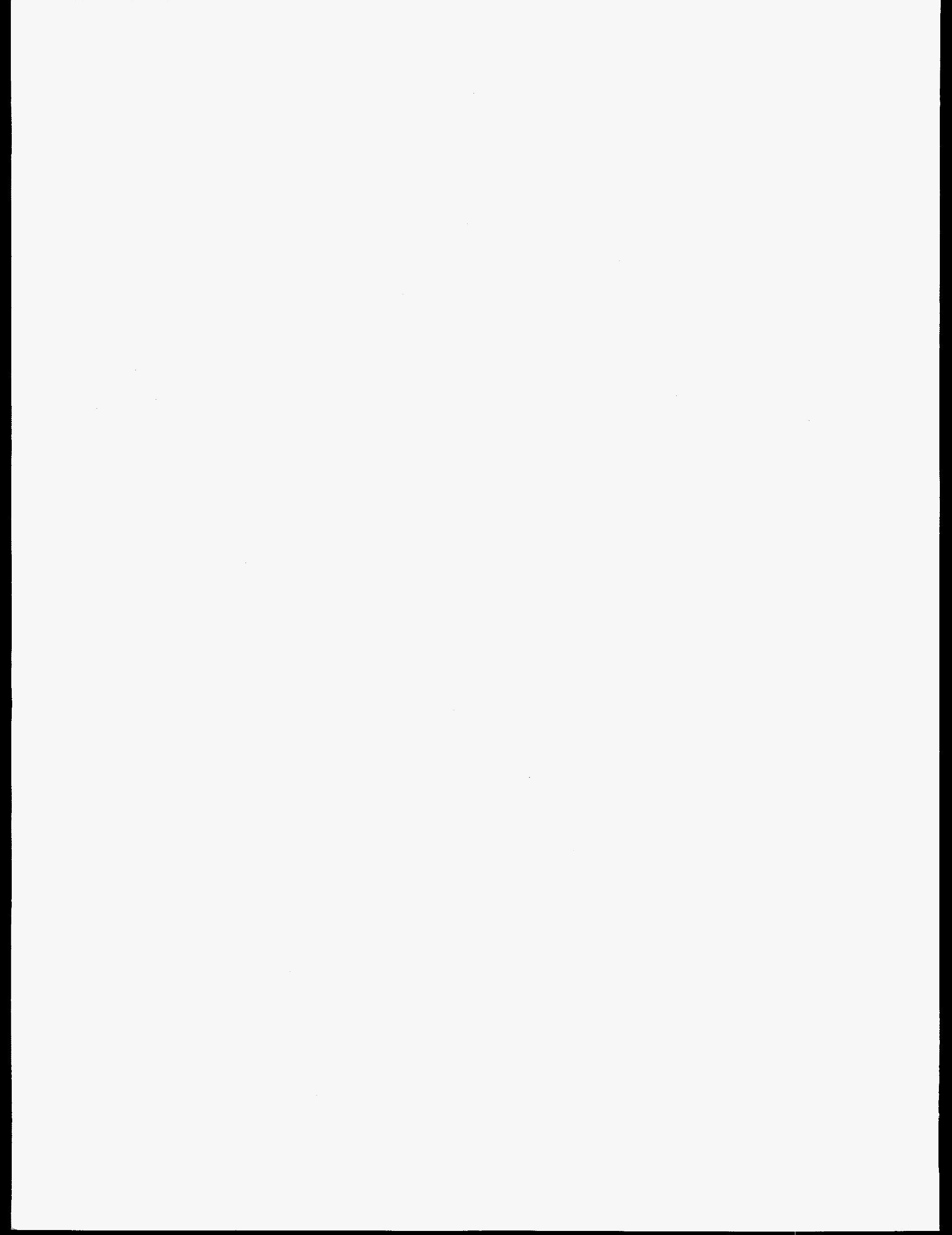




\section{EXECUTIVE SUMMARY}

The U.S. regulations for transport of fissile material are contained within Title 10 of the Code of Federal Regulations, Part 71 (10 CFR 71). Included within 10 CFR 71 are general licenses for fissile-material shipments and criteria that allow exemptions from classification as a fissile-material package. These sections of 10 CFR 71 have recently been modified via emergency rule making to address potential criticality safety concerns. This study was undertaken to review the current regulations, to assess and document their adequacy relative to the technical basis for ensuring criticality safety, and finally, to evaluate the need for additional rule making. The regulations were also reviewed to ensure that regulatory implementation of the technical criteria was clear and concise to preclude misapplication by a licensee. Public comments provided on the recent modifications were reviewed and considered, as were discussions with licensees relative to the impact of the recent modifications.

The study concludes that the general licenses are in need of an update, not so much for the correction of a safety deficiency, but to provide a simpler and more straightforward interpretation of the criteria consistent with other portions of 10 CFR 71 (e.g., the general licenses have some holdover criteria more consistent with Fissile Class III shipments than with sole use of the transport index (TI) to control the accumulation of packages). A concern with a lack of clear packaging integrity was addressed by recommending that the packaging standards of $\$ 71.43$ be incorporated into the general license requirements. This change also provides a solid basis for raising the mass limits allowed in the shipments while still ensuring that a neutron multiplication factor $\left(k_{\text {eff }}\right)$ less than 0.95 was maintained under normal conditions of transport (NCT) and hypothetical accident conditions (HAC) consistent with the requirements for certifying fissile material packages per $\$ \S 71.55$ and 71.59 . With a TI for criticality control limiting the package shipments to fissile-material masses that would provide a $\mathrm{k}_{\text {eff }}<0.95$ for water-reflected systems, the current restriction on select moderating materials can be relaxed to eliminate their accumulation as an effective reflector. Specific recommendations for implementing a consolidation of the general licenses and providing revised criteria are developed and provided.

An assessment of the fissile-material exemptions under $\$ 71.53$ also provided some recommendations for improvement. Although the current exemptions use critical-safe parameters based on water-moderated, water-reflected systems, there is no provision to ensure that these parameter values can be maintained under all situations that could be encountered during NCT and HAC. To remedy this historical situation, the latest modification to $10 \mathrm{CFR} 71$ added a control on accumulation of mass by limiting consignment mass; however, industry practice in the United States has been to routinely combine fissile-exempt consignments on one conveyance, thus somewhat negating the consignment control on mass. To address these concerns and the industry concerns relative to restriction on select moderators and limited mass per conveyance, the recommendations in this report are based on a new approach. The new approach specifies a fissile-mass-to-nonfissile mass ratio, together with a package mass limit and selected minimum package standards (integrity during NCT). This approach relaxes the current restriction on select moderators and, it precludes the use of a TI.

Recommendations are also made to add certain definitions (consignment, consignor, shipper) and to clarify the radioactive material exemptions of $\$ 71.10$ as they affect transport of fissile material. 


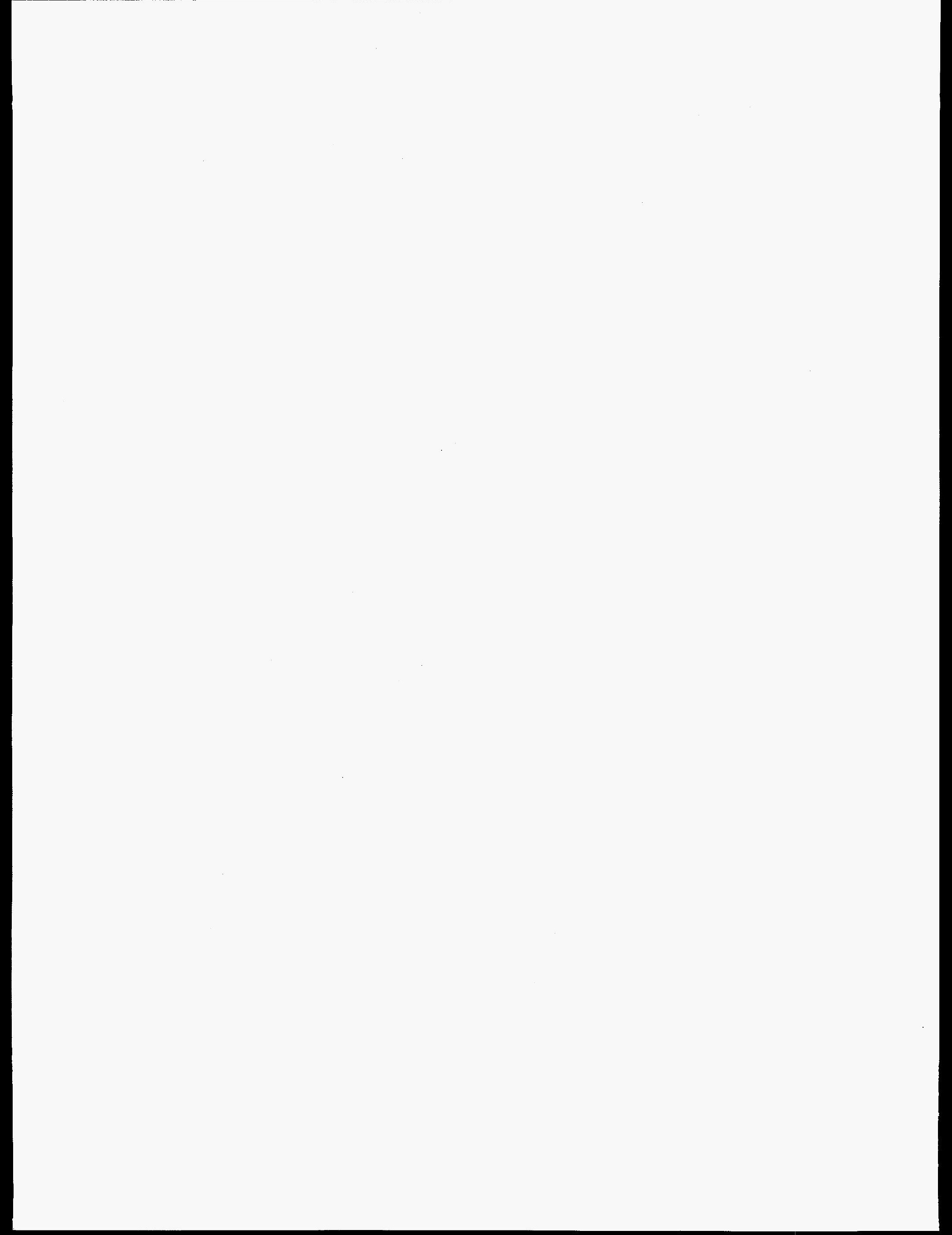




\section{ACKNOWLEDGMENTS}

The authors would like to acknowledge the work of Brad Rearden of ORNL who performed the calculations for subcritical mass values of ${ }^{233} \mathrm{U}$ and ${ }^{239} \mathrm{Pu}$. This report was benefited from the direction and review provided by $P$. G. Brochman of the NRC. The technical reviews of R. M. Westfall and H. R. Dyer of ORNL are also appreciated. The authors are also very appreciative of efforts of C. H. Shappert who performed a timely and efficient final edit of the report. Finally, the excellence and patience with which W. C. Carter prepared this manuscript made the authors' job all that much easier. 


\section{BACKGROUND}

For decades, fissile-material exemptions and general licenses for packaging and transportation of radioactive material have been specified by the U.S. Nuclear Regulatory Commission (NRC) and promulgated as Title 10 of the Code of Federal Regulations, Part 71 (10 CFR 71), Subparts B, C and E. These fissile-material exemptions (cf. §71.53) and general licenses $(\S \S 71.18,71.20 .71 .22$, and 71.24$)$ have changed very little since their initial specification, which was predicated upon available knowledge and historic practice. The available knowledge and historic practice indicated that there needed to be little or no regulatory oversight of the packaging and/or shipments of fissile material that met the criteria of the cited sections. Thus, as packaging and shipment controls in other portions of 10 CFR 71 were changing, there was no ready mechanism, and little incentive, to identify the need for changes in the fissile-material exemptions and general licenses. However, scrutiny of the fissile-material exemptions and general licenses have increased in recent years as practical situations have arisen to challenge the lack of constraints against broad and extreme conditions.

The international community initiated changes in the subject areas with removal of the general-license provisions in the 1985 Edition of the IAEA Regulations for Safe Transport of Radioactive Material. ${ }^{1}$ However, in the rule-making process to address 10 CFR 71 compatibility with the 1985 Edition of the IAEA Regulations, ${ }^{2}$ the decision was made not to delete the general-license provisions without further assessment. Then, during the revision process for the 1996 Edition of the IAEA Regulations, ${ }^{3}$ a lengthy review and discussion of the fissile-material exemptions was initiated by an LAEA Member State concern regarding uncontrolled accumulation of packages containing exempt quantities of fissile material. This eventually led to fissile material exemption specifications that limit the fissile-material mass in a consignment and restrict the presence of select moderators with very low neutron-absorption properties (i.e., "special" moderators). Responding to identified concerns regarding the potential for inadequate criticality safety in certain shipments of exempted quantities of fissile material (beryllium oxide containing low-concentration of high-enriched uranium), the NRC initiated an emergency rule making ${ }^{4}$ of $10 \mathrm{CFR} 71$ that also limited the consignment mass for fissile-material exemptions and restricted the presence of beryllium, deuterium, and graphite.

This recent emergency rule was issued without prior public comment. Subsequent to the release of the emergency rule, negative comments ${ }^{5-10}$ were offered by nearly all NRC fuel cycle facility licensees and other interested parties. These public comments demonstrate a perception that unnecessary conservatism was imposed to eliminate a very limited set of potential, yet usually impractical, conditions that might be allowed by the fissile material exemption and general licenses. The public comments and the concerns of the NRC staff, relative to potential inconsistencies or unidentified deficiencies, led to the decision to further assess the revised 10 CFR 71 exemptions and general licenses. The objectives of the assessment are the following:

1. to document perceived deficiencies in the technical or licensing bases that might be adverse to maintaining adequate subcriticality under normal conditions of transport and hypothetical accident conditions;

2. to identify areas where regulatory wording could cause confusion among licensees and potentially lead to subsequent safety concerns;

3. to study and identify the practical aspects of transportation or licensing that could mitigate, justify, or provide a historical basis for any identified potential deficiencies; and

4. to develop recommendations for revising the current regulations to minimize operational and economic impacts on licensees while maintaining safe practices and correcting identified deficiencies.

As indicated above, the most recent amendment ${ }^{4}$ of $10 \mathrm{CFR} 71$ adopted technical specifications for fissile-material exemptions that are consistent with the 1996 Edition of the IAEA regulations; thus, many of the assessment comments and recommendations of this report are pertinent to the 1996 Edition of the IAEA regulations regarding fissile material exceptions. 



\section{INTRODUCTION}

This report provides the results of an assessment of the current 10 CFR 71 fissile-material exemptions and general licenses for packaging and transportation. Additionally, example technical bases are provided for preliminary recommendations to be considered in future regulatory revisions. Section 2.1 introduces the fundamentals of criticality safety pertinent to an understanding of the issues. Section 2.2 provides a review of the existing regulatory requirements for fissile-material exemptions and general licenses, while Sect. 2.3 presents the approach used to perform the assessment and formulate preliminary recommendations.

\subsection{Pertinent Criticality Safety Fundamentals}

Three fates are possible for a neutron in a fissile material package. The neutron may encounter a fissile nuclide and induce fission, producing additional neutrons to continue the fission chain; the neutron may be removed from the fission chain through absorption by a nuclide constituent of the package or contents or through absorption by a fissile nuclide without fissioning; or the neutron may escape the single-package system by leaking from the package and thus be removed from the fission chain. Criticality is achieved when there is a balance between neutron production by fission and neutron loss by absorption in, and leakage from, the system. The criticality of a system is often discussed in terms of an effective multiplication factor, $\mathrm{k}_{\mathrm{eff}}$, which is defined as the ratio of the neutron production rate to the neutron loss rate from the system. For the system to remain subcritical, $\mathrm{k}_{\text {eff }}$ must be less than unity. The $\mathrm{k}_{\text {eff }}$ of the system can be maintained by ensuring adequate control of the parameters that affect the neutron balance. The principal parameters of concern in controlling the criticality safety of transportation packages are

1. type, mass, and form of the fissile material;

2. moderator-to-fissile material ratio (degree of moderation);

3. amount and distribution of moderator and absorber materials;

4. package geometry-internal and external; and

5. reflector effectiveness.

Since the fissile-material exemptions and general licenses of 10 CFR 71 provide no requirements for packaging assessment relative to criticality safety, any control provided by the package geometry or absorber/moderator materials cannot be relied upon in the assessment of the regulatory specifications. The effectiveness of water as a reflector and the abundance of it in nature has made water the reflector material of choice for evaluation of fissile material packages. This leaves the first two items of the above list as the available criteria that can be used in considering specifications for ensuring the criticality safety of shipments containing fissile material in packages that are exempt from a criticality safety assessment. Thus, exemption and general-license specifications are limited to considering only the type, mass, and form of the fissile material, together with the presence of moderators.

The type $\left({ }^{235} \mathrm{U},{ }^{239} \mathrm{Pu}\right.$, etc.), mass, and form (homogeneous, heterogeneous, metal, oxide, etc.) of the fissile material will affect the neutron production in a system because each has different energy-dependent probabilities for the absorption of neutrons (i.e., neutron absorption cross sections). The effective fission cross section varies both with the type and the form of the fissile material, although the fission cross section is highest at low-neutron energies. The mass of ${ }^{235} U$ is typically defined in terms of the enrichment, or weight percent, of ${ }^{235} U$ in the specified uranium content of the package. For plutonium, which often consists of several different isotopes, the weight percent of the individual isotopes is specified, together with the total mass of plutonium. In the absence of information on the ${ }^{235} \mathrm{U}$ enrichment or the plutonium isotopic distribution, it is typically prudent to assume that uranium is all ${ }^{235} \mathrm{U}$ and that the plutonium is all ${ }^{239} \mathrm{Pu}$.

As an example of the importance of the fissile material form, consider the general observation that homogeneous uraniummoderator mixtures above about $7 \mathrm{wt} \%{ }^{235} \mathrm{U}$ enrichment are typically more reactive (produce higher $\mathrm{k}_{\text {eff }}$ ) than a corresponding heterogeneous uranium-moderator mixture with the same mass and degree of moderation. ${ }^{11}$ (Moderators are 
materials that are made up of light nuclei, such as hydrogen or carbon, which readily slow the velocity of high-energy neutrons from fission down to the energy level, where the probability or cross section for further fission of fissile nuclei is the greatest.) However, a heterogeneous system of high-density uranium (e.g., metal, fuel pins, etc.) containing uranium enriched below about $7 \mathrm{wt} \%{ }^{235} \mathrm{U}$ is more reactive than the corresponding homogeneous system. This characteristic change of uranium-moderated systems is caused by the fact that the isolation of the moderator in heterogeneous systems allows high-energy neutrons that escape from the fissile material to easily scatter to the low energy desired for ${ }^{235} \mathrm{U}$ fission prior to re-entry into the fissile material. Thus neutron loss is minimized in the intermediate-energy range, where the high parasitic capture cross section of ${ }^{238} U$ dominates. As the enrichment of ${ }^{235} U$ increases, the loss of neutrons due to large ${ }^{238} U$ cross-section resonances becomes less important and the homogeneous mixing of uranium and moderator is more effective. More recently, it has been demonstrated that heterogeneous systems can have a higher reactivity than homogeneous systems if the individual units are very small (tiny particles) and the system is not well-thermalized. ${ }^{12}$ Thus, the form of the fissile material (homogeneous or heterogeneous) can have an impact on the safe mass that can be specified and the integrity of the form during normal conditions of transport and hypothetical accident conditions is an important consideration.

Fast neutrons that are produced by the fission process lose energy in collisions with atomic nuclei. The decrease of neutron kinetic energy due to elastic scattering is called moderation. The lower the atomic mass number (A) of the scattering material, the greater the neutron energy that can be lost in a single collision. The moderator effectiveness of low- $A$ materials, coupled with the fact that fissile isotopes have their largest fissile cross-section values at low energies, means that hydrogenous materials are the best moderators for efficiently obtaining a critical system. Water is an excellent moderator because of its high hydrogen content. The common occurrence of water in nature makes it the major moderating material of concern in criticality safety. Beryllium (Be), carbon $(C)$, and deuterium oxide $\left(\mathrm{D}_{2} \mathrm{O}\right.$ or heavy water) are less common materials and have a higher atomic mass value than hydrogen. Although their higher atomic mass values cause these materials to be less efficient than hydrogen in moderating neutrons to low energies, each of these materials has a much lower absorption cross section than hydrogen. Thus systems with large quantities of $\mathrm{Be}, \mathrm{C}$, or $\mathrm{D}_{2} \mathrm{O}$ can effectively moderate neutrons to low energies because, although the neutron energy loss per scatter is not as great as for hydrogen, the neutrons can experience more scatter interactions since the parasitic absorption (i.e., neutron absorption without neutron production) is less than that of hydrogen.

The optimum ratio of moderator-to-fissile nuclei defines the minimum critical mass of a fissile material that can be made critical in a finite system (e.g., a sphere). For an infinite system, there is no leakage to consider and the relative amount of moderator-to-fissile nuclei is the only parameter of interest. Thus, for infinite critical systems, the fissile material concentrations for systems with $\mathrm{Be}, \mathrm{C}$, and $\mathrm{D}_{2} \mathrm{O}$ will be lower than ordinary water systems because parasitic absorption by these moderators is less than that of hydrogen. However, for finite systems, the available space, volume, or neutron pathlength available for slowing neutrons by scattering must be considered; the efficiency of hydrogen as a moderator means that the minimum mass of fissile material necessary for criticality will occur with an optimally water-moderated system (discounting, for now, materials with a higher hydrogen density than water). So it is possible to have large $\mathrm{Be}, \mathrm{C}$, or $\mathrm{D}_{2} \mathrm{O}$ systems that can be critical with a fissile material concentration much lower than that of a water-moderated system, but the total mass of fissile material needed for criticality will be greater than that of an optimally moderated water system. One can study Figure F-1 to see an illustration of this phenomenon. For ordinary water, as the volume fraction of ${ }^{235} U$ decreases the moderation provided by the hydrogen causes the total mass for criticality to decrease. However, as the ${ }^{235} \mathrm{U}$ volume fraction decreases further, the volume of water becomes such that the neutrons are absorbed in hydrogen before they can interact with ${ }^{235} \mathrm{U}$, thus creating an increase in the ${ }^{235} \mathrm{U}$ mass required for criticality. For the other systems illustrated in Figure F-1, a larger volume of moderator material per ${ }^{235} U$ volume (smaller ${ }^{235} U$ volume fraction) is needed to effectively nooderate the neutrons. However, the minimum total mass of ${ }^{235} U$ necessary for criticality in a finite system will occur in a hydrogenmoderated system. This conclusion is verified by the results shown in Figures A-5, B-5, C-5, D-5, and E-5 of Appendixes A-E (summarized in Table 3-1 of Sect. 3). 
In summary, any fissile material exemption and general-license specifications that rely on the form and/or concentration of the material must ensure that there is no practical means to alter the form and/or concentration in a manner adverse to maintaining subcriticality. This premise is a difficult one when considering extreme, but plausible, scenarios specified by the hypothetical accident conditions (HAC) of 10 CFR 71. For example, Figures C-5, D-5, and E-5 of the appendixes indicate that the exempt concentration [see $\$ 71.53(\mathrm{a})(3)]$ of $5 \mathrm{~g}$ of fissile material per $10 \mathrm{~L}$ is inadequate to prevent criticality. Similarly, if the 10-L volume consists of contaminated combustibles, there is no assurance of maintaining the subcritical concentration if, under accident conditions, the matrix material is burned and the fissile material becomes concentrated and moderated. A number of extreme, but plausible, situations have been identified ${ }^{13,14}$ where the conditions specified by the exemptions (as specified by Refs. 1-2) might not be sufficient in themselves to prevent a potential for criticality. These postulated systems are generally characterized by large volumes, lack of absorbing impurities, and/or the presence of very selective materials. These types of postulated systems, together with an actual system of potential concern, led the NRC and IAEA to implement $t^{3,4}$ the consignment mass limits for the exemption criteria of $\S 71.53(\mathrm{a})(1)-(3)$.

\subsection{Review of Current Regulations}

The purpose of 10 CFR 71 is to provide packaging standards and shipping regulations for the transport of fissile material or radioactive material exceeding a Type A quantity. The portion of the regulations considered in this report are

1. Subpart B - Exemptions $§ 71.10$;

2. Subpart C-General Licenses

- $\quad \$ 71.18$ Fissile material, limited quantity per package;

- $\quad \$ 71.20$ Fissile material, limited moderator per package;

- $\quad \$ 71.22$ Fissile material, limited quantity, controlled shipment;

- $\quad \$ 71.24$ Fissile material, limited moderator, controlled shipment; and

3. Subpart E- Package Approval Standards

- $\quad \$ 71.53$ Fissile-material exemptions.

Exemptions from the requirement to license under 10 CFR 71 are provided in $\$ 71.10$. The exemptions are based primarily on the radioactivity of the material:

1. $\$ 71.10$ (a) exempts any material with less than $70 \mathrm{~Bq} / \mathrm{g}$ from any requirements of $10 \mathrm{CFR} 71$;

2. $\$ 71.10(b)$ exempts less than Type A quantities, certain low-specific-activity (LSA) material with acceptable radiation limits, and limited quantities of special-form Pu or Am from all requirements, except DOT compliance and shipmentby-air requirements, provided there is no fissile material or the fissile-material exemptions of $\$ 71.53$ are satisfied; and

3. $\$ 71.10(\mathrm{c})$ exempts LSA-I and surface-contaminated objects (SCO-I) from all requirements, except those for compliance with the U.S. Department of Transportation (DOT) regulations and shipment-by-air requirements.

The general licenses specified by $\$ 71.18, \S 71.20, \S 71.22$, and $\$ 71.24$ allow less than Type A quantities of fissile material to be transported with no packaging requirements, except as specified by DOT for nonfissile material. ${ }^{15}$ The specifications of the general licenses ensure the quantity of fissile material in a shipment, even under exclusive use, is much less than the measured minimum critical mass for a homogeneous, optimally water-moderated system. The control for $\$ 71.18$ and $\$ 71.22$ is strictly based on limiting the fissile-material mass; $\$ 71.20$ and $\$ 71.24$ allow increased mass limits for ${ }^{235} U$ based on knowledge of the ${ }^{235} \mathrm{U}$ enrichment. Limited quantities per package and a transport index (TI) for nuclear criticality are defined for $\S 71.18$ and $\$ 71.20$ to provide conveyance control for the material. Similarly, $\$ 71.22$ and $\$ 71.24$ allow 
"controlled shipments" of fissile material that have $25 \%$ more mass than allowed under $\$ 71.18$ and $\S 71.20$. This additional mass still ensures adequate subcriticality of the shipment in comparison to measured critical mass limits.

Under the Package Approval Standards of 10 CFR 71, Subpart E, the current regulations provide criteria in $\S 71.53$ whereby fissile material can be exempt from the requirements and controls necessary for certification of packages containing fissile material as specified in $\S \S 71.55$ and 71.59 . Briefly, these criteria are

1. packages with $15 \mathrm{~g}$ or less of fissile material, $\$ 71.53(\mathrm{a})(1)$;

2. select homogeneous solutions [hydrogenous, $\$ 71.53(\mathrm{a})(2)$ and uranyl nitrate, $\$ 71.53(\mathrm{c})$ ] or mixtures of fissile material with limits specified on combinations of mass, ${ }^{235} \mathrm{U}$ enrichment, hydrogen content, and/or solution concentration;

3. packages that can be demonstrated to have less than $5 \mathrm{~g}$ of fissile material in any $10-\mathrm{L}$ volume, $\$ 71.53(\mathrm{a})(3)$;

4. packages containing uranium enriched in ${ }^{235} U$ to a maximum of $1 \mathrm{wt} \%, \S 71.53$ (d); and

5. packages with less than $1 \mathrm{~kg}$ of plutonium, if together with the ${ }^{239} \mathrm{Pu}$ and ${ }^{241} \mathrm{Pu}$, are less than $20 \%$ of the total plutonium mass, $\S 71.53(\mathrm{e})$.

Consignment limits equal to one-half the measured minimum critical mass of ${ }^{235} U$ in an optimally moderated, homogeneous system are required for criteria 1 and 3 and the hydrogenous mixtures of criteria 2. And, as indicated in Sect. 1, the most recent amendment to the regulations included a significant restriction on quantities of beryllium, graphite, and. hydrogenous materials enriched in deuterium that could be present in fissile exempt material or fissile material shipped under the general licenses.

\subsection{Assessment Approach}

The assessment considered various interpretations and inferences derived from written responses of NRC fuel cycle facility licensees to the February 10, 1997, amendment ${ }^{4}$ and historic implementation of 10 CFR 71 obtained from discussions with industry and NRC personnel. This process indicated that there were often varying interpretations of the regulatory language and that, on occasion, industry practice was inadequate because the regulatory language was inconsistent or unclear with respect to the original technical basis.

Besides discussions with industry and NRC staff, the assessment process considered the available literature on parameters that ensure subcritical dimensions under various conditions (e.g., minimum critical mass for water-moderated and waterreflected systems) and performed independent computational analyses to provide a basis for considering practical aspects of transportation. These analyses were performed to explore potential bounding specifications for fissile-material exemptions and general licenses for homogeneous mixtures of ${ }^{235} \mathrm{U}$ with various moderating materials. The influence of common materials (e.g., water, polyethylene, silicon dioxide) and the influence of "special" moderating materials (e.g., Be, $\mathrm{C}$, and $\mathrm{D}_{2} \mathrm{O}$ ) on nuclear criticality safety were considered relative to the values specified for fissile-material transportation under the portions of 10 CFR 71 discussed in Sect. 2.2.

The results of nuclear criticality computational studies of ${ }^{235} U$ that is commingled with common materials or special moderators are provided in Appendixes A-F of this report. These results were used to assess existing exemption and general-license specifications and assist in the development of recommendations for consideration in future regulatory revisions. The recommendations were developed with the intent to provide a near-equivalent level of safety assurance to that required for packages certified to carry fissile material: the recommended general-license limit values are based upon the expected lack of moderation control and potential redistribution of material under normal conditions of transpiort (i.e., §71.71) and under hypothetical accident conditions (i.e., §71.73). 
Section 3 summarizes the models, methods, and assumptions used for the computational studies in Appendixes A-E.

Section 4 of this report provides specific assessment comments and recommendations relevant to pertinent portions of the fissile-material exemptions and general licenses. The technical basis for the regulations is provided as appropriate in this section. Section 5 provides a general assessment and discussion of the recommendations based on the detailed information of Sect. 4. 


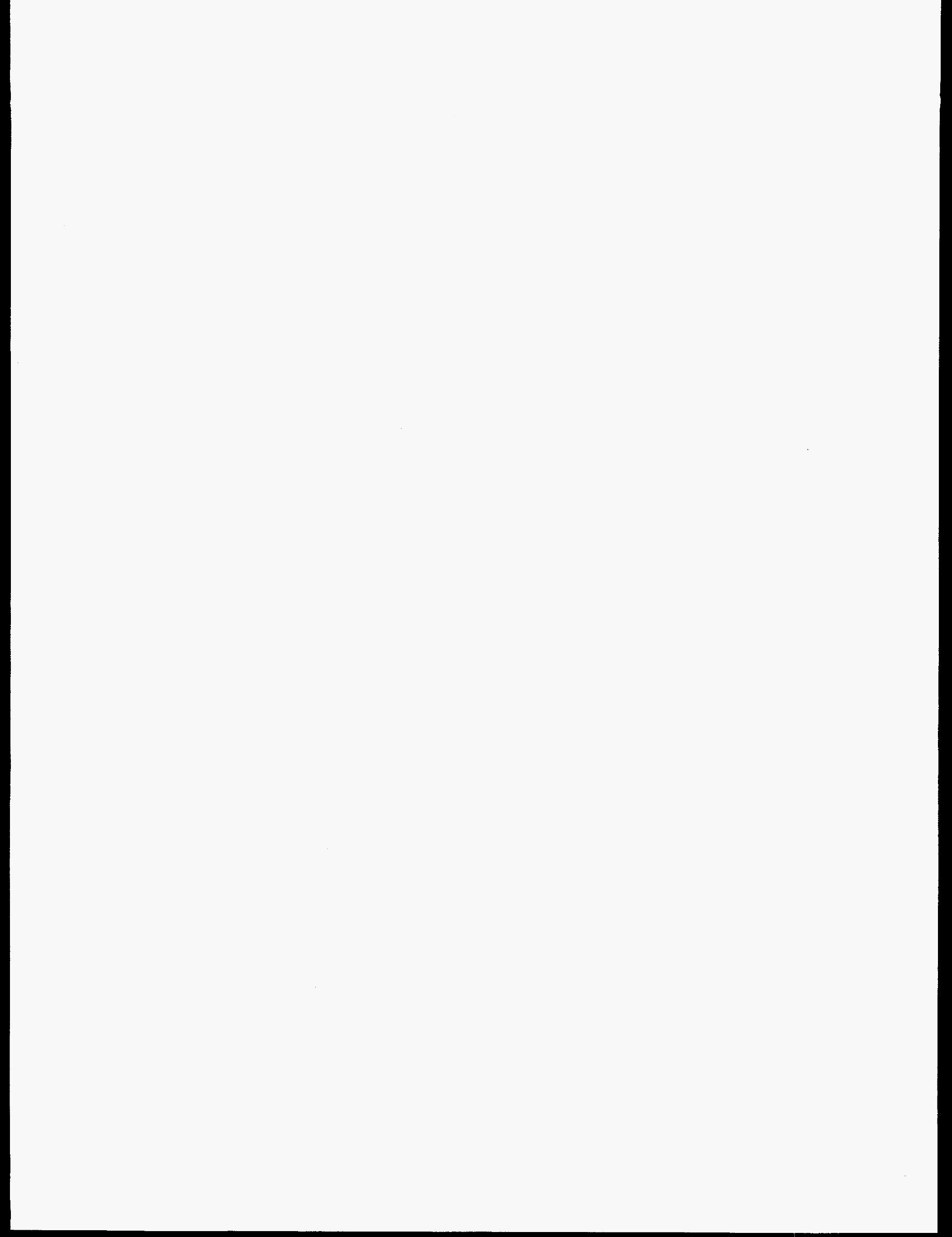




\section{COMPUTATIONAL STUDIES}

A series of computational criticality studies was performed to bound subcritical parameters of uranium, hypothetically comprised of $100 \mathrm{wt} \%{ }^{235} \mathrm{U}$, as homogeneously mixed with various neutron-moderating materials. The models were developed to consider binary mixtures of pure ${ }^{235} \mathrm{U}$ with water and tertiary mixtures of pure ${ }^{235} \mathrm{U}$ and water in combination with either $\mathrm{Be}, \mathrm{C}, \mathrm{D}_{2} \mathrm{O}$, or silicon dioxide $\left(\mathrm{SiO}_{2}\right)$. Beryllium, carbon, and deuterium oxide were selected for study because of their effectiveness as low neutron-absorbing moderators, and $\mathrm{SiO}_{2}$ was selected because of its bounding representation as dirt, glass, or common waste matrix material. Each material mixture was evaluated as an infinite media, as a fully waterreflected finite sphere, and as a fully water-reflected array of packages in an array volume of about $584 \mathrm{~m}^{3}$. The array of packages was analyzed in an attempt to estimate the effect of actual package loadings and materials on the $k_{\text {eff }}$ of the systems. The volume of $584 \mathrm{~m}^{3}$ was selected to represent the maximum volume of five public highway transportation vehicles (i.e., each vehicle consisting of two tandem trailers pulled by a single tractor).

The criticality calculations were performed with the SCALE ${ }^{16}$ computer code system. Infinite and one-dimensional (1-D) systems were analyzed with the discrete-ordinates transport theory code sequence CSAS1X. The 27-energy-group library, based on ENDF/B-IV data, was used for this portion of the study because the number of groups would enable the large number of calculations (covering the range of binary and tertiary mixtures) to be efficiently analyzed and because the historic experience of ORNL with similar systems indicated the calculated $k_{\text {eff }}$ results would be slightly conservative. Array systems requiring three-dimensional (3-D) modeling were analyzed with the Monte Carlo transport code sequence CSAS26. The SCALE 238-neutron-energy-group library derived from ENDF/B-V was used because the additional energy groups provide improved rigor with insignificant effect on the calculation time.

The CSAS1X sequence was used for calculating three types of systems: (1) infinite homogeneous media, (2) a homogeneous finite sphere (584- $\mathrm{m}^{3}$ volume) reflected with $30.48-\mathrm{cm}$-thick water, and (3) minimum critical masses of the hypothetical materials as 30.48-cm-thick, water-reflected spheres. The CSAS26 sequence was used for calculating 30.48-cm-thick waterreflected arrays (approximately $584-\mathrm{m}^{3}$ total array volume) of packages. The arrays were comprised of the hypothetical material mixtures contained within 110-gal drums that were modeled as two joined 55-gal, 20-gauge 316-stainless steel DOT-17E drums. These drums were selected because of the minimum quantity of iron (a neutron-absorbing material) that would be represented. The hypothetical homogeneous tertiary mixtures using $\mathrm{SiO}_{2}, \mathrm{C}, \mathrm{Be}$, or $\mathrm{D}_{2} \mathrm{O}$ were assumed to be at $60 \%$ of their theoretical densities, thereby permitting the introduction of various uranium and water fractions into the remaining $40 \%$ of the matrix volume. In the instance of the ${ }^{235} \mathrm{U}$ and water binary mixture, the hydrogen-to- ${ }^{235} \mathrm{U}$ atom ratio, $\mathrm{H}^{235} \mathrm{U}=2500$, was selected as a limiting subcritical ${ }^{235} \mathrm{U}$ density equal to the $10.41 \mathrm{~g}{ }^{235} \mathrm{U}$ per liter concentration that would maintain $\mathrm{k}_{\text {eff }}<0.93$ for an infinite homogeneous mixture of ${ }^{235} \mathrm{U}$ metal and water.

For each of these four types of models, parametric searches were performed to determine the limiting values (i.e., masses, densities, and material atom ratios) for the considered matrixes that would ensure a "subcritical" neutron multiplication factor, $\mathrm{k}_{\mathrm{inf}}$ or $\mathrm{k}_{\mathrm{eff}}$, of less than 0.93 . The rationale for the computational models and assumptions are summarized below:

1. The subcritical neutron multiplication factor, $\mathbf{k}_{\text {inf }}$ or $\mathbf{k}_{\text {eff }}$, of 0.93 was selected to provide an adequate margin of subcriticality accounting for both an administrative margin and uncertainties in neutron cross sections and the unusual mixtures of nuclei for which very limited critical experiments exist. The $7 \%$ margin of subcriticality is consistent with an upper subcritical limit for very broad-based historic validation studies.

2. The basic matrix materials (i.e., $\mathrm{SiO}_{2}, \mathrm{C}, \mathrm{Be}$, and $\mathrm{D}_{2} \mathrm{O}$ ) were assumed to be $60 \%$ of their theoretical densities to simulate tamped densities of relatively homogeneous loose powders, dirt, and process wastes that would normally have pour densities ranging from $20 \%$ to $30 \%$ of their theoretical densities.

3. Pure ${ }^{235} \mathrm{U}$ was assumed as the fissile material to envelop the general needs of $\mathrm{NRC}$ licensees. No other uranium enrichments would need to be considered if the ${ }^{235} \mathrm{U}$ values are applied to total uranium (i.e., consider other isotopes of 
uranium to be ${ }^{235} \mathrm{U}$ in the determination of allowable mass or concentration). Only limited analyses needed to formulate criteria consistent with final recommendations were performed for ${ }^{233} \mathrm{U}$ and ${ }^{239} \mathrm{Pu}$.

4. The infinite media calculations were performed to determine subcritical atom or mass ratios of the various matrixes to define an "exemption for low-level materials" in an infinite media to be consistent with the implicit safety intended to be provided by $\$ 71.10(a)$.

5. The 30.48-cm-thick, water-reflected array volume of $584 \mathrm{~m}^{3}$ was used for the spherical or near-cubic drum systems to be representative of the maximum volume available in five public highway transport vehicles (i.e., each vehicle consisting of a tractor pulling two tandem trailers). The selection of five transport volumes [cf. $\$ 71.59(\mathrm{a})(1)]$ instead of two [cf. $\$ 71.59(\mathrm{a})(2)]$ was made to ensure the large volume associated with normal conditions of transpoit are accommodated together with the moderator and configuration changes that might occur under hypothetical accident conditions.

6. The 30.48-cm-thick, water-reflected homogeneous spherical media cases were selected to examine the effects of minimal or no containerization of the matrixes, thereby providing minor neutron absorption relative to the total system volume (e.g., large containers made of plastic, fiberboard, wood, or thin-steel boxes, etc.).

7. The 30.48-cm-thick, water-reflected, near-cubic array of homogeneous matrixes in thin-walled stainless steel drums were modeled to examine the impact of package geometry and the potential for assigning minimum transport indexes to packages for transportation.

The figures and tables containing the results of the computational studies are provided in Appendixes A-E. These studies are limited by their absence of consideration for:

1. lesser uranium enrichments;

2. analysis of fissile and moderating material heterogeneity effects;

3. inclusion of various packaging configurations and materials (aside from the drum steel of the array analyses); and

4. consideration of other finite systems for simulating variable conveyance volumes (e.g., rail cars, etc.) for hypothetical accident (twice the damaged shipment) and normal conditions of transport (five times the undamaged shipment) analyses.

The analyses performed in Appendixes A-E and the reference literature on criticality safety parameters were used as the technical basis for the recommendations of Sect. 5.3. Of particular importance are the subcritical mass values determined for each fissile major nuclide in the various moderators of interest. These results are shown in Table 3-1 and will be referenced as needed in the text. 
Table 3-1 Critical and subcritical minimum mass values calculated for selected moderators

\begin{tabular}{|c|c|c|c|c|c|c|}
\hline \multirow{2}{*}{$\begin{array}{l}\text { Moderator } \\
\text { description }\end{array}$} & \multirow{2}{*}{$\begin{array}{l}\text { Fissile } \\
\text { material }\end{array}$} & \multicolumn{2}{|c|}{$\begin{array}{c}\text { Calculated minimum mass } \\
\text { values }(\mathrm{g})\end{array}$} & \multicolumn{2}{|c|}{$\begin{array}{l}\text { Moderator mass (g) } \\
\text { at minimum value }\end{array}$} & \multirow{2}{*}{$\begin{array}{l}\text { Reference } \\
\text { Appendix }\end{array}$} \\
\hline & & $k_{\text {eff }} \leq 0.95$ & $\mathrm{k}_{\mathrm{eff}}=1.0$ & $\mathrm{k}_{\text {eff }} \leq 0.95$ & $\mathrm{k}_{\text {eff }}=1.0$ & \\
\hline $0.996 \mathrm{~g} \mathrm{H}_{2} \mathrm{O} / \mathrm{cm}^{3}$ & $\begin{array}{l}{ }^{235} \mathrm{U} \\
{ }^{233} \mathrm{U} \\
{ }^{239} \mathrm{Pu}\end{array}$ & $\begin{array}{l}614 \\
437 \\
379 \\
\end{array}$ & $\begin{array}{l}820^{a} \\
600^{a} \\
510^{a}\end{array}$ & $\begin{array}{r}11,760 \\
7,600 \\
12,840 \\
\end{array}$ & $\begin{array}{l}15,700 \\
10,000 \\
18,000 \\
\end{array}$ & A \\
\hline $0.96 \mathrm{~g} \mathrm{CH}_{2} / \mathrm{cm}^{3}$ & ${ }^{{ }^{235} \mathrm{U}}$ & $\begin{array}{l}\text { N.C. } \\
\text { N.C. } \\
\text { N.C. }\end{array}$ & $\begin{array}{l}527 \\
\text { N.C. }{ }^{b} \\
\text { N.C. }\end{array}$ & $\begin{array}{l}\text { N.C. } \\
\text { N.C. } \\
\text { N.C. }\end{array}$ & $\begin{array}{l}7,394 \\
\text { N.C. } \\
\text { N.C. }\end{array}$ & $A$ \\
\hline $1.6 \mathrm{~g} \mathrm{SiO}_{2} / \mathrm{cm}^{3}$ & ${ }^{{ }^{235} \mathrm{U}}$ & $\begin{array}{r}147,000 \\
61,616 \\
72,688\end{array}$ & $\begin{array}{l}\text { N.C. } \\
\text { N.C. } \\
\text { N.C. }\end{array}$ & $\begin{array}{l}43,162,000 \\
17,453,000 \\
52,919,000\end{array}$ & $\begin{array}{l}\text { N.C. } \\
\text { N.C. } \\
\text { N.C. }\end{array}$ & B \\
\hline $2.1{\mathrm{~g} \mathrm{C} / \mathrm{cm}^{3}}^{3}$ & $\begin{array}{l}{ }^{235} \mathrm{U} \\
{ }^{233} \mathrm{U} \\
{ }^{239} \mathrm{Pu}\end{array}$ & $\begin{array}{l}2,186 \\
1,722 \\
1,212\end{array}$ & $\begin{array}{l}\text { N.C. } \\
\text { N.C. } \\
\text { N.C. }\end{array}$ & $\begin{array}{l}2,792,000 \\
1,951,000 \\
2,677,000\end{array}$ & $\begin{array}{l}\text { N.C. } \\
\text { N.C. } \\
\text { N.C. }\end{array}$ & $\mathrm{C}$ \\
\hline $1.85 \mathrm{~g} \mathrm{Be} / \mathrm{cm}^{3}$ & $\begin{array}{l}{ }^{235} \mathrm{U} \\
{ }^{233} \mathrm{U} \\
{ }^{239} \mathrm{Pu}\end{array}$ & $\begin{array}{l}765 \\
605 \\
424 \\
\end{array}$ & $\begin{array}{l}\text { N.C. } \\
\text { N.C. } \\
\text { N.C. }\end{array}$ & $\begin{array}{l}351,600 \\
233,700 \\
335,300\end{array}$ & $\begin{array}{l}\text { N.C. } \\
\text { N.C. } \\
\text { N.C. }\end{array}$ & $\mathrm{D}$ \\
\hline $1.1 \mathrm{~g} \mathrm{D}_{2} \mathrm{O} / \mathrm{cm}^{3}$ & $\begin{array}{l}{ }^{235} \mathrm{U} \\
{ }^{233} \mathrm{U} \\
{ }^{239} \mathrm{Pu}\end{array}$ & $\begin{array}{r}1,044 \\
851 \\
602\end{array}$ & $\begin{array}{l}\text { N.C. } \\
\text { N.C. } \\
\text { N.C. }\end{array}$ & $\begin{array}{l}444,300 \\
219,000 \\
378,000\end{array}$ & $\begin{array}{l}\text { N.C. } \\
\text { N.C. } \\
\text { N.C. }\end{array}$ & $\mathrm{E}$ \\
\hline
\end{tabular}

${ }^{a}$ Obtained from Ref. 17.

SN.C. $=$ Not calculated. 


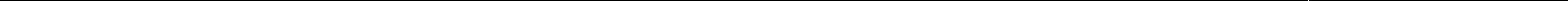




\section{ASSESSMENT COMMENTS}

This section provides assessment comments and recommendations for sections and subsections pertinent to nuclear criticality safety for the fissile material general licenses and exemptions as provided in 10 CFR 71 . Various subsections that have no bearing on the assessment are not addressed.

\section{\$71.4 Definitions.}

The distinctions between the definitions and meanings of words and phrases in 49 CFR 173, Subpart I "Radioactive Materials" and 10 CFR 71 - "Packaging and Transportation of Radioactive Materials" need to be clarified or eliminated to ensure consistency within federal regulations (e.g., words such as exemption - exception - exclusion, manifest - consignment, shipment - conveyence, controlled shipment - exclusive use, etc.).

Recommendation 1: Revise definitions and text of 10 CFR 71 for intent and internal consistency, perhaps considering relationships between 49 CFR $173^{15}$ and IAEA No. ST-1. ${ }^{3}$

\$71.4 Definitions. Fissile material means plutonium-238, plutonium-239, plutonium-241, uranium-233, uranium-235, or any combination of these radionuclides. Unirradiated natural uranium and depleted uranium, and natural uranium or depleted uranium that has been irradiated in thermal reactors only are not included in this definition. Certain exclusions from fissile material controls are provided in $\$ 71.53$.

The use of the phrase fissile material is inappropriate in conjunction with ${ }^{238} \mathrm{Pu},{ }^{240} \mathrm{Pu}$, or other nuclei that can maintain a self-sustaining chain reaction only with fast neutrons. From a technical viewpoint, for nuclei to be defined as fissile, the nuclei must be able to maintain a self-sustaining chain reaction with thermal neutrons (i.e., ${ }^{233} \mathrm{U},{ }^{235} \mathrm{U},{ }^{239} \mathrm{Pu},{ }^{241} \mathrm{Pu}$, etc). If nonfissile nuclei (i.e., ${ }^{238} \mathrm{Pu}$ ) are to be considered in the regulations, the appropriate technical phrase to use is fissionable material. The words fissile and fissionable have very specific meanings ${ }^{18-21}$ and potentially conflicting applications. Considering the very limited nuclear criticality safety packaging and transportation concerns associated with ${ }^{238} \mathrm{Pu}$ and other nonfissile fissionable nuclei, it may be appropriate to remove ${ }^{238} \mathrm{Pu}$ from the definition of fissile material as provided in $\S 71.4$. The removal of ${ }^{238} \mathrm{Pu}$ from the definition would be consistent with the 1996 Revision of the International Atomic Energy Agency (IAEA) regulations. ${ }^{3}$ Besides providing a clear and technically correct definition, the need to include ${ }^{238} \mathrm{Pu}$ as a fissile (regulatory) material does not appear warranted as discussed in the advisory text associated with Ref. 3 . Reference 22 indicates that the minimum critical mass for a water-reflected system of ${ }^{238} \mathrm{Pu}$ is over $6 \mathrm{~kg}$. The $0.57 \mathrm{~W} / \mathrm{g}$ decay heat inherent from the alpha decay of ${ }^{238} \mathrm{Pu}$ will cause excessive temperatures and associated significant practical obstacles to accumulate anywhere near this quantity of ${ }^{238} \mathrm{Pu}$.

Within 10 CFR 71, the term "fissile material" is used both to refer to fissile nuclides and to material containing fissile nuclides. Any revision to the regulations should consider changes to the definition and usage that help clarify intent. This inconsistency in usage was noted but not addressed within the recent IAEA revision process. ${ }^{23}$ Also, the word "fissile" appears in numerous locations throughout 10 CFR 71; any substitution or change in the definition would need further considerations relative to specific intent.

Recommendation 2: Remove ${ }^{238} \mathrm{Pu}$ from the definition of fissile material and review the text for consistency and meaning relative to the word "fissile" and "fissile material."

\$71.10 Exemption for low-level materials. (a) A licensee is exempt from all requirements of this part with respect to shipment or carriage of a package containing radioactive material having a specific activity not greater than $70 \mathrm{~Bq} / \mathrm{g}$ $(0.002 \mu \mathrm{Ci} / \mathrm{g})$.

This exemption basically provides the definition for radioactive material. If the material has an activity less than $70 \mathrm{~Bq} / \mathrm{g}$ the licensee does not need to demonstrate that the packages containing the specified material meet any of 
the requirements of 10 CFR 71 OR 49 CFR 173. As discussed below, the specific activity of uraniura is such that several grams of ${ }^{235} \mathrm{U}$ can be transported in a package and not be defined as radioactive material. However, the nature of ${ }^{235} \mathrm{U}$ as a fissile nuclide would seem to justify a need for some minimum package criteria: ensure that the package is of sufficient size, maintains containment security with a positive fastening device, is constructed of materials to inhibit containment degradation, will survive normal conditions of transport without loss of contents. Since this limit seems to have been developed based strictly on biological dose concerns, there may be a need to reconsider the need for some minimal packaging requirement for quantities of fissile material that exceed some minimal mass rather than some minimal dose. The intent would be to provide a low enough exemption mass that dispersion to the public would be inconsequential OR unacceptable accumulation would be impractical.

Recommendation 3: Review the need to demonstrate some minimal requirements (e.g., \$71.43) for construction of packages containing fissile materials exceeding a certain minimal mass. Otherwise exclude fissile material from the allowable materials to be considered under $\$ 71.10(\mathrm{a})$.

\$71.10 Exemption for low-level materials. (a) A licensee is exempt from all requirements of this part with respect to shipment or carriage of a package containing radioactive material having a specific activity not greater than $70 \mathrm{~Bq} / \mathrm{g}$ $(0.002 \mu \mathrm{Ci} / \mathrm{g})$.

For illustration, Table A-3 of 10 CFR 71 indicates the specific activity of uranium enriched to $93 \mathrm{wt} \%{ }^{235} \mathrm{U}[\mathrm{U}(93)]$ is $70 \mu \mathrm{Ci} / \mathrm{g} \mathrm{U}(93)$. Therefore, a 55-gal container (208-L) loaded with an exempt concentration of low-level materials at a bulk density of approximately $1.0 \mathrm{~g} / \mathrm{cm}^{3}$ could contain approximately $5.94 \mathrm{~g} \mathrm{U}(93)$ [i.e., $\left(208,000 \mathrm{~cm}^{3}\right)\left(1.0 \mathrm{~g}\right.$ exempt low-level material $\left./ \mathrm{cm}^{3}\right)(0.002 \mu \mathrm{Ci} / \mathrm{g}$ exempt low-level material $)(\mathrm{g} \mathrm{U}(93) / 70 \mu \mathrm{Ci})=$ $5.94 \mathrm{~g} \mathrm{U}(93)]$. This value equates to approximately $0.029 \mathrm{~g} \mathrm{U}(93) / \mathrm{L}$ of low-level materials. For U(5), the reduced specific activity $(2.7 \mu \mathrm{Ci} / \mathrm{g})$ means the drum could hold $154 \mathrm{~g}$ of $\mathrm{U}(5)$ or $7.7 \mathrm{~g}$ of ${ }^{235} \mathrm{U}$. Considering the extreme and implausible limit of pure ${ }^{235} \mathrm{U}$, the specific activity of $2.2 \mu \mathrm{Ci} / \mathrm{g}$ would enable $189 \mathrm{~g}$ of ${ }^{235} \mathrm{U}$ to be placed in the drum. With no controls on accumulation, these activity limits can produce large masses of enriched uranium, given a sufficiently large conveyance or conveyances.

When this exemption criteria is applied to common mixtures, chemical compounds or alloys comprised of water, hydrocarbons, or other elements of atomic weights greater than carbon it can be readily demonstrated that an infinite, water-moderated media containing uranium is subcritical. For instance, $0.002 \mu \mathrm{Ci}$ of $\mathrm{U}(93)$ per gram of material or approximately $0.029 \mathrm{~g} \mathrm{U}(93) / \mathrm{L}$ of water is far below the minimum critical concentration ${ }^{17}$ of approximately $12 \mathrm{~g} \mathrm{U}(93) / \mathrm{L}$ of water. However, the application of this exemption limit to an implausible, but authorized, infinite media of heavy water (i.e., $D_{2} O$ ) contaminated with $0.029 \mathrm{~g} \mathrm{U}(93) / \mathrm{L}$ exceeds the evaluated infinite media subcritical value of $0.0192 \mathrm{~g}^{235} \mathrm{U} / \mathrm{L}$ at a $\mathrm{D} /{ }^{235} \mathrm{U}$ atom ratio equal to $1.35 \times 10^{6}$, as shown in Appendix E. Appendix F discusses the implication of the specified limit of $0.002 \mu \mathrm{Ci}$ fissile material $/ \mathrm{g}$ of low-level materials for some finite systems of limiting authorized mixtures. This discussion demonstrates the need to consider plausible criticality safety concerns when developing limits or exemptions based solely on radioactivity.

Recommendation 4: Modify $\$ 71.10$ (a) text to read ". . not greater than $70 \mathrm{~Bq} / \mathrm{g}(0.002 \mu \mathrm{Ci} / \mathrm{g})$, provided the packages contain no fissile material." and consider providing separate exemption limits for use with fissile material. The intent would be to provide a low enough exemption mass that dispersion to the public would be inconsequential OR unacceptable accumulation would be impractical. These limits could be based on the infinite media subcritical values evaluated in the appendixes. Using $D_{2} O$ to provide the limiting concentration value $(0.0192 \mathrm{~g} / \mathrm{L}$ from Appendix $E)$ and using the specific activity associated with U(93), the limiting radiclogical value to preclude any theoretical concern with criticality safety would be $43 \mathrm{Bg} / \mathrm{g}$. 
Note that the ${ }^{235} U$ exemption limit provided for the 1996 Revision of the IAEA Regulations is $10 \mathrm{~Bq} / \mathrm{g}$ and the consignment limit is $10^{4} \mathrm{~Bq}$. The consignment limit provides another practical barrier to transport of systems such as those postulated in Appendix $F$. However, making this limit a conveyance limit would better prevent unacceptable accumulation. Thus, if the exemption approach of the IAEA is adopted within 10 CFR 71, the associated limits should be selected to resolve any potential criticality safety concerns relative to exemption from the regulations.

\$71.18 General license: Fissile material, limited quantity per package. (a) A general license is issued to any licensee of the Commission to transport fissile material, or to deliver fissile material to a carrier for transport, without complying with the package standards of subparts $E$ and $F$ of this part, if the material is shipped in accordance with this section.

Since the radioactive material must be less than a Type A quantity, the packaging to be used for this general license could be the minimum specified by 49 CFR 173 (e.g., $§ 173.410$ ), which are judged by this assessment to be inadequate for the mass of fissile material allowed per package. Minimum standards consistent with $\$ 71.43$ are judged to be needed.

Recommendation 5: There is a need for some limited specification on the packaging to be used under this general license.

\$71.18 General license: Fissile material, limited quantity per package. (c) Except as provided in paragraph (d) of this section, this general license applies only when a package contains no more than a Type A quantity of radioactive material, including only one of the following:

(1) Up to $40 \mathrm{~g}$ of uranium-235;

(2) Up to $30 \mathrm{~g}$ of uranium-233;

(3) Up to $25 \mathrm{~g}$ of the fissile radionuclides of plutonium, except that for encapsulated plutonium-beryllium neutron sources in special form, an $A_{1}$ quantity of plutonium may be present; or ...

The mass limits allowed per package are important, but of primary importance is the package limit, together with the $\mathrm{TI}$ for criticality control. The formula for determining the TI of a package is provided in $\$ 71.18(\mathrm{f})$, but there is no definition for limiting the $T I$ of an array of packages in a shipment. For the purposes of this assessment it is assumed that the aggregate $T I$ allowed for a shipment is 50 for nonexclusive use and 100 for exclusive use. This assumption is based on the specifications provided in Subpart E, $\$ 71.59(\mathrm{c})(1)$; however, the general license provisions are not subject to the "package standards of Subpart E." Thus, any revision of $\$ 71.18$ should clarify the limit on the shipment TI.

Using ${ }^{235} \mathrm{U}$ as the example fissile material and the shipment $\mathrm{TI}$ limits of $\$ 71.59(\mathrm{c})$, the package mass limits of $\S 71.18(\mathrm{c})$ and the TI specification of $\$ 71.18(\mathrm{f})(1)$ cause the maximum mass in an exclusive-use shipment $(\mathrm{TI}=100)$ to be $400 \mathrm{~g}$ of ${ }^{235} \mathrm{U}$. Accumulation of this mass would require rearrangement of the all the package contents under some type of hypothetical accident. For criticality evaluation purposes, this total shipment mass is assumed to be optimally moderated to maximize reactivity and the neutron absorbing properties typical of most package materials is assumed to be nonexistent. Even with these assumptions, the $400-\mathrm{g}{ }^{235} \mathrm{U}$ limitation is conservatively subcritical; that is, less than one-half the minimum critical mass of approximately $820 \mathrm{~g}^{235} \mathrm{U}$ as optimumly moderated and reflected U(93) with water. ${ }^{17}$ In addition, computational results presented in Appendixes A-E confirm that the 400 -g limit for ${ }^{235} \mathrm{U}$ is more than $200 \mathrm{~g}$ less than the pure ${ }^{235} \mathrm{U}$ mass values associated with $\mathrm{k}_{\text {eff }} \leq 0.95$ for various moderator matrices: $614 \mathrm{~g}$ in $\mathrm{H}_{2} \mathrm{O}$ only; $147,000 \mathrm{~g}$ in $\mathrm{SiO}_{2}$ only; $2,186 \mathrm{~g}$ carbon only; $765 \mathrm{~g}$ in beryllium only; and $1,044 \mathrm{~g}$ in $\mathrm{D}_{2} \mathrm{O}$ only. Stratification of the ${ }^{235} \mathrm{U}$ in a water mixture may reduce the critical mass by approximately $15 \%(820 \mathrm{~g}$ to approximately $700 \mathrm{~g})$. 
Packages certified under 10 CFR 71 to carry fissile material must satisfy the array requirements of $\$ 71.59$. For discussion purposes here, this requirement will be interpreted in a simple fashion: the nonexclusive-use shipment should be limited such that twice the number of packages as damaged under hypothetical accident conditions (HAC) and five times the number of packages under normal conditions of transport (NCT) should be subcritical. Under nonexclusive use $\$ 71.18$ would allow packages to carry a maximum aggregate mass of $200 \mathrm{~g}$ in a shipment and twice that mass would be subcritical. However, relating to the $\$ 71.59$ requirement that five times the undamaged packages be subcritical, the $200 \mathrm{~g}$ value is not consistent, rather a shipment limit of $160 \mathrm{~g}(800 \mathrm{~g}$ divided by five) would seem more rigorously consistent. If a packaging requirement for a container that met NCT was imposed, the reactivity credit for the packaging would easily enable one to show the $200-\mathrm{g}$ limit is less than five times the minimum critical mass. The appendixes use optimal ${ }^{235} U$ densities that are considered reasonable for shipment of waste or industrial mixtures and demonstrate that, when considering volumes equal to five truck shipments and minimum packaging materials, the ${ }^{235} \mathrm{U}$ subcritical mass limit is an order of magnitude larger than the $200-\mathrm{g}$ value.

For shipment in an exclusive-use vehicle, $\$ 71.59$ allows a doubling of the TI limit (from 50 to 100 ). For discussion purposes here, this can be viewed simply as a doubling of the mass allowance per conveyance; that is, the number of packages in a shipment must be subcritical if damaged and 2.5 times the number of packages in a shipment must be subcritical under NCT. The 400-g limit allowed for exclusive-use shipments of ${ }^{235} \mathrm{U}$ under $\$ 71.18$ would meet the specification for an array of damaged packages, but again 2.5 times the $400-\mathrm{g}$ limit exceeds the minirnum critical mass value of $820 \mathrm{~g}$ and some package credit for NCT is needed.

Given the small quantities per package and the fact that damaged packages are typically more reactive than undamaged packages (due to loss of absorbing material and configuration control), it is judged that the requirements of $\$ 71.18$ provide sufficient consistency with $\S 71.59$ that a decrease in the package mass limits for ${ }^{233} \mathrm{U}$, ${ }^{235} \mathrm{U}$, and $\mathrm{Pu}$ are not justified. In fact, it could be argued that with standards that ensure package integrity under NCT, the mass limits could be raised since $614 \mathrm{~g}$ of ${ }^{235} \mathrm{U}$ has a $\mathrm{k}_{\text {eff }}<0.95$ for an optimally water-moderated, water-reflected system.

However, the $\$ 71.18(\mathrm{c})(3)$ allowance for an $\mathrm{A}_{1}$ quantity of ${ }^{239} \mathrm{Pu}$ in special form as encapsulated plutoniumberyllium neutron sources does present a potential criticality safety concern. The $A_{1}$ quantity of ${ }^{239} \mathrm{Pu}$ is approximately $873 \mathrm{~g}$. Assuming a maximum TI of 10 for a package and applying the TI multiplier provided in $\$ 71.18(\mathrm{f})(2)$ (i.e., 0.025 times the number of grams of the fissile radionuclides of plutonium), a package would be limited to $400 \mathrm{~g}$ of ${ }^{239} \mathrm{Pu}$ as neutron sources in a single package. Without considerations and restrictions regarding the neutron source construction and packaging of the sources (e.g., not permitting optimumly interstitially moderated multiple 5-g sources in high-density polyethylene neutron radiation shields), $2,000 \mathrm{~g}$ of ${ }^{235} \mathrm{Pu}$ (i.e., 5 packages) in a nonexclusive-use shipment may not be subcritical. Compounding this problem is the fact that, under exclusive use, 10 packages with a total ${ }^{239} \mathrm{Pu}$ quantity of $4,000 \mathrm{~g}$ could be transported. The bases for subcriticality and safety related to allowing this quantity of plutonium in a shipment is not known. It could be that some knowledge of the neutron source and how they are (or were) transported served to justify the quantities. However, these shipment quantities provide a potential for situations adverse to criticality safety unless some sprecifications are provided related to grams of Pu per gram of nonfissile material in the sources or spacing between sources. Specification of packaging requirements that would ensure subcriticality is another possible alternative.

Recomendation 6: Clarify the aggregate TI for a shipment of packages under the general license. Require the packages to meet NCT as specified in 71.43. This might enable the mass limits to be raised since an cirgument could be made that criticality safety concerns would then be dictated by $H A C$. 
Investigate the nature of plutonium-beryllium sources and how they are shipped to determine how to best modify the regulations to ensure subcriticality of the large quantity of plutonium allowed per package. Suggestions to consider are the following: (1) lowering the allowed quantity per package, (2) specifying a gram Pu per gram of nonfissile, noncombustible material, (3) specifying limiting materials of construction and packaging, or (4) removing this allowance from the general license.

\$71.18 General license: Fissile material, limited quantity per package. (d) For packages where fissile material is mixed with substances having an average hydrogen density greater than water, this general license applies only when a package contains no more than a Type A quantity of radioactive material, including only one of the following:

(1) Up to $29 \mathrm{~g}$ of uranium-235;

(2) Up to $18 \mathrm{~g}$ of uranium-233;

(3) Up to $18 \mathrm{~g}$ of fissile radionuclides of plutonium, or

(4) A combination of fissile radionuclides in which the sum of the ratios of the amount of each radionuclide to the corresponding maximum amounts in paragraphs (d) (1), (2), and (3) of this section does not exceed unity.

This subparagraph was added with the latest amendment ${ }^{4}$ to 10 CFR 71 in recognition of the lower critical mass limits that can be obtained with moderators having a hydrogen density greater than water. As discussed above, the mass limits of $\S 71.18(\mathrm{c})(1-3)$ are judged appropriate for water-moderated systems. The potential reduction in fissile mass due to the effect of hydrogen densities greater than water should be consistent for all three fissile nuclides. However, the mass reduction proportion for ${ }^{233} \mathrm{U}$ is not consistent with the mass reduction proportion used for ${ }^{235} \mathrm{U}$ and plutonium. There is no known basis for having a reduction percentage for ${ }^{233} U$ that is greater than the reduction percentage for the other fissile nuclides.

As a means to simplify the general-license requirements, the potential for eliminating $\$ 71.18$ (d) could be considered. Use of high-density polyethylene to optimally moderate pure ${ }^{235} U$ could reduce the minimum critical mass to approximately $527 \mathrm{~g}$. But this value is still greater than the $400-\mathrm{g}$ limit on an exclusive-use shipment as derived from $\$ 71.18(\mathrm{c})$ and appears to provide an adequate margin of safety (albeit reduced from the margin available with ordinary-density water). Maintaining consistency with $\$ 71.59$ relative to five times the number of undamaged packages being subcritical presents a similar discrepancy as discussed above for $\$ 71.18(\mathrm{c})$ and should be considered.

Also, the current regulations have no guidance on how much moderator with a hydrogen density greater than water is needed to require the mass limits of $\S 71.18(\mathrm{~d})$ to be used rather than those of $\S 71.18(\mathrm{c})$.

Recommendation 7: As a minimum, consider revising $\$ 71.18(d)(2)$ to increase the allowed quantity of ${ }^{233} U$ per package to $22 \mathrm{~g}$. A simplification to the section could be obtained if this additional mass reduction for materials with higher hydrogen densities is eliminated. The consequences to safety are a reduction in the current margin, but yet a significant mass margin (greater than $25 \%$ ) even for exclusive use $(T I=100)$ would still be in place.

Providing a minimum specification on the materials of construction for the packaging would further strengthen the justification. Another approach that would relax the mass limits would be to retain the separate limits, but raise the values as noted in Recommendation 6.

A statement should be added to indicate that the mass criteria of $\$ 71.18(d)$ apply whenever the mass of moderator with hydrogen density greater than water exceeds $15 \%$ of the total moderator mass in the package. This percentage is based on assuming the critical mass is inversely proportional to the square of the hydrogen moderator number density (as derived from reference 17). Then, using the critical mass values from Table 3-1 for ${ }^{235} U$ in high-density 
polyethylene and water, together with respective hydrogen number densities, one can determine that the critical mass for a water-moderated sphere will only decrease from 820 to $765 \mathrm{~g}$ if the percentage of high-density moderator is $15 \%$. Thus, using $15 \%$ as the transition criteria for moving to the mass limits of $\$ 71.18(d)$ is judged to be acceptable since there could only be a $7 \%$ decrease $(820 \mathrm{~g}$ to $765 \mathrm{~g})$ in the limiting critical mass.

\$71.18 General license: Fissile material, limited quantity per package. (e) Except for the beryllium contained within the special form plutonium-beryllium sources authorized in paragraph (c) of this section, this general license applies only when beryllium, graphite, or hydrogenous material enriched in deuterium is not present in quantities exceeding $0.1 \%$ of the fissile material mass.

A liter $(1,000 \mathrm{~g})$ of natural water contains $0.017 \mathrm{~g}$ of deuterium. For illustration, the current regulatory restriction limiting beryllium, graphite, and deuterium-enriched material to $0.1 \%$ of the fissile mass would prohibit the shipment of less than $18 \mathrm{~g} \mathrm{U}(93) / 1,000 \mathrm{~g}$ of natural water because the quantity of deuterium would be approximately $0.1 \%$ of the fissile mass. Thus, a shipment with less than $18 \mathrm{~g} \mathrm{U}(93) / \mathrm{L}$ would need to add fissile material - a concept adverse to safety. As a reference point, consider that calculations performed for Appendix A indicate that $10.4 \mathrm{~g}^{235} \mathrm{U} / \mathrm{L}$ natural water is adequately subcritical $\left(\mathrm{k}_{\text {inf }}<0.93\right)$ in an infinite system.

As discussed above, the shipment limit of $400 \mathrm{~g}$ of ${ }^{235} \mathrm{U}$ as allowed under $\$ 71.18$ is well below the subcritical mass limits $\left(\mathrm{k}_{\text {eff }}<0.95\right)$ for ${ }^{235} \mathrm{U}$ as shown in Table 3-1 for water and other materials of concern $\left(\mathrm{Be}, \mathrm{C}, \mathrm{D}_{2} \mathrm{O}\right.$, and $\mathrm{SiO}_{2}$ ). In fact, as discussed in Sect. 2, Table 3-1 illustrates that if mass is used to control criticality safety, water moderation is the limiting system of concern for a water-reflected package. However, if it is possible for the $\mathrm{Be}, \mathrm{C}$, or $\mathrm{D}_{2} \mathrm{O}$ to appear as a reflector to the water-moderated fissile material the critical mass could be lower than the values of Table 3-1. A restriction to limit the quantity of these materials to less than that required to surround a spherical volume of the fissile material by a $2-\mathrm{cm}$ shell may be a cumbersome but comprehensive addition.

Recommendation 8: Delete section $\$ 71.18(e)$. Consider the need to restrict such materials to the point that bulk quantities would not be present to serve as a reflector.

\$71.20 General license: Fissile material, limited moderator per package. (a) A general license is issued to any licensee of the Commission to transport fissile material, or to deliver fissile material to a carrier for transport, without complying with the package standards of subparts $E$ and $F$ of this part if the material is shipped in accordance with this section.

Since the radioactive material must be less than a Type A quantity, the packaging to be used for this general license could be the minimum specified by 49CFR173 (e.g., §173.410) which are judged by this assessment to be inadequate for the mass of fissile material allowed per package. Minimum standards consistent with $\$ 71.43$ are judged to be needed.

\section{See Recommendation 5.}

\$71.20 General license: Fissile material, limited moderator per package. (c) This general license applies only when -

(2) Neither beryllium nor hydrogenous material enriched in deuterium is present;

(3) The total mass of graphite present does not exceed 7.7 times the total mass of uranium-235 plus plutonium;

(4) Substances having a higher hydrogen density than water (e.g., certain hydrocarbon oils), are not present, except that polyethylene may be used for packing or wrapping, 
Tables I and II referenced by $\S 71.20$ provide package mass limits as a function of ${ }^{235} \mathrm{U}$ enrichment. Taking these mass limits together with the TI definition that is provided (10 times the mass of the package divided by the table limit) indicates that an exclusive-use transport of packages under $\$ 71.20$ would have an aggregate fissile mass limit less than the water-moderated, minimum critical mass (see Fig. 4-1). Because the maximum allowable shipment masses are based upon optimumly moderated systems, the inclusion of ${ }^{238} \mathrm{U}$ due to lower uranium enrichments and greater epithermal and thermal neutron capture results in larger subcritical ${ }^{235} \mathrm{U}$ masses than allowed under $\$ 71.18$. As discussed above for $\$ 71.18$ such mass limits for water-moderated systems are minimum values - there is no expectation that the presence of $\mathrm{Be}, \mathrm{C}, \mathrm{D}_{2} \mathrm{O}$, or certain hydrocarbons should lower the mass limits of these tables. It is postulated that these moderator materials were excluded from the license provisions initially because the tables used to derive the mass limits were for hydrogen-moderated systems. As discussed in Sect. 2.1 and demonstrated in the appendixes, these mass limits should be the minimum for all moderators, except for substances that might have a higher hydrogen density than water.

Recommendation 9: Delete $\$ 71.20$ (c)(2-3). Also, as indicated in Recommendation 6, there is a need to clarify the aggregate TI allowed in a shipment of these packages. Exclusion of the $\mathrm{Be}, \mathrm{C}$, and $\mathrm{D}_{2} \mathrm{O}$ as reflector materials may be prudent (see Recommendation 8).

\$71.20 General license: Fissile material, limited moderator per package. (c) This general license applies only when (6)(i) If the fissile radionuclides are not uniformly distributed, the maximum amount of uranium-235 per package may not exceed the value given in Table $I$ of this part; or ...

There is no conditional statement or definition regarding the qualification for ". . not uniformly distributed ..." In Ref. 17, page 47, it is reported that the "... critical mass minimum is far below the smallest rod diameter shown; in fact, computations indicate that it should occur at a diameter of approximately $0.35 \mathrm{~cm}$. The corresponding volume would be extremely large." This statement, taken together with the statement from page 51 of the Ref. 17 - "Below about $10 \%{ }^{235} \mathrm{U}$ enrichment, heterogeneous critical masses are smaller than corresponding homogeneous values" indicates that it is appropriate to consider the development of a definition that provides criteria for establishing when the ${ }^{235} \mathrm{U}$ mass should be considered as not uniformly distributed.

Based on discussions with licensees and the authors' experience, the issue of determining uniform versus nonuniform (i.e., homogeneous versus heterogeneous) is difficult both because of the lack of a regulatory definition and the licensees' ability to ensure homogeneity under all transport conditions. Systems having lumps of fissile material as small as 127 microns are technically considered to be heterogeneous. ${ }^{17}$ Thus, generating a regulatory definition for establishing uniformity will not be straightforward.

A more desirable and straightforward approach is to remove the need to distinguish between uniform and nonuniform by creating a new table that uses the lower of the two mass limits from Tables I and II of 10 CFR 71 . The conveyance mass values derived from these tables and the assumed shipment $T I$ limit of 100 are conservatively below the mass limit curves shown in Figure 4-1 (10 CFR 71 mass limits shown in the figure are for $T I=125$ consistent with the allowance limits of $\$ 71.24$ ). This figure illustrates the increased mass that can be allowed if the system is truly homogeneous (uniform). The mass values in the regulatory tables appear to be established to maintain the same margin of subcriticality for uniform and nonuniform systems. Using only the nonuniform data (Table I) would be conservative but would "penalize" shippers of material with enrichments less than 3 wt \% who can truly demonstrate homogeneity. The advantage to using one table is the elimination of the potential for being nonconservative by declaring a nonuniform system to be uniform. 


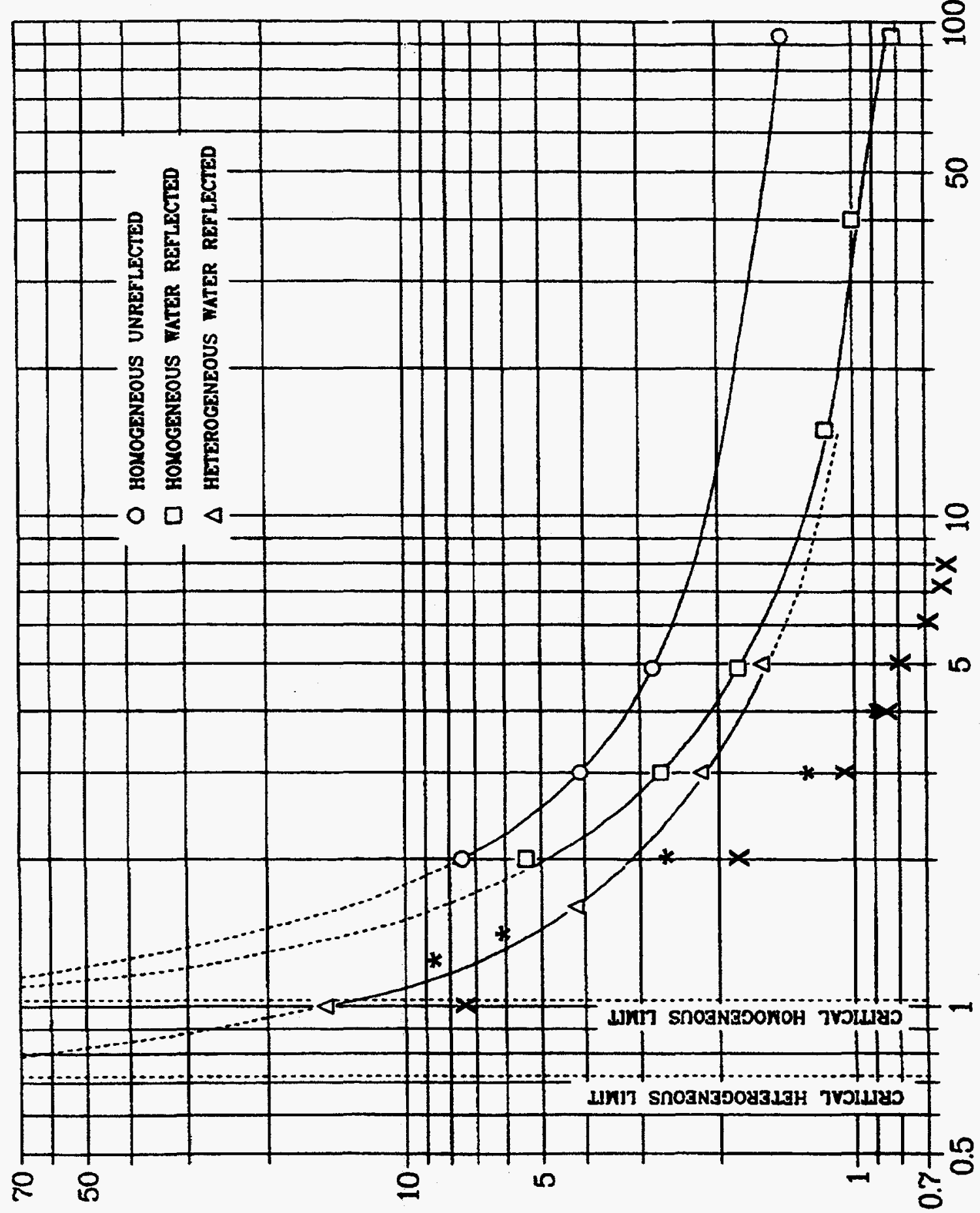

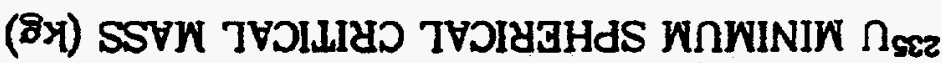


Recommendation 10: Revise the regulations to remove the need for distinguishing between uniform and nonuniform. Depending on the perceived impact on transport, the alternative would be to develop and add a definition to \$71.4 for "Nonuniform distribution" that can be clearly interpreted by the licensees.

\$71.22 General license: Fissile material, limited quantity, controlled shipment. (a) A general license is issued to any licensee of the Commission to transport fissile material, or to deliver fissile material to a carrier for transport, without complying with the package standards of subparts $\mathbf{E}$ and $\mathbf{F}$ of this part if limited material is shipped in accordance with this section.

Since the radioactive material must be less than a Type A quantity, the packaging to be used for this general license could be the minimum specified by 49 CFR 173 (e.g., $\$ 173.410$ ), which are judged by this assessment to be inadequate for the mass of fissile material allowed per package. Minimum standards consistent with $\$ 71.43$ are judged to be needed.

\section{See Recommendation 5.}

\$71.22 General license: Fissile material, limited quantity, controlled shipment. (c) This general license applies only when a package contains no more than a Type A quantity of radioactive material and no more than $400 \mathrm{~g}$ total of the fissile radionuclides of plutonium encapsulated as plutonium-beryllium neutron sources in special form. (d) This general license applies only when: ... (2) the encapsulated plutonium-beryllium neutron sources are in special form and total mass of fissile radionuclides in the shipment does not exceed $2500 \mathrm{~g}$.

The $400-\mathrm{g}{ }^{239} \mathrm{Pu}$ per package is less than the $510-\mathrm{g}{ }^{239} \mathrm{Pu}$ critical mass reported in Ref. 17 , page 65 . However, the total permissible $2500 \mathrm{~g}^{239} \mathrm{Pu}$ mass in a controlled shipment, with no restrictions on specifications for the construction (i.e., mass of encapsulating material to mass of ${ }^{239} \mathrm{Pu}$ ) or use of interstitially moderating neutron shielding material (i.e., high-density polyethylene), cannot be technically justified to provide an equivalence of safety with the other fissile-material exemptions or general licenses. As in $\$ 71.18$, there are no known documented bases for the safety of the permitted $2500-\mathrm{g}{ }^{239} \mathrm{Pu}$ as neutron sources. Another point of concern is that the $2500-\mathrm{g}$ ${ }^{239} \mathrm{Pu}$ controlled shipment "limit" is less than the 4000 -g quantity of plutonium-beryllium sources that is implicitly allowed as an exclusive use shipment $(\mathrm{TI}=100)$ under $\$ 71.18$.

Recommendation 11: Determine and specify, in a revised section, the controlled shipment conditions under which the $2500-\mathrm{g}{ }^{239} \mathrm{Pu}$ permissible mass limit stated in $\$ 71.22(d)(2)$ is acceptable and/or develop acceptable permissible mass limits. See recommendation 6.

\$71.22 General license: Fissile material, limited quantity, controlled shipment. (d)(1) The mass of fissile radionuclides in the shipment is limited such that the

$$
\frac{\text { grams of uranium-235 }}{X}+\frac{\text { grams of other fissile material }}{Y} \leq 1
$$

where $\mathrm{X}$ and $\mathrm{Y}$ are the mass defined in the table following paragraph(d)(2) of this section;... 
Permissible mass limits for shipments of fissile material

\begin{tabular}{|c|c|c|}
\hline Fissile material & $\begin{array}{c}\text { Fissile material mass }(\mathrm{g}) \text { mixed } \\
\text { with substances having a } \\
\text { hydrogen density less than or } \\
\text { equal to water }\end{array}$ & $\begin{array}{c}\text { Fissile material mass }(\mathrm{g}) \text { mixed } \\
\text { with substances having a } \\
\text { hydrogen density greater than } \\
\text { water }\end{array}$ \\
\hline Uranium-235 $(\mathrm{X}) \ldots \ldots \ldots \ldots \ldots \ldots$ & $\mathbf{5 0 0}$ & 290 \\
\hline Other fissile material $(\mathrm{Y}) \ldots \ldots \ldots \ldots$ & 300 & 180 \\
\hline
\end{tabular}

According to the title for $\$ 71.22$, the table of permissible mass limits is for a "controlled shipment." Under $\$ 71.18$ an exclusive-use shipment would enable $400 \mathrm{~g}$ of ${ }^{235} \mathrm{U}$ or $250 \mathrm{~g}$ of ${ }^{239} \mathrm{Pu}$. Thus, the only known rationale for increasing the limit is the reliance on the pre-1996 10 CFR 71 criteria for a Fissile Class III shipment. Under a Fissile Class III shipment the number of packages was limited to the smaller of one-half the number of undamaged packages that was subcritical or the actual number of damaged packages that was subcritical. Using this logic, one can demonstrate that the aggregate TI for a Fissile Class III shipment limited by the undamaged package configuration could be 125 , thus providing a $25 \%$ increase over an exclusive-use shipment limited by a TI $=100$. However, this shipment increase over an exclusive-use shipment of packages is inconsistent with the current provisions of $\$ 71.59(\mathrm{c})(1)$. Another inconsistency of this paragraph is that there is not an increase in mass limit (consistent with a $\mathrm{TI}=125$ value) for fissile material mixed with substances having a hydrogen density greater than water. Notice for this situation that the limit of $290 \mathrm{~g}$ of ${ }^{235} \mathrm{U}$ or $180 \mathrm{~g}$ of other fissile material is consistent with the exclusive-use limit $(\mathrm{TI}=100)$ allowed under $\$ 71.18$.

Recommendation 12: Eliminate $\$ 71.22$ and combine within $\$ 71.18$ by indicating maximum TI for exclusive-use shipments.

\$71.22 General license: Fissile material, limited quantity, controlled shipment. (e) Except for the beryllium contained within the special form plutonium-beryllium sources authorized in paragraphs (c) and (d) of this section, this general license applies only when beryllium, graphite or hydrogenous material enriched in deuterium is not present in quantities exceeding $0.1 \%$ of the fissile material mass.

As discussed above in $\$ 71.18(\mathrm{e})$, this requirement is not necessary for the permissible mass limits specified.

Recommendation 13: Delete $\S 71.22(e)$. Consider need to restrict potential for material to serve as reflector.

\$71.24 General license: Fissile material, limited moderator, controlled shipment. (a) A general license is issued to any licensee of the Commission to transport fissile material, or to deliver fissile material to a carrier for transport, without complying with the package standards of subparts $E$ and $F$ of this part if limited material is shipped in accordance with this section.

Since the radioactive material must be less than a Type A quantity, the packaging to be used for this general license could be the minimum specified by 49 CFR 173 (e.g., $\$ 173.410$ ), which are judged by this assessment to be inadequate for the mass of fissile material allowed per package. Minimum standards consistent with $\$ 71.43$ are judged to be needed.

\section{See Recommendation 5.}


\$71.24 General license: Fissile material, limited moderator, controlled shipment. (c) This general license applies only when ...

(3) Neither beryllium nor hydrogenous material enriched in deuterium is present;

(4) The total mass of graphite present does not exceed 7.7 times the total mass of uranium-235 and plutonium;

(5) Substances having a higher hydrogen density than water (e.g., certain hydrocarbon oils) are not present, except that polyethylene may be used for packing or wrapping;

These requirements are comparable to those in $\$ 71.20(\mathrm{c})$. As indicated in Fig. 4-1, the maximum allowable shipment masses are based upon optimumly water-moderated systems for minimum mass and only a provision to exclude materials with a hydrogen density greater than water needs to be allowed.

Recommendation 14: Delete $§ 71.24(c)(3-4)$.

\$71.24 General license: Fissile material, limited moderator, controlled shipment. (c) This general license applies only when - (6)(i) If the fissile radionuclides are not uniformly distributed, the maximum amount of uranium-235 per package may not exceed the value given in Table III of this part; or

As in $\$ 71.20(\mathrm{c})$ there is no conditional statement or definition regarding the qualification for "... not uniformly distributed ...."

Results reported by Los Alamos ${ }^{17}$ confirm the subcriticality of the permissible shipment masses reported in Tables III and IV of 10 CFR 71. Figure 4-1 shows selected points from Table III (X) and Table IV $(*)$ in relation to critical mass limits based on experimental data. Although the figure indicates the subcritical margin appears appropriate for the permissible shipment masses, these masses are approximately $25 \%$ higher than that allowed by an exclusive use shipment of packages per \$71.20.

Recommendation 15. Revise consistent with Recommendation 10 action. Eliminate $\$ 71.24$ and combine within $\$ 71.20$ by indicating maximum TI for exclusive use shipments.

\$71.53 Fissile material exemptions. Fissile materials meeting the requirements of one of the paragraphs in (a) through (d) of this section are exempt from fissile material classification and from the fissile material package standards of $\$ \$ 71.55$ and 71.59 , but are subject to all other requirements of this part. These exemptions apply only when beryllium, graphite, or hydrogenous material enriched in deuterium is not present in quantities exceeding 0.1 percent of the fissile material mass.

As indicated in the discussion of $\$ \S 71.18(\mathrm{e})$ and $71.22(\mathrm{e})$, the specification to exclude these special moderators is not required for the "consignment" mass limits of $\$ 71.53(\mathrm{a})(1)$-(3) provided multiple consignments are not allowed per conveyance. There is the potential, however, for the placement of multiple consignments on a single conveyance (see below). If the recommendation (see No. 17 below) for conveyance control is implemented, this exclusion on selected special moderators should be removed. If conveyance control is not implemented, some decision is needed on what constitutes an acceptable criteria that can substitute for conveyance control. At that point the results from Appendixes A-E and additional calculations as needed should be used to develop criteria that are less restrictive than the unacceptably low $0.1 \%$ criteria of the current rule. A criteria that provides for a gram of fissile material per gram of noncombustible, nonfissile material may allow a removal of both the moderator restriction and the consignment mass limit. 
The need for a restriction on these special moderators is also not justified for $\$ 71.53(\mathrm{~b})$ because homogeneous material with uranium enriched to less than $1 \mathrm{wt} \%{ }^{235} \mathrm{U}$ should be subcritical even with these special moderators. Also, the nature of the criteria specified for $\$ 71.53$ (c) (uranyl nitrate) and the neutronic characteristics of $\S 71.53$ (d) eliminates the need for such a restriction in these cases.

This introduction to $\$ 71.53$ only exempts the package carrying the material from meeting the requirements of $\S 71.55$ and $\S 71.59$. All other package requirements (e.g., $\$ 71.43)$ must be met. However, if the package contents are less than a Type A quantity of material or satisfy the criteria $\$ 71.10(\mathrm{~b})$ then the package would revert back to any package requirements of 49 CFR 173 just as the general licenses currently do. Thus, as recommended for the general licenses, it is recommended that select fissile exempt packages be required to always meet the requirements of $\$ 71.43$.

Recommendation 16: Based on a resolution to ensure the conveyance is properly limited, the criteria for restricting the special moderators identified in $\$ 71.53$ should be eliminated or revised. Also, see Recommendation 5. A requirement for package standards that satisfy $\$ 71.43$ should be added as appropriate.

\$71.53 Fissile material exemptions. (a) Fissile material such that

$$
\frac{\text { grams of uranium }-235}{X}+\frac{\text { grams of other fissile material }}{Y} \leq 1
$$

for and individual consignment, where $X$ and $Y$ are the mass limits defined in the table following paragraph (a)(3) of this section, provided that:

As discussed in $\$ 71.4$ above, the word "consignment" is not defined in $\S 71.4$. It has been inferred from licensees that there are frequently variable understandings or usages of the words "manifest," "conveyance," "shipment," and "consignment." The variable use of these words seems to be a source of confusion in the licensee cormmunity. It is inferred from discussions with some licensees that, prior to the recent emergency rule making, licensees would offer multiple "manifests," "shipments," or "consignments" of fissile material for transport on a single conveyance in order to limit the total quantity of ${ }^{235} \mathrm{U}$ officially transferred between licensees per the inventory change reports (DOE/NRC Form-741). This point of confusion caused by multiple word usage in the regulations needs to be remedied.

Discussions with licensees have revealed that multiple consignments, individually qualifying as fissile-material exemptions, have been offered (by single consignors) for transport on a single conveyance, thereby potentially exceeding a minimum subcritical mass of fissile material. The logic behind the consignment limit added in the 1996 Edition of the IAEA Regulations (and subsequently 10 CFR 71) was that a consignor would not typically provide multiple consignments to a shipper; in fact, representatives to the IAEA revision process indicated that typical European practice would be that the carrier would insist on having all material from one shipper to one location handled as one consignment. In this country, the shippers have been dividing their material for transport into separate consignments; in one instance because the receiving site that disposes of the material below ground can only handle $350 \mathrm{~g}$ on site above ground. Thus, multiple consignments on a transport allow the transport vehicle to remain at the site boundary, while each single ( $<350 \mathrm{~g}$ consignment) is separately brought on site for disposal. This practice was perfectly legitimate under previous regulatory rules and remains strictly legitimate under the current rule because the fissile mass restriction only applies to the consignment.

Since the table referenced under $\$ 71.53(\mathrm{a})$ provides mass limits per consignment that are consistent with exclusive use conveyances allowed under $\$ 71.18$, this practice of offering multiple consignments can thereby cause one conveyance to have quantities of fissile exempt material greater than any quantity permitted under the general 
license provisions. Even though there are other conditions and criteria that must be met for exemption status under \$71.53(a), there appears to be an inconsistency in the margin of safety provided between general licenses and the fissile exemptions unless some accumulation control is provided.

Finally, the title of the referenced table is "THE REQUIREMENTS FOR PACKAGES CONTAINING FISSILE MATERIAL" not "INDIVIDUAL MASS LIMITS FOR AN INDIVIDUAL CONSIGNMENT," thereby further confounding the intent of a package - consignment - shipment issue.

Recommendation 17: As a minimum the table title needs to be changed to be consistent with its intent of limiting the consignment mass. However, it is probably more appropriate to limit the quantity of fissile material exempted from the requirements of $\$ 71.53(a)$ by restricting the permissible mass per conveyance to the values shown in the reference table. These masses are consistent with an exclusive-use shipment allowed under \$71.18. The only means for ensuring conveyance mass limits is to implement use of a TI based on the mass quantity of fissile material in the package or consignment. The TI would be defined such that the sum of the TIs for the packages and/or consignments on the conveyance would be limited to 100. (See discussion below relative to assessment of need for exclusive use shipment.). A simple alternative to implementing a TI for exempt quantities is to merely add a sentence to the introduction of $\$ 71.53(a)$ that states, "These exemptions apply only for a single consignment per conveyance."

It is further recommended that the impact of implementing a TI on a fissile exempt package be carefully considered relative to the impact on shippers of limited quantities of radioactive material under \$173.421. Currently, this DOT regulation allows a package to be exempt from packaging, marking, and labeling specifications provided certain constraints are met and the fissile quantity is limited to $15 \mathrm{~g}$ of ${ }^{235} \mathrm{U}$. The need to label such a package with a TI could have a major, and potentially unnecessary, impact on the isotope industry. Lowering the ${ }^{235} U$ limit or providing a criteria for allowable grams of ${ }^{235} U$ per gram of other material (see Sect. 5) are possible solutions that should be considered.

The best possibility for eliminating the need for conveyance control and current moderator restrictions would be to implement criteria related to the ratio of the mass of fissile material to the mass of nonfissile material. If this approach is applied, the nonfissile material included in the determination should be insoluble-in-water and noncombustible. Also, the mass of $\mathrm{Be}, \mathrm{D}_{2} \mathrm{O}$, or $\mathrm{C}$ in the package should be excluded from determination of the ratio.

\$71.53 Fissile material exemptions. (b) Uranium enriched in uranium-235 to a maximum of 1 percent by weight, and with total plutonium and uranium-233 content of up to 1 percent of the mass of uranium-235, provided that the fissile material is distributed homogeneously throughout the package contents and does not form a lattice arrangement within the package.

The requirement for homogeneity is similar to the requirement for nonuniformity in $\$ 71.20(\mathrm{c})(6)(\mathrm{i})$ and $\$ 71.24(\mathrm{c})(6)(\mathrm{i})$ which is discussed above. If the concentration of the fissile material remains within $5 \%$ throughout the matrix material, then this criteria appears to be acceptable. ${ }^{24}$ However, one still must ensure homogeneity to this $5 \%$ variation and also ensure prevention of a "lattice arrangement." Removing the requirement for homogeneity and lattice prevention would cause a need to reconsider moderator restriction requirements since heterogeneous systems of material with less than $1 \mathrm{wt} \%{ }^{235} \mathrm{U}$ can be made critical in high-purity moderators such as $\mathrm{Be}, \mathrm{D}_{2} \mathrm{O}$, or $\mathrm{C}$.

Recommendation 18: Develop a definition of homogeneity that can be clearly understood for use with material having enrichments less than 1 wt $\%{ }^{235} U$. Analyses such as those performed for Ref. 12 should be considered. 
Clarify the term "lattice arrangement" or eliminate its use. If definitions and clarifications cannot be provided, then a restriction on $\mathrm{Be}, \mathrm{D}_{2} \mathrm{O}$, and $\mathrm{C}$ should be maintained for this provision. 


\section{DISCUSSION AND RECOMMENDATIONS}

Section 4 provides specific assessment comments and recommendations for change relative to the fissile material general licenses and the fissile-material exemptions of 10 CFR 71. These separate recommendations of Sect. 4 address detailed inconsistencies, unnecessary constraints, and potential inadequacies while confirming the overall adequacy of the regulations. The purpose of this section is to provide a more general assessment and discussion that will focus on the major issues related to understanding the current specifications and the potential impact of the recommended changes.

\subsection{Technical and Regulatory Basis}

\subsubsection{General Licenses}

The requirements of the general licenses for fissile material appear to have been developed to control transport of less than Type A quantities of fissile material by specifying safe-mass limits. The general licenses ( $\$ \$ 71.22$ and 71.24$)$ allow for an increased quantity of fissile material within a controlled shipment (assumed to be same as an exclusive-use shipment), presumably in recognition of the added margin of safety afforded by a controlled shipment. Only licensees of the NRC with an approved quality assurance program can transport using a general license, and shipments are controlled via use of a transport index (TI) for each package ( $\$ \S 71.18$ and 71.20 ) or via DOT shipment requirements that prevent commingling with other fissile material shipments ( $\$ \S 71.22$ and 71.24 ). However, the lack of specifications for the package integrity (aside from radiological requirements of 49 CFR 173) is felt to be a deficiency that should be corrected. The regulatory basis for not specifying clear package standards is not known, but it could be that there was reliance on the licensee experience with handling fissile material and the associated quality assurance program to maintain adequate packaging and controls. If this is the case, providing some minimal packaging specifications would be prudent and should not affect operations of a licensee with a properly implemented program for handling fissile material.

The quantities of fissile material allowed in a shipment under any of the general licenses have a sound technical basis related to information on minimum critical masses of water-reflected, water-moderated systems. As discussed in Sect. 2.1 and shown in Appendixes A-E, the minimum critical mass will always occur for hydrogenous-moderated systems. And, as Appendix $A$ indicates, subcriticality $\left(k_{\text {eff }} \leq 0.95\right)$ is readily maintained with a water-moderated fissile-material mass value $\left(614 \mathrm{~g}\right.$ of $\left.{ }^{235} \mathrm{U}\right)$ greater than allowed by the general-license provisions of $\$ 71.18\left(400 \mathrm{~g}^{235} \mathrm{U}\right)$ and $\$ 71.22\left(500 \mathrm{~g}^{235} \mathrm{U}\right)$. The reference-measured critical mass value for similar systems is $820 \mathrm{~g}$ (see Ref. 17). Similarly, Tables I-IV of $\S 71.20$ and $\$ 71.24$ provide prudently conservative mass limits for fissile material shipments of varying enrichment depending on the classification as a uniform or nonuniform mixture. The shipment limits are compared with reference measured critical mass values in Figure 4-1.

In some instances, details of the rationale behind certain requirements in the general licenses have become blurred by time and inconsistencies in word usage and inferred intent. One example is the limited moderator specifications of $\S 71.20$ and $\$ 71.24$ and the more-recent moderator restrictions placed in $\$ 71.18$ and $\$ 71.20$. With the fissile material quantities allowed (below the minimum for water-moderated, water-reflected systems), even in an exclusive use shipment, the need for limiting the moderator is not technically necessary, except perhaps in the case of the Pu-Be neutron sources. It is speculated that the moderator limitations were included only because information on their effect was not available when the regulatory language was first developed. Unfortunately, even with moderator limitations, the technical basis for the quantity of Pu-Be neutron sources allowed in a shipment could not be verified by this work. Scenarios allowed under the regulations (see Sect. 4) can be easily demonstrated as adverse to criticality safety. If practical information related to the formation and packing of neutron sources is determined to substantially mitigate the challenges to criticality safety identified by these scenarios, then this information needs to be incorporated into the regulations.

Another example of the blurring of the original intent of the regulations relates to the retention of specific sections (i.e., $\$ 71.22$ and $\$ 71.24$ ) for controlled shipments. No aggregate TI limits are specified in the associated sections for packages 
(i.e., $\$ 71.18$ and $\S 71.20$ ), thus it is assumed that shipments are limited to a $T I=50$ for nonexclusive use and $T I=100$ for exclusive use per $\$ 71.59$. This assumption raises the issue as to why there are currently separate sections for the controlled or exclusive-use type of shipments, particularly in light of the fact that these sections (i.e., \$71.22 and \$71.24) allow a greater mass (approximately 25\%) of fissile material per shipment than allowed by an exclusive use shipment under $\$ 71.18$ and $\$ 71.20$. The basis is apparently a holdover from the pre-1996 regulations, where application of fissile classes provided an opportunity for a shipper to transport $25 \%$ more mass in a Fissile Class III shipment than in a shipment of Fissile Class II packages if the package TI was limited by the normal conditions of transport. This inconsistency with the current approach of the regulations as presented in $\$ 71.59$ (never allow more than $T I=100$ ) needs to be addressed.

\subsubsection{Fissile-Material Exemptions}

Unlike the general licenses, the fissile-material exemptions of $\$ 71.53$ can apply to packages with greater than "Type A quantities of material. The exemptions only allow packages that meet the content specifications of $\$ 71.53$ to ignore the standards and controls of $\S \S 71.55$ and 71.59 regarding fissile material packages. Many of the criteria that must be met prior to classification as fissile exempt material have direct links to available reference information on critical-safe parameter values (parameter values that, if maintained, will ensure subcriticality) for water-moderated, water-reflected systems. ${ }^{25}$ The critical-safe parameter values can be readily found in many reference handbooks, such as Ref. 17, and many can be derived from the results shown in Appendix A.

Historically, the major technical and regulatory weakness of the fissile exemption criteria has been that they rely on assurance that the as-presented fissile-exempt package will not be affected by transport conditions to the detriment of the critical-safe parameter values upon which safety was based. This rationale cannot be provided generically for all possible shipment scenarios. With this recognition, the IAEA and subsequently the NRC provided ${ }^{3,4}$ selected consignment mass limits in addition to the applicable fissile exempt criteria. The consignment limit was assumed to provide ad hoc control for ensuring the fissile mass on the conveyance was limited. As demonstrated by dialogue with shippers, this approach does not appear to be satisfactory based on shipment practice in the United States, where multiple consignments per conveyance have been provided to limit the official transfer of fissile mass quantities. Licensees have also expressed concern that the consignment restrictions are far too limiting based on the subcritical characteristics of the exemption criteria and the small risk of $\mathrm{HAC}$ rearranging the fissile material to a form that would cause a criticality concern.

The limit on the $\mathrm{Be}, \mathrm{C}$, and $\mathrm{D}_{2} \mathrm{O}$ allowed in a fissile-exempt material is overly restrictive, as discussed in Sect. 4 . However, the technical need for some limit is valid unless the quantity of fissile material per conveyance is controlled or criteria are implemented to mitigate the potential effect of their presence. The reason for this conclusion is that criteria such as the 5-g-per-10-L criteria of $\$ 71.53$ (a)(3) assume a water-moderated system; much lower concentrations would be needed if the fissile material was mixed with $\mathrm{Be}, \mathrm{C}$, or $\mathrm{D}_{2} \mathrm{O}$. However, if the quantity (mass) of fissile material on a conveyance is controlled by a limiting mass for water-moderated, water-reflected systems, then a moderator restriction could be eliminated. Another alternative may be the use of a gram fissile/gram nonfissile ratio that excludes $\mathrm{Be}, \mathrm{C}$, and $\mathrm{D}_{2} \mathrm{O}$ from the ratio determination.

One inconsistency between the mass limits provided for the select fissile-material exemptions and those of the general licenses is that the quantity allowed under the fissile exemptions is equal to the quantity allowed on an exclusive-use vehicle under the general license. However, the mode of transport for the package shipped under the fissile-material exemptions would be determined based on the TI for radiological control. This could be put forth as an argument for lowering the consignment limits under the fissile-material exemptions or raising the mass limits allowed under the general licenses (subject to specification of minimal package integrity standards). 
A fundamental question to address when considering criteria modifications for the fissile exemptions is whether the criteria must ensure inherent safety based on a theoretical basis or can credible arguments be formulated about what can and will be shipped or what can and will happen. The latter approach seems to be the basis for the initial formulation of the exemptions and general licenses for fissile material. The difficulty with this approach is that "what can and will be shipped" changes with the needs of the industry and "what can and will happen" varies with the shipper and the conditions of shipment. Compounding this problem is the fact that shipments made under fissile exemption are not monitored to the degree that a clear picture can be provided of what has been shipped historically. However, taking a strict theoretical approach leads one to a criteria that may be viewed as unreasonable based on historic practice and safety record.

\subsection{Equivalent Safety}

One of the basic premises of the transport regulations is that subcriticality be maintained under both normal conditions of transport and hypothetical accident conditions. The regulations are formulated to ensure subcriticality by specifying requirements that must be met for packages containing fissile material and implementing operational controls (e.g., transport index) for the shipment. These package requirements seek to ensure that the chemical, physical, and material conditions of the package necessary for subcriticality are maintained under normal conditions of transport and hypothetical accident conditions. The operational controls have been implemented to allow straightforward procedures for safe handling of the packages by transportation personnel who are not criticality specialists.

Table 5-1 provides a comparison of the various criteria provided under the general license sections and the fissile exemption section for transport of high-enriched uranium. The table basically highlights the inconsistencies discussed in Sect. 5.1 relative to shipment requirements, package requirements, and allowed fissile mass. Developing a judgement on the equivalency of the requirements compared in Table 5-1 is difficult because it cannot be made on a firm quantitative basis.

Table 5-1 Comparison of allowable limits and requirements for shipment of ${ }^{235} U$ under the general licenses or fissile exemptions

\begin{tabular}{|c|c|c|c|c|c|}
\hline Provision & $\begin{array}{l}{ }^{235} \mathrm{U} \text { mass limit, } \\
\text { nonexclusive use }\end{array}$ & $\begin{array}{l}{ }^{235} \mathrm{U} \text { mass limit, } \\
\text { exclusive use }\end{array}$ & $\begin{array}{l}\text { Package } \\
\text { requirement }\end{array}$ & $\begin{array}{l}\text { NRC shipper } \\
\text { requirements }\end{array}$ & Comments \\
\hline$\S 71.18$ & $200 \mathrm{~g}$ & $400 \mathrm{~g}$ & $\begin{array}{l}\text { Based on } \\
\text { radioactivity } \\
\text { (<Type A) }\end{array}$ & $\begin{array}{l}\text { NRC licensee w/ } \\
\text { approved QA } \\
\text { program }\end{array}$ & $\begin{array}{l}\text { Controlled } \\
\text { via TI }\end{array}$ \\
\hline$\S 71.20$ & $\begin{array}{l}200 \mathrm{~g}(>24 \% \\
\left.\text { enriched in }{ }^{235} \mathrm{U}\right)\end{array}$ & $\begin{array}{l}400 \mathrm{~g}(>20 \% \\
\left.\text { enriched in }{ }^{235} \mathrm{U}\right)\end{array}$ & $\begin{array}{l}\text { Based on } \\
\text { radioactivity } \\
\text { (<Type A) }\end{array}$ & $\begin{array}{l}\text { NRC licensee w/ } \\
\text { approved QA } \\
\text { program }\end{array}$ & $\begin{array}{l}\text { Controlled } \\
\text { via TI }\end{array}$ \\
\hline$\S 71.22$ & - & $500 \mathrm{~g}$ & $\begin{array}{l}\text { Based on } \\
\text { radioactivity } \\
(<\text { Type A) }\end{array}$ & $\begin{array}{l}\text { NRC licensee w/ } \\
\text { approved QA } \\
\text { program }\end{array}$ & $\begin{array}{l}\text { Exclusive use } \\
\text { control }\end{array}$ \\
\hline$\S 71.24$ & -- & $\begin{array}{l}520 \mathrm{~g}(>20 \% \\
\left.\text { enriched in }{ }^{235} \mathrm{U}\right)\end{array}$ & $\begin{array}{l}\text { Based on } \\
\text { radioactivity } \\
\text { (<Type A) }\end{array}$ & $\begin{array}{l}\text { NRC licensee w/ } \\
\text { approved QA } \\
\text { program }\end{array}$ & $\begin{array}{l}\text { Exclusive use } \\
\text { control }\end{array}$ \\
\hline$\S 71.53(\mathrm{a})$ & $\begin{array}{l}400 \mathrm{~g} \text { per } \\
\text { consignment }\end{array}$ & $\begin{array}{l}400 \mathrm{~g} \text { per } \\
\text { consignment }\end{array}$ & $\begin{array}{l}\text { All except } \\
\$ 71.55 \text { and } \\
\$ 71.59\end{array}$ & $\begin{array}{l}\text { Depends on } \\
\text { material }\end{array}$ & $\begin{array}{l}\text { Satisfy } \\
\text { exempt } \\
\text { criteria }\end{array}$ \\
\hline
\end{tabular}


However, the mass inconsistency between an exclusive-use shipment made under $\$ 71.18$ or $\$ 71.20$ versus one made under $\$ 71.22$ or $\$ 71.24$ is apparent and should be corrected. Comparison of the fissile exemption and general license criteria for equivalent safety is more difficult and hinges on whether the fissile-exempt criteria that must be met at shipment provide sufficient additional restriction to allow uncontrolled (no TI) transport of fissile material. The conclusion drawn from Sect. 4 is that the exempt criteria are not sufficient to allow consignment limits with no conveyance control. A follow-on question is whether the criteria for classification as fissile-exempt material are sufficient to warrant allowance of $400 \mathrm{~g}$ in any nonexclusive-use shipment rather than $200 \mathrm{~g}$ as provided by the general licenses.

The lack of packaging integrity for the general licenses and fissile-material exemptions should be clearly reflected in the restrictions placed on the transport. However, the limiting conditions for the general licenses and fissile-material exemptions do not clearly correlate with subcriticality and safety for the packaging and transportation of fissile material under both normal conditions of transport (where at least five times the number of undamaged packages per shipment is adequately subcritical) and hypothetical accident conditions (where at least two times the number of damaged packages per shipment is adequately subcritical). In other words, it is easy to conceive of instances (perhaps not altogether practical, but possible from the regulations) where the subcritical margin provided by a fissile material exemption shipment is perhaps less than that provided by a certified fissile package.

Of course the real subcritical safety margin for certified packages and fissile-exempt packages will vary with the individual packages. The lack of specification for packages used under general license and fissile exemption provisions means that equivalency is best evaluated by consistency with $\$ 71.55$ and $\$ 71.59$ requirements. In particular, consider the discussion of Sect. 4 relative to the fact that the $200-\mathrm{g}$ limit for nonexclusive-use transport of ${ }^{235} \mathrm{U}$ under $\$ 71.18$ is more than $1 / 5$ the measured minimum critical mass value of $820 \mathrm{~g}$ for a water-reflected, homogeneous system. Because there is no knowledge of the package, no credit can be provided. Thus, pure equivalency with the requirements of $\$ 71.59$ is not provided. However, the $820 \mathrm{~g}$ value for ${ }^{235} \mathrm{U}$ is a measured minimum and accumulation of such a mass would require complete loss of packaging and an optimized, idealized spherical configuration under normal conditions of transport - a rather improbable occurrence. The mass limits under $\$ 71.18$ and $\$ 71.20$ do provide for assurance that, even under exclusive use, twice the quantity would be subcritical - a requirement of $\$ 71.59$ for accident conditions of transport. The HAC provide the potential situations where the $820 \mathrm{~g}$ value is most likely to be challenged in actual transport. Implementation of some minimum packaging standards would also provide a normal condition subcritical value greater than the minimum critical value discussed here and most likely would be far greater than $1000 \mathrm{~g}$, the minimum needed for consistency with the $1 / 5$ specification of $\$ 71.59$. Examples of the effect that packaging material can have on neutron multiplication can be found in the analysis of Appendixes A-E and Ref. 25.

In summary it would be difficult to formulate a definitive theoretical argument that the transport safety criteria. for general licenses and exemptions for fissile material conform with the transport safety criteria imposed by the standard requirements and controls for packages containing fissile material. However, consideration of practical arguments relative to the events that must occur to compromise safety indicate adequate equivalence is provided relative to the quantities of materials allowed, assuming conveyance control or its equivalence is provided for the fissile exemptions. In fact, the assessment further indicates that a requirement to use packaging that meets $\$ 71.43$ should enable the fissile-material mass limits to be raised for the general licenses.

\subsection{Recommendations}

The bases for and clarity of the general licenses for fissile material and the exemptions for fissile material in 10 CFR 71 have become increasingly obfuscated with adjustments and accommodations of the regulations over time, as well as with shipper (consignor) interpretations and applications. Any proposed revision of these portions of the regulations should seek to provide clear, unambiguous, and straightforward specifications. The regulations should specify simplified bounding 
requirements that provide fissile material general licenses and exemptions with a near equivalency in safety as that applied to packages certified to transport fissile material.

Section 4 provides a discussion of the issues as well as numerous recommendations to ensure that 10 CFR 71 provides broad, yet simple requirements. The recommendations of Sect. 4 often include more than one approach to improving the regulations and the best approach to select requires an overall consideration of all the recommendations. This section provides and discusses a consistent set of recommendations that are judged to be the most straightforward and effective for consideration in any future rule-making process.

\subsubsection{General Recommendations}

- Consistency in definition and stated intent needs to be provided to the extent possible. It is recommended that definitions for "consignment," "consignor," and "shipper" be provided. Furthermore, the licensee is subject to possible confusion because of the differences between the wording used in 49 CFR 173 and 10 CFR 71 . Even within 10 CFR 71 there are instances where no guidance or definition of words is provided to help clearly identify or explain the required specifications. For example, the regulations need to eliminate the wording "controlled shipment" or distinguish it from "exclusive-use shipment."

- The definition of fissile material should be simplified and made technically correct by eliminating the nuclide ${ }^{238} \mathrm{Pu}$ from the definition. The impracticality of obtaining a large enough mass required for criticality $(6 \mathrm{~kg})$ and the high decay heat rate prevent any conceived consequences of this change that are adverse to criticality safety. Similarly, the usage of the words "fissile material" in the regulations needs to be clarified; sometimes it is used to specify fissile nuclides, while other times it is used to imply material containing fissile nuclides.

- The criteria for exempting fissile material from consideration as radioactive material regulated by 10 CFR 71 [e.g., $\$ 71.10(a)]$ should be revised to not allow material with known quantities of fissile material from being included in the radioactive material exemption. This is the simplest and most straightforward approach. An alternative would be to lower the exemption concentration such that an infinite system would be subcritical. These criteria correspond to a value of $43 \mathrm{~Bq} / \mathrm{g}$ and are judged to be sufficiently limiting for all materials. An infinite medium subcritical concentration is sufficiently small, and the associated volume for criticality so large, that a change in concentration associated with the required volume for criticality is not deemed probable in a practical system.

- Although not discussed previously in the assessment, it is also recommended that $\$ 71.10$ (b) be modified to ensure that exemptions are not provided to fissile material which should meet some packaging requirement (e.g., §71.53(d)). The recommendations under Sect. 5.3.3 include some additional packaging requirements for selected fissile-material exemptions.

- The fissile-material exemptions should be moved to Subpart B - "Exemptions." Placement of the fissile-material exemptions under Subpart B would be more consistent with the placement of other exemptions of 10 CFR 71 .

- The NRC or DOT should consider keeping a database of shipments made under fissile-material exemptions and general license(s). The database should include a description of material shipped; the mass of fissile material in the consignment or shipment; the TI of the shipment, if applicable; the exemption criteria satisfied, if applicable; and the package description, if applicable. The database would be used to provide the NRC with historical information to better understand the type of material being shipped under the fissile-material exemptions and general licenses so that a more informed decision can be made relative to the impacts of any future changes to these portions of the regulations. 


\subsubsection{Recommendations for General Licenses}

- The provisions related to shipment of Pu-Be sources should be removed from the general licenses. It may be possible to develop a separate general license for Pu-Be sources that addresses the concerns cited in Sect. 4 . The quantity of plutonium currently allowed to be shipped as Pu-Be sources is not technically justified based on available information and the lack of packaging requirements provided in the current regulations. Any new section that is developed should revise the quantity of plutonium allowed to be shipped as $\mathrm{Pu}$-Be neutron sources and/or provide packaging requirements that prevent challenges to the basis for criticality safety.

- The general licenses for controlled shipments ( $\$ \$ 71.22$ and 71.24$)$ should be merged with the general licenses for limited quantity per package ( $\$ \$ 71.18$ and 71.20 ) to provide a single general license paragraph that consolidates the needed technical criteria and operational controls. This merger, together with a clear specification of the aggregate TI allowed for nonexclusive use and exclusive use, should provide consistency with the approach of $\$ 71.59$ and simplify the regulations.

- The distinction between quantities of ${ }^{235} U$ that can be shipped as a uniform distribution and nonuniform distribution should be eliminated. The bounding nonuniform quantities should be used. This change is recommended because the simplicity offered by this solution outweighs the complexity and confusion that would result from trying to develop a comprehensive definition for "nonuniform," which is currently lacking in the regulations.

- Restrictions on quantities of $\mathrm{Be}, \mathrm{C}$, and $\mathrm{D}_{2} \mathrm{O}$ should be removed from the general licenses, except perhaps to indicate these materials should not be present as a reflector material. Restricting its presence in quantities that might provide reflection of neutrons should be fairly simple and would be prudent since these packages are not under regulatory review. Limiting the quantity of these materials to $500 \mathrm{~g}$ per package should eliminate any concern relative to their effectiveness as a reflector.

- Maintaining a separate mass control (cf. §71.18) or restriction (cf. $\$ 71.20$ ) for moderators having a hydrogen density greater than water is recommended. Where separate mass limits are provided, the fissile mass limit associated with moderators having hydrogen density greater than water should be used whenever such a high-density hydrogenous moderator exceeds $15 \%$ of the mass of hydrogenous moderator in the package.

- Minimum package requirements as provided by $\$ 71.43$ should be specified for shipments under the general licenses. The intent is to include good practice that an NRC licensee should have in place under a quality assurance program that handles shipment of fissile material with low specific activity.

- The package mass limits currently allowed by $\$ 71.18$ and $\$ 71.20$ should be increased to provide similar safety equivalence provided by certified packages per the criteria of $\S \S 71.55$ and 71.59 . Justification for these increases is based partly on the implementation of an improved minimum packaging standard ( $\$ 71.43)$, as discussed above. The recommended mass values are provided in Tables 5-2 and 5-3. The values in Table 5-2 were obtained by raising the mass limits to just under the mass values that ensure subcriticality $\left(k_{\text {eff }} \leq 0.95\right)$ based on the information of Table 3-1. The fissile-material mass values for systems with moderators having a hydrogen density greater than water were subsequently obtained by using a scaling factor based on the ${ }^{235} \mathrm{U}$ critical mass values for a water-moderated system $(820 \mathrm{~g})$ and a system moderated by high-density polyethylene $(527 \mathrm{~g})$. The values of Table $5-2$ were obtained using a scaling factor based on the ratio of the new water-moderated ${ }^{235} \mathrm{U}$ limit shown in Table 5-1 (60 g) and the existing value of $\S 71.18(40 \mathrm{~g})$. 
Table 5-2 Mass limits for general-license packages containing mixed quantities of fissile material or ${ }^{235} \mathrm{U}$ of unknown enrichment

\begin{tabular}{|c|c|c|}
\hline Fissile material & $\begin{array}{l}\text { Fissile-material mass } \\
\text { (g) mixed with } \\
\text { moderating substances } \\
\text { having an average } \\
\text { hydrogen density less } \\
\text { than or equal to } \mathrm{H}_{2} \mathrm{O}\end{array}$ & $\begin{array}{l}\text { Fissile-material mass } \\
(\mathrm{g}) \text { mixed with } \\
\text { moderating substances } \\
\text { having an average } \\
\text { hydrogen density } \\
\text { greater than } \mathrm{H}_{2} \mathrm{O}^{a}\end{array}$ \\
\hline 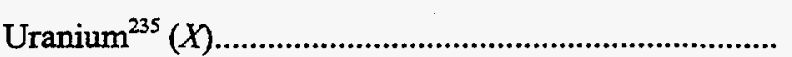 & 60 & 38 \\
\hline Uranium $^{233}(Y)$ & 43 & 27 \\
\hline 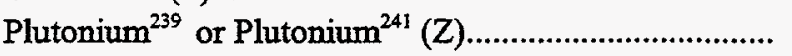 & 37 & 24 \\
\hline
\end{tabular}

${ }^{a}$ For mixtures of moderating substances: if more than $15 \%$ of the moderating substance has an average hydrogen density greater than $\mathrm{H}_{2} \mathrm{O}$, then the lower mass limits shall be used.

Table 5-3 Mass limits for general-license packages containing ${ }^{235} \mathbf{U}$ of known enrichment

\begin{tabular}{c|c}
\hline $\begin{array}{c}\text { Uranium enrichment in weight } \\
\text { percent of }{ }^{235} \mathrm{U} \text { not exceeding }\end{array}$ & $\begin{array}{c}\text { Permissible maximum grams } \\
\text { of }{ }^{235} \text { U per package }(\mathrm{X})\end{array}$ \\
\hline 24 & 60 \\
20 & 63 \\
15 & 67 \\
11 & 72 \\
10 & 76 \\
9.5 & 78 \\
9 & 81 \\
8.5 & 82 \\
8 & 85 \\
7.5 & 88 \\
7 & 90 \\
6.5 & 93 \\
6 & 97 \\
5.5 & 102 \\
5 & 108 \\
4.5 & 114 \\
4 & 120 \\
3.5 & 132 \\
3 & 150 \\
2.5 & 180 \\
2 & 246 \\
1.5 & 408 \\
1.35 & 480 \\
1 & 1,020 \\
0.92 & 1,800 \\
\hline &
\end{tabular}




\subsubsection{Recommendations for Fissile-Material Exemptions}

- The mass-limited exemptions of $\$ 71.53$ (a) should be revised to provide criteria based on a ratio of the mass of fissile material per mass of nonfissile material. The nonfissile material considered in the ratio determination should be insoluble-in-water and noncombustible. It may be necessary to provide a definition and/or criteria for such material. Mass quantities of $\mathrm{Be}, \mathrm{C}$, and $\mathrm{D}_{2} \mathrm{O}$ should be excluded from consideration as nonfissile material for the purposes of determining the ratio value. This approach would

1. add enhanced ensurance in preventing a potential transport situation that could provide a criticality safety concern; and

2. maintain flexibility for regulators, licensees, and operators by precluding the need to prescribe and use a TI for transport control.

Mass ratios are often easier for licensees to determine than values related to volumetric concentration, and they can be defined to provide sufficient control under HAC (i.e., ensurance that desired volumes are maintained during HAC is much more difficult than ensurance that mass values are maintained). The recommended ratios of fissile-to-nonfissile mass for the various exemption considerations are provided in Table 5-4 and discussed in Appendix $G$. If the approach using mass ratios is not acceptable, then conveyance control based on a $T I$ should be incorporated into the fissile exemptions.

- The restriction on $\mathrm{Be}, \mathrm{C}$, and $\mathrm{D}_{2} \mathrm{O}$ in $\$ 71.53(\mathrm{a}), \S 71.53(\mathrm{c}), \S 71.53(\mathrm{~d})$ should be removed if either approach (defined mass ratios or TI) discussed in the previous bullet is adopted.

- The exemption for uranyl nitrate solutions should be revised to incorporate packaging standards of $\S 71.43$.

- The exemption for uranium enriched to less than $1 \mathrm{wt} \%{ }^{235} \mathrm{U}$ should be modified to remove the requirement for homogeneity and prevention of a lattice arrangement. Instead, the moderator criteria restricting the mass of $\mathrm{Be}, \mathrm{C}$, or $\mathrm{D}_{2} \mathrm{O}$ to less than $0.1 \%$ of the fissile mass should be maintained. This change removes the need to provide definitions which are difficult to define and to apply practically, such as "homogeneous"and "lattice arrangement."

Table 5-4 Proposed fissile-exempt mass ratios to replace criteria of $\$ 71.53(a)$

\begin{tabular}{c|c}
\hline Package fissile material limit & Ratio: Fissile-to-nonfissile \\
\hline $15 \mathrm{~g}$ & $1: 200$ \\
$350 \mathrm{~g}$ & $1: 2000$ \\
$350 \mathrm{~g}$ & $1: 200^{\circ}$ \\
\hline
\end{tabular}

${ }^{a}$ Packaging required to satisfy standards for NCT. 


\section{SUMMARY}

From the review of $10 \mathrm{CFR} 71$ and interviews with personnel knowledgeable on fissile material transport applications made under the general license and fissile-material exemptions, it is perceived that there are no significant and immediate criticality safety hazards associated with the practical applications of the general licenses and exemptions. The reason for this conclusion is that the typical qualifying fissile material matrix in a general license or exempt consignment is relatively stable as dry activated waste or in a nearly noncombustible form. The consignment mass limits added to the fissile-material exemptions with the latest amendment to 10 CFR 71 enhance the safety margin. However, the fissile material general licenses and exemptions have not had an understandable and defensible equivalency of safety with the packaging and transportation of fissile material in certified packages. There are areas where shipments that adhere to the regulations could compromise the safety margin deemed acceptable for transportation. In addition, the confusion over what is intended by the general provisions and exemptions could cause inconsistency among shippers based on interpretation and, in some cases, could result in an unsafe practice. For example, the basis of the $15 \mathrm{-g}$ limit for fissile-exempt packages was always predicated on an assumed limit to the aggregate mass on a shipment, but the controls for this were not placed in the regulations; therefore, the basis was lost to the shipper seeking safe transport of material in conformance with the regulations. Similarly, there is some over simplification relative to the restriction on $\mathrm{Be}, \mathrm{C}$, and $\mathrm{D}_{2} \mathrm{O}$ being set so low as to exclude inherently safe packages of fissile material from being exempt. In fact, the restriction of deuterium to $0.1 \%$ of the fissile mass can even prevent some inherently safe water-moderated shipments from being made as an exempted shipment.

The reduced regulatory oversight provided to exempt and general-license shipments makes it important that the technical and licensing basis for these portions of the regulations be well documented and understood by the transport community. This report has sought to provide an assessment of the fissile-material general licenses and fissile exemptions that can be used to understand the technical issues related to the current regulations and to provide recommendations that should be considered in implementation of future changes. 


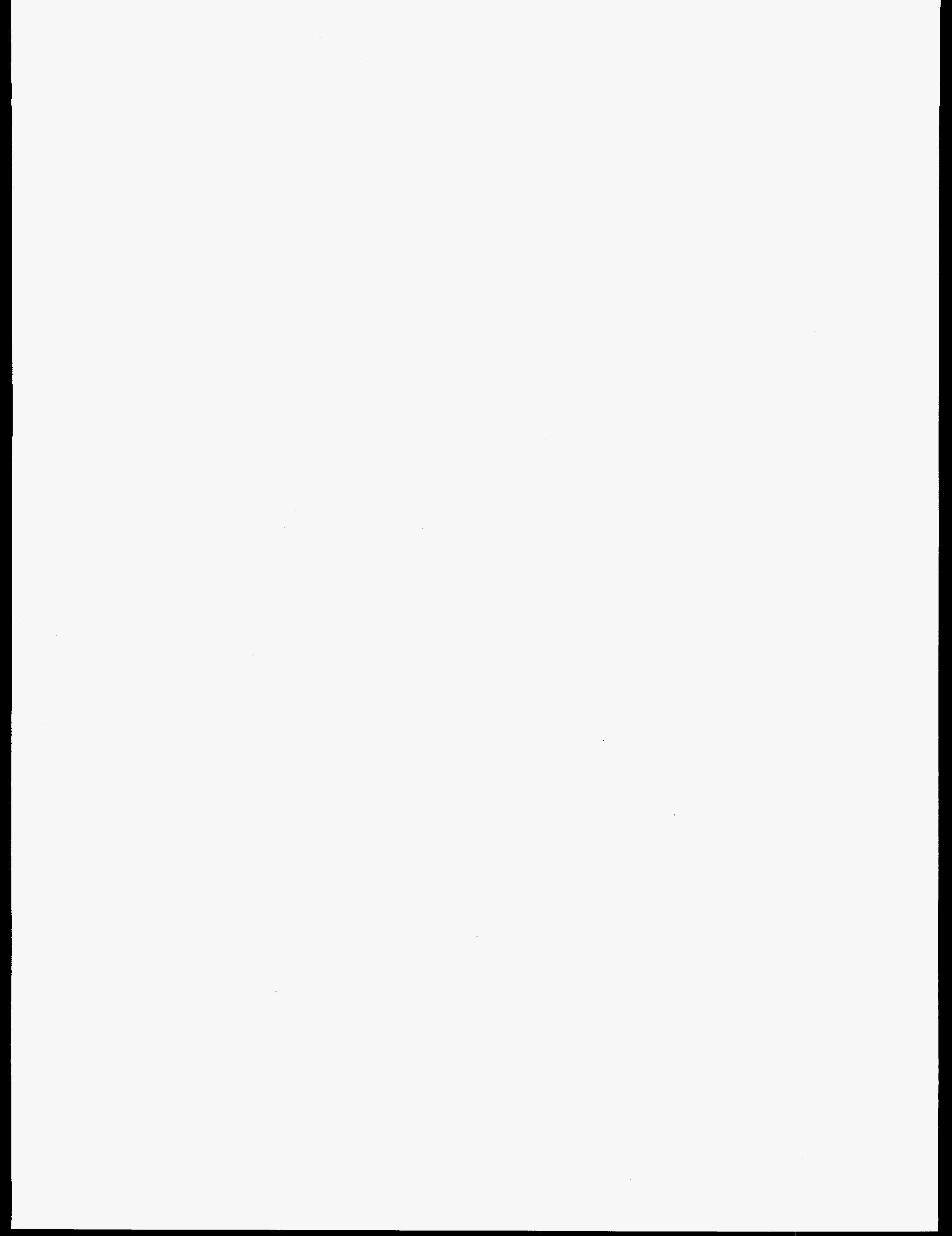




\section{REFERENCES}

1. IAEA Safety Series No. 6. Regulations for the Safe Transport of Radioactive Material, 1985 Edition (As Amended 1990), International Atomic Energy Agency, Vienna, 1990.

2. Federal Register / Vol 60, No. 188 / Thursday, September 28, 1995 / Rules and Regulations 10 CFR Part 71, Compatibility With the International Atomic Energy Agency (IAEA).

3. Regulations for the Safe Transport of Radioactive Material - 1996 Edition - Safety Standards Series No. ST-1, International Atomic Energy Agency, Vienna, 1996.

4. Federal Register / Vol 62, No. 27 / Monday, February 10, 1997 / Rules and Regulations 10 CFR Part 71, Fissile Material Shipments and Exemptions.

5. A. F. Olsen (Babcock \& Wilcox, a McDermott company, Naval Nuclear Fuel Division) March 12, 1997, letter to U.S. Nuclear Regulatory Commission, ATTN: Docketing and Service Branch.

6. R. J. Rena (General Electric Company, GE Nuclear Energy) March 12, 1997, letter to U.S. Nuclear Regulatory Commission, ATTN: Docketing and Service Branch.

7. M. E. Wangler (U.S. Department of Energy, Office of Transportation, Emergency Management and Analytical Services, EM-76) letter retrieved March 12, 1997, from Electronic Bulletin Board --- ATB to U.S. Nuclear Regulatory Commission, Docketing and Service Branch.

8. M. K. Sheaffer (Individual, 2795 Superior Drive, Livermore, Calif. 94550) March 7, 1997, letter to U.S. Nuclear Regulatory Commission.

9. T. S. Baer (Nuclear Fuel Services, Inc.) March 12, 1997, letter to U.S. Nuclear Regulatory Commission, ATTN: Docketing and Service Branch.

10. J. B. Edgar (Siemens Power Corporation, Nuclear Division) June 13, 1997 letter to U.S. Nuclear Regulatory Commission, ATTN: Docket and Service Branch.

11. E. D. Clayton, Anomalies of Nuclear Criticality, PNL-SA-4868, Rev. 5, Pacific Northwest Laboratory, June 1979.

12. J. J. Lichtenwalter, Heterogeneous Reactivity Effects in Medium-and High-Enriched Uranium Metal-Water Systems, pp. 171-176 in Proceedings of the Criticality Safety Challenges in the Next Decade, American Nuclear Society, Chelan, Wash., September 7-11, 1997.

13. D. Mennerdahl, Fissile Package Design Basis: Regulations or Analysis?, pp. 449-456 in Proceedings of The $11^{\text {th }}$ International Conference on the Packaging and Transportation of Radioactive Materials (PATRAM'95), Las Vegas, Nev. (1996).

14. M. K. Shaeffer et al., Recent Developments in Fissile Material Exemptions for Shipping Packages, pp. 214-218 in Proceedings of the Criticality Safety Challenges in the Next Decade, American Nuclear Society, Chelan, Wash., September 7-11, 1997.

15. Title 49 of the Code of Federal Regulations Part 173, Office of the Federal Register National Archives and Records Administration, Subpart I, Sept. 28, 1995. 
16. SCALE: A Modular Code System for Performing Standardized Computer Analyses for Licensing Evaluations, NUREG/CR-0200, Rev. 4 (ORNL/NUREG/CSD-2/R4). Vols. I, II, and III (April 1995). Available from Radiation Shielding Information Center as CCC-545.

17. H. C. Paxton, and N. L. Pruvost, Critical Dimensions of Systems Containing ${ }^{235} U$, ${ }^{239} P u$, and ${ }^{233} U$, LA-10860-MS, Los Alamos National Laboratory, 1986 Revision.

18. E. P. Blizard, editorial in Nucl. Sci. and Eng. 9, No. 3, p. I (1961).

19. G. R. Keepin, Physics of Nuclear Kinetics, Addison-Wesley Publishing Company, Inc., Reading, Mass., 1965.

20. H. Alter, Chairman, Glossary of Terms in Nuclear Science and Technology, American Nuclear Society, La Grange Park, Ill., 1986.

21. H. C. Paxton, "Glossary of Nuclear Criticality Terms," LA-11627-MS, Los Alamos National Laboratory (October 1989).

22. Nuclear Criticality Control of Special Actinide Elements, American National Standard ANSI/ANS-8.15, American Nuclear Society, La Grange Park, Ill. (1981).

23. C. V. Parks, Report of Foreign Travel to Vienna, Austria (January 11-18, 1997), ORNL/FTR-6074, Lockheed Martin Energy Research Corp., Oak Ridge Natl. Lab., February 1997.

24. H. Okuno and T. Sakai, "Criticality Safety Studies Related to Advisory Material for the IAEA Regulations," pp. 217-223 in Proceedings of PATRAM 98 The International Conference on the Packaging and Transportation of Radioactive Materials, Vol. 1, May 10-15, 1998, Paris, France.

25. N. J. Barton and C. K. Wilson, "Review of Fissile Exception Criteria in LAEA Regulations," pp. 9-15 in Proceedings of the $5^{\text {th }}$ International Conference on Nuclear Criticality Safety, Vol II, September 17-21, 1995. 


\section{APPENDIX A}

Subcritical Water- or Polyethylene-Moderated Systems 


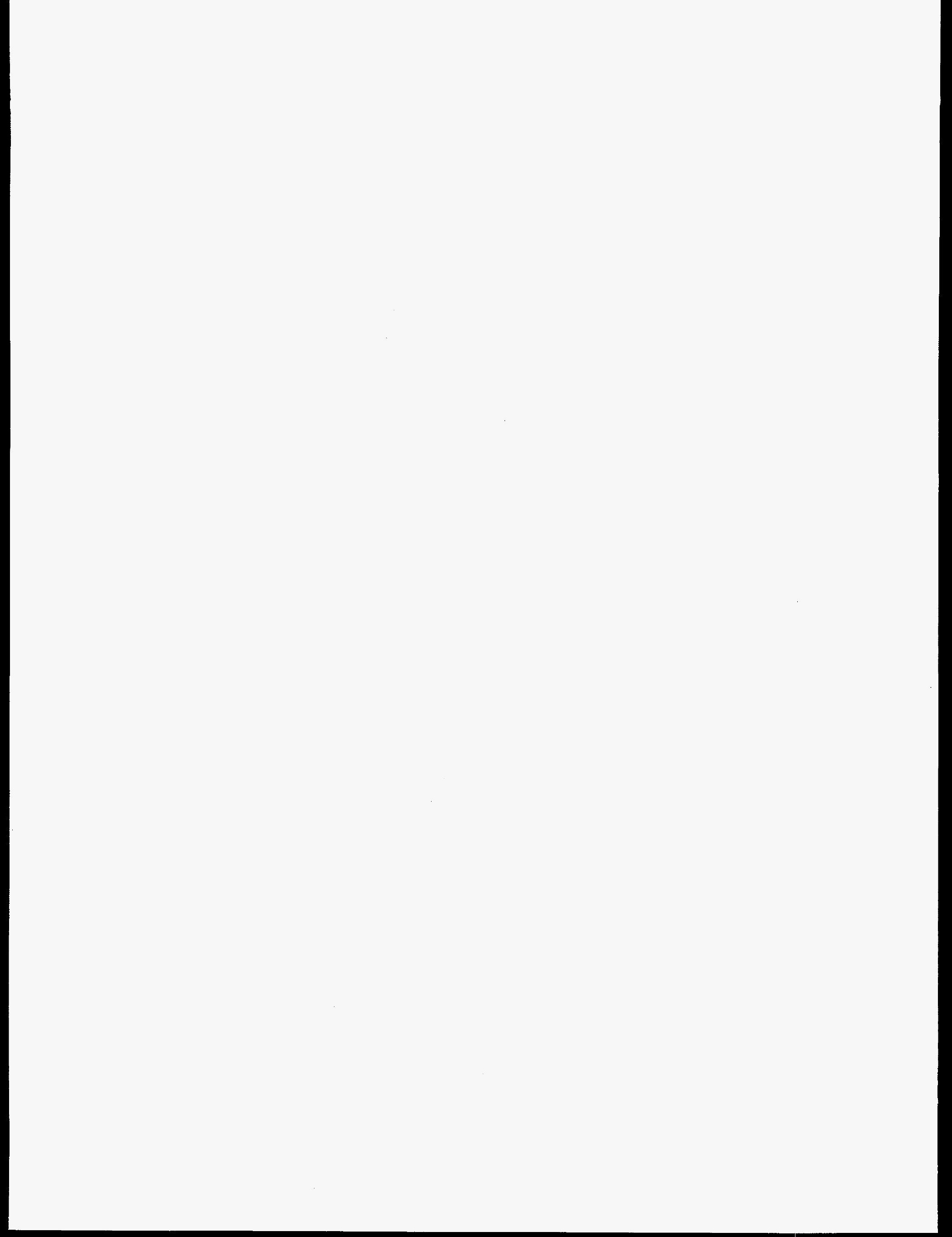




\section{APPENDIX A}

\section{Subcritical Water- or Polyethylene-Moderated Systems}

The exemption and general-license specifications are limited to considering only the type, mass and form of fissile material, together with the moderator. In this study, $100 \%$-enriched ${ }^{235} \mathrm{U}[\mathrm{U}(100)],{ }^{239} \mathrm{Pu}$ or ${ }^{233} \mathrm{U}$ homogeneously mixed with water or polyethylene $\left(\mathrm{CH}_{2}\right)$ were considered. $\mathrm{U}(100)$ in a homogenous mixture was chosen because the high enrichment is most reactive and for such enrichments the simple homogeneous uranium-moderator mixtures are typically more reactive than corresponding heterogeneous uranium-moderator mixtures. Likewise the ${ }^{239} \mathrm{Pu}$ and ${ }^{233} \mathrm{U}$ studies were assumed to be $100 \mathrm{wt} \%$ to avoid lack of conservatism regarding nonfissile isotopes of plutonium or uranium.

Infinite systems of $U(100)$ were analyzed first to determine subcritical atom or mass ratios of various mixtures to define an "exemption for low-level materials" consistent with safety intended to be provided by $\$ 71.10(a)$. For an infinite system there is no leakage and the moderator-to-fissile nuclei ratio (e.g., $\mathrm{H}^{235} \mathrm{U}$ ) is the only parameter of interest. The infinite system results for homogeneous ${ }^{235} \mathrm{U}$ and water or polyethylene are given in Table A-1 and plotted in Figure A-1. The difference in $\mathrm{k}_{\mathrm{inf}}$ for the two moderators is nearly indistinguishable. Because of this near equivalence only water-moderated systems were analyzed in order to reduce the problem complexity. The $\mathrm{U}(100)$ and $\mathrm{H}_{2} \mathrm{O}$ infinite homogeneous system subcritical neutron multiplication factor is 0.9208 , corresponding to a concentration of $10.41 \mathrm{~g}{ }^{235} \mathrm{U} / \mathrm{L}$ at an $\mathrm{H}^{235} \mathrm{U}$ of 2500 . The subcritical neutron multiplication factor of 0.93 was selected to provide an adequate margin of subcriticality that is consistent with upper subcritical limits from broad-based historical validation studies.

Table A-1 Infinite homogeneous ${ }^{235} \mathrm{U}$ and hydrogen

\begin{tabular}{ccc}
\hline & \multicolumn{2}{c}{$\mathrm{k}_{\text {inf }}$} \\
\cline { 2 - 3 } $\mathrm{H}^{235} \mathrm{U}$ & $\mathrm{H}_{2} \mathrm{O}$ & $\mathrm{CH}_{2}$ \\
\hline 10 & 1.8133 & 1.8181 \\
50 & 1.8953 & 1.9010 \\
100 & 1.8995 & 1.9045 \\
250 & 1.8105 & 1.8141 \\
500 & 1.6435 & 1.6468 \\
1000 & 1.3763 & 1.3781 \\
1500 & 1.1819 & 1.1828 \\
2000 & 1.0352 & 1.0357 \\
2400 & 0.9416 & 0.9417 \\
2500 & 0.9208 & 0.9209 \\
2750 & 0.8725 & 0.8725 \\
3000 & 0.8291 & 0.8289 \\
\hline
\end{tabular}




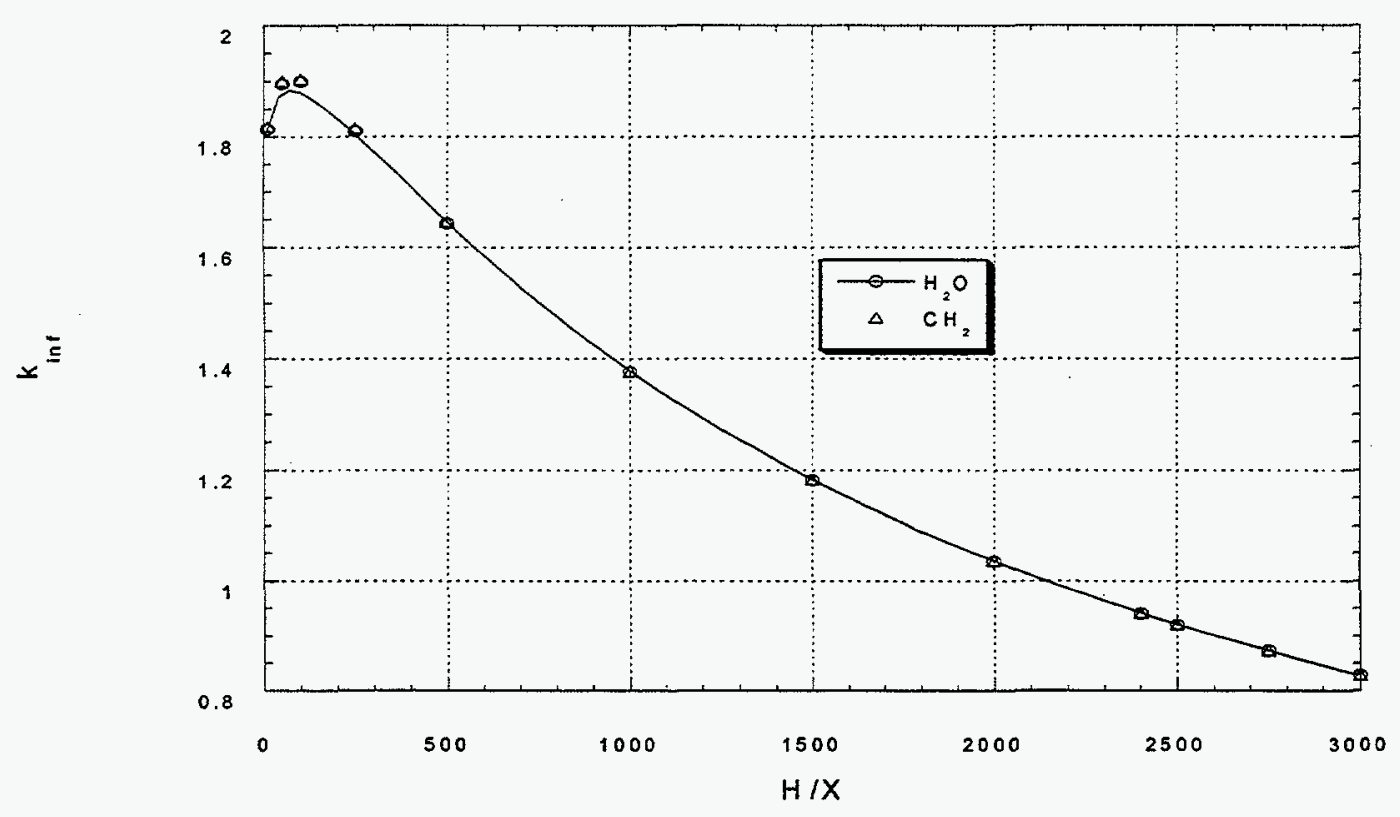

Figure A-1 Infinite homogeneous ${ }^{235} \mathrm{U}$ and $\mathrm{H}_{2} \mathrm{O}$

The subcritical $\mathrm{H}^{235} \mathrm{U}$ of 2500 for the infinite system calculations provides a good starting point for determining subcritical finite systems of the same mixture. Because of increased leakage, the subcritical $\mathrm{H}^{235} \mathrm{U}$ for the corresponding finite system is somewhat less than 2500 . The finite system was evaluated as a fully water-reflected sphere of homogeneous $U(100)$ and water at an $\mathrm{H}^{235} \mathrm{U}$ less than 2500 and a volume of about $584 \mathrm{~m}^{3}$. No container was considered in the calculational models due to the nonconservative introduction of neutron-absorbing materials. The selected volume of $584 \mathrm{~m}^{3}$ is representative of the maximum volume available in five public highway transportation vehicles (i.e., two tandem trailers pulled by a single tractor). The selection of five vehicles [cf. $\$ 71.59$ (a)(1)] was made instead of two [cf. $\$ 71.59(\mathrm{a})(2)$ ] to ensure that the large volume associated with normal conditions of transport are accommodated, together with changes that might occur under hypothetical accident conditions. The $k_{\text {eff }}$ values from these finite-system calculations are given in Figure A-2 versus ${ }^{235} \mathrm{U}$ concentration for five $\mathrm{H}^{235} \mathrm{U}$ ratios.

The ${ }^{235} \mathrm{U}$ concentrations of Figure A-2 yielding $\mathrm{k}_{\text {eff }}$ values of 0.93 are plotted in Figure A-3 versus their matching $\mathrm{H}^{235} \mathrm{U}$ ratio. More data of $\mathrm{H}^{235} \mathrm{U}$ ratios and ${ }^{235} \mathrm{U}$ concentrations that calculate 0.93 have been added to Figure $\mathrm{A}-3$ to give a more complete picture. A sampling of the data in Figure A-3 is given in Table A-2. The five-vehicle and 55-gal drum ${ }^{235} \mathrm{U}$ masses in the table are based on the determined ${ }^{235} \mathrm{U}$ concentrations and $584-\mathrm{m}^{3}$ and $208-\mathrm{L}$ volumes. From Figure A-3, one sees that only a homogeneous uranium-water mixture with either a ${ }^{235} \mathrm{U}$ concentration less than $0.87 \mathrm{~g}^{235} \mathrm{U} / \mathrm{L}$ or an $\mathrm{H}^{23} \mathrm{U}^{3}$ ratio greater than 2410 always less than the upper subcritical limit. Above $10.9 \mathrm{~g}^{235} \mathrm{U} / \mathrm{L}$ the finite system always exceeds the upper subcritical limit. 


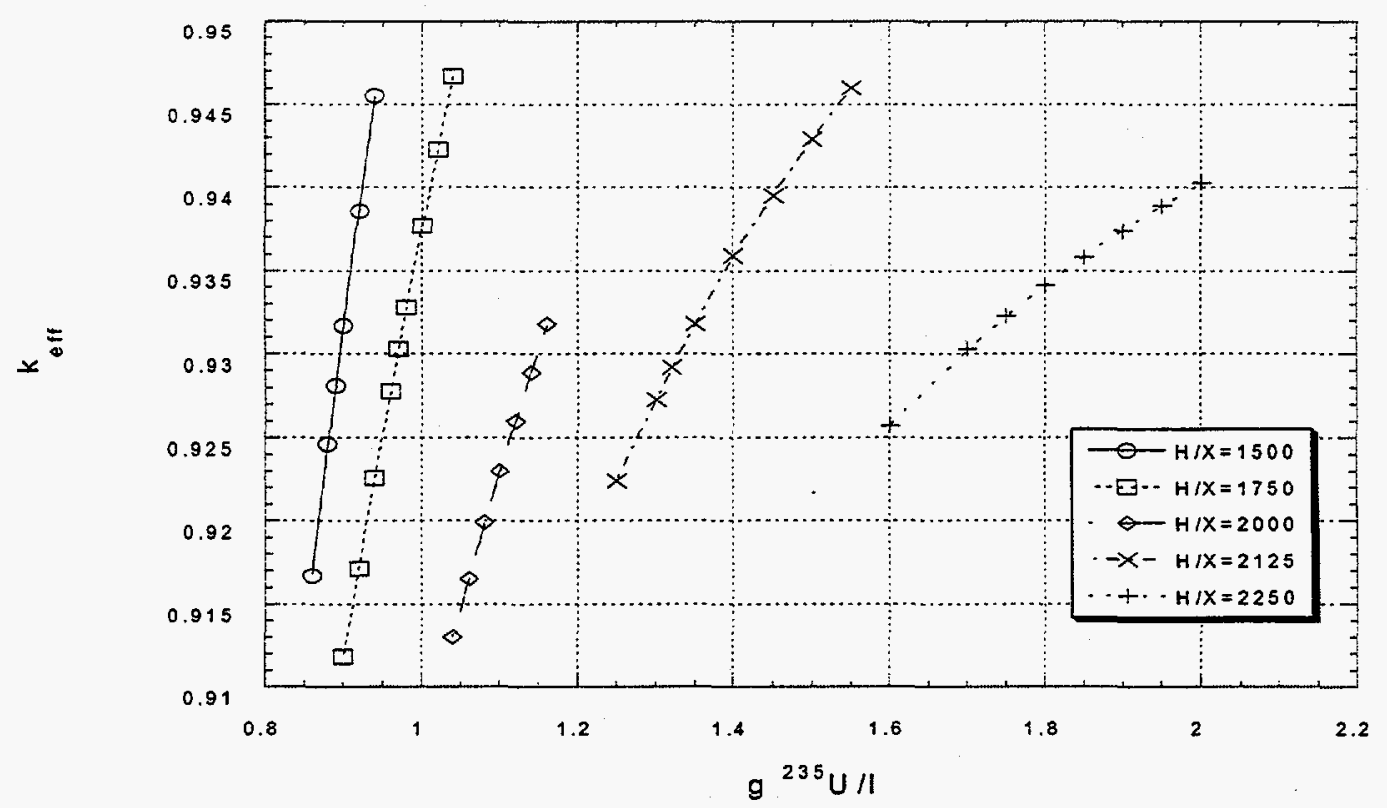

Figure A-2 Water-reflected, five-vehicle volume of homogeneous ${ }^{235} \mathrm{U}$ and $\mathrm{H}_{2} \mathrm{O}$

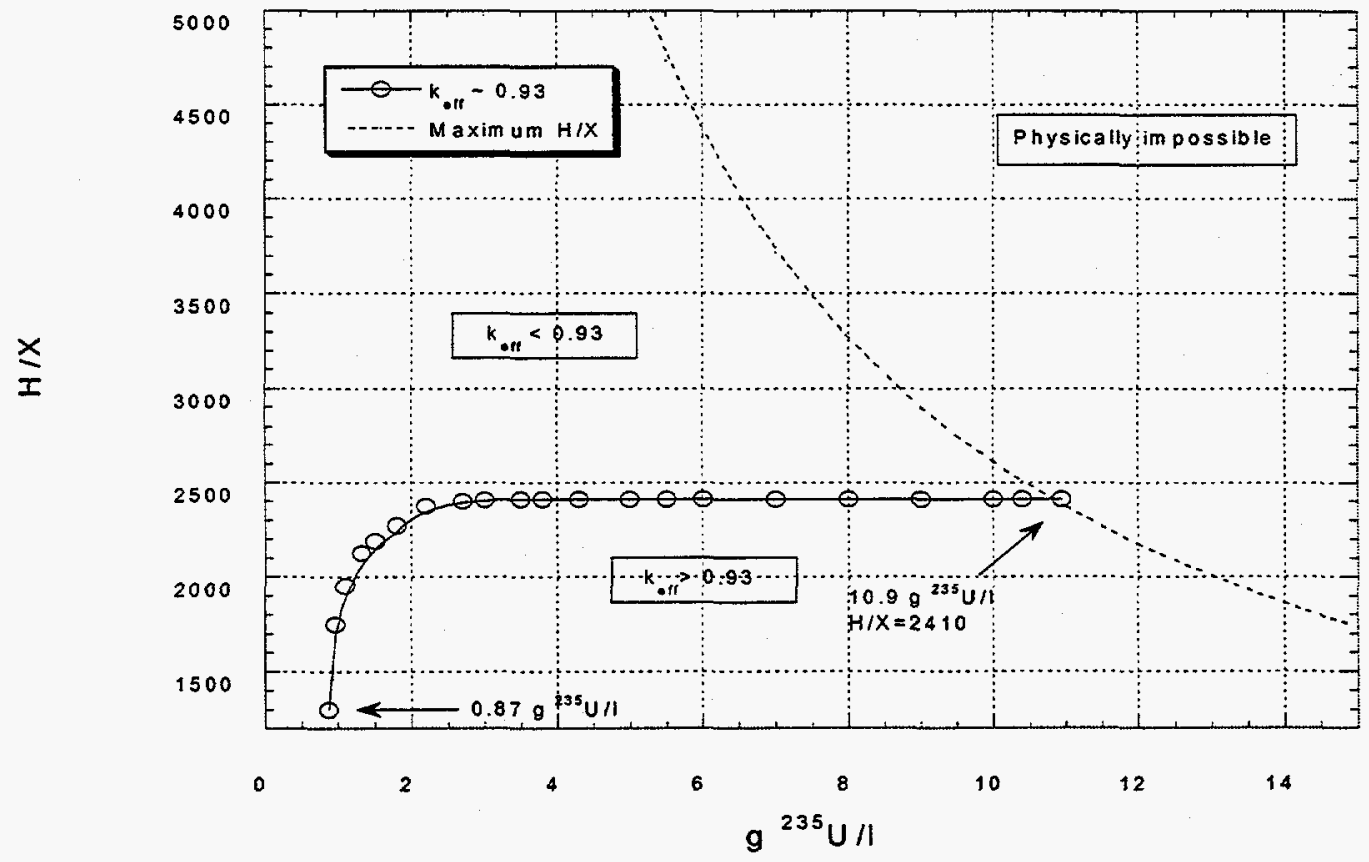

Figure A-3 Water-reflected, five-vehicle volume of homogeneous ${ }^{235} \mathrm{U}$ and $\mathrm{H}_{2} \mathrm{O}$; $k_{\text {eff }} \sim 0.93$ 
Table A-2 Homogeneous ${ }^{235} \mathrm{U}$ and $\mathrm{H}_{2} \mathrm{O}$ subcritical masses

\begin{tabular}{|c|c|c|c|c|}
\hline $\mathrm{g}^{235} \mathrm{U} / \mathrm{L}$ & $\mathrm{H}^{235} \mathrm{U}$ & $k_{\text {eff }}$ & $\begin{array}{c}\mathrm{kg}^{235} \mathrm{U} \text { per five } \\
\text { vehicle }\end{array}$ & $\begin{array}{c}\mathrm{g}^{235} \mathrm{U} \text { per } \\
\text { drum }^{a}\end{array}$ \\
\hline 10.4 & 2410 & 0.9319 & 6074 & 2166 \\
\hline 7.0 & 2410 & 0.9302 & 4088 & 1458 \\
\hline 5.0 & 2410 & 0.9302 & 2920 & 1041 \\
\hline 3.0 & 2405 & 0.9276 & 1752 & 625 \\
\hline 1.8 & 2270 & 0.9303 & 1051 & 375 \\
\hline 1.32 & 2125 & 0.9292 & 770 & 275 \\
\hline 1.1 & 1950 & 0.9304 & 642 & 229 \\
\hline 0.97 & 1750 & 0.9303 & 556 & 202 \\
\hline 0.87 & $1300^{b}$ & 0.9276 & 508 & 181 \\
\hline 0.83 & $1300^{b}$ & 0.9091 & 484 & 172 \\
\hline 0.67 & $1200^{b}$ & 0.8130 & 391 & 139 \\
\hline
\end{tabular}

${ }^{a}$ Based on 55-gal drum volume.

Wear optimum for ${ }^{235} \mathrm{U}$ concentration.

To show that $0.87 \mathrm{~g}^{235} \mathrm{U} / \mathrm{L}$ is always less than the upper subcritical limit, calculations were performed where the $\mathrm{H}^{235} \mathrm{U}$ ratio was varied until the optimum $\mathrm{H}^{235} \mathrm{U}$ was found. The results of these calculations are presented in Figure A-4. At the optimum $\mathrm{H}^{235} \mathrm{U}$ ratio of 1300 for $0.87 \mathrm{~g}^{235} \mathrm{U} / \mathrm{L}, \mathbf{k}_{\text {eff }}$ equaled 0.9276 .

In an effort to assign minimum transport indexes to packages for transportation, arrays of drum-type packages were evaluated. Package loadings and materials were considered to determine their effect on the $\mathrm{k}_{\text {eff }}$ of the arrays. The packages analyzed were modeled in a near-cubic (optimal), triangular-pitch (optimal) $27 \times 27 \times 6$ array reflected by 30.48-cm of water. The total array volume was approximately $584 \mathrm{~m}^{3}$ with $\sim 20 \%$ interstitial void between packages. The volume between the drum-type packages was selected as void to maximize the array $\mathbf{k}_{\text {eff }}$. The packages were comprised of uranium-moderator mixture in a 110-gal drum that was modeled as two joined 55-gal 20-gauge (0.823-mm body thickness) 316-stainless steel DOT-17E drums. 316-Stainless steel was picked because it contained the minimum quantity of neutron-absorbing material. The 110-gal package was selected to minimize the quantity of steel mass to fissile material mass; however, the tabulated mass of fissile material per drum is provided for the volume of 55-gal drums, a more common drum-type container used by industry.

Table A-3 presents results of the drum-array calculations. For each $\mathrm{H}^{235} \mathrm{U}$ ratio, the maximum subcritical ${ }^{235} \mathrm{U}$ concentration is given for the minimum drum body thickness; this calculation is less than the $7 \%$ margin of subcriticality. For the maximum and minimum analyzed $\mathrm{H} /{ }^{235} \mathrm{U}$ ratios, the effect on $\mathrm{k}_{\text {eff }}$ from increasing the drum-wall thickness by a factor of $\sim 3$ or completely removing drum material were examined. The given ${ }^{235} U$ mass that is permissible per drum is based on the subcritical ${ }^{235} \mathrm{U}$ concentration at a given $\mathrm{H}^{235} \mathrm{U}$ and a $208-\mathrm{L}$ drum volume for the minimum drum body thickness only. 


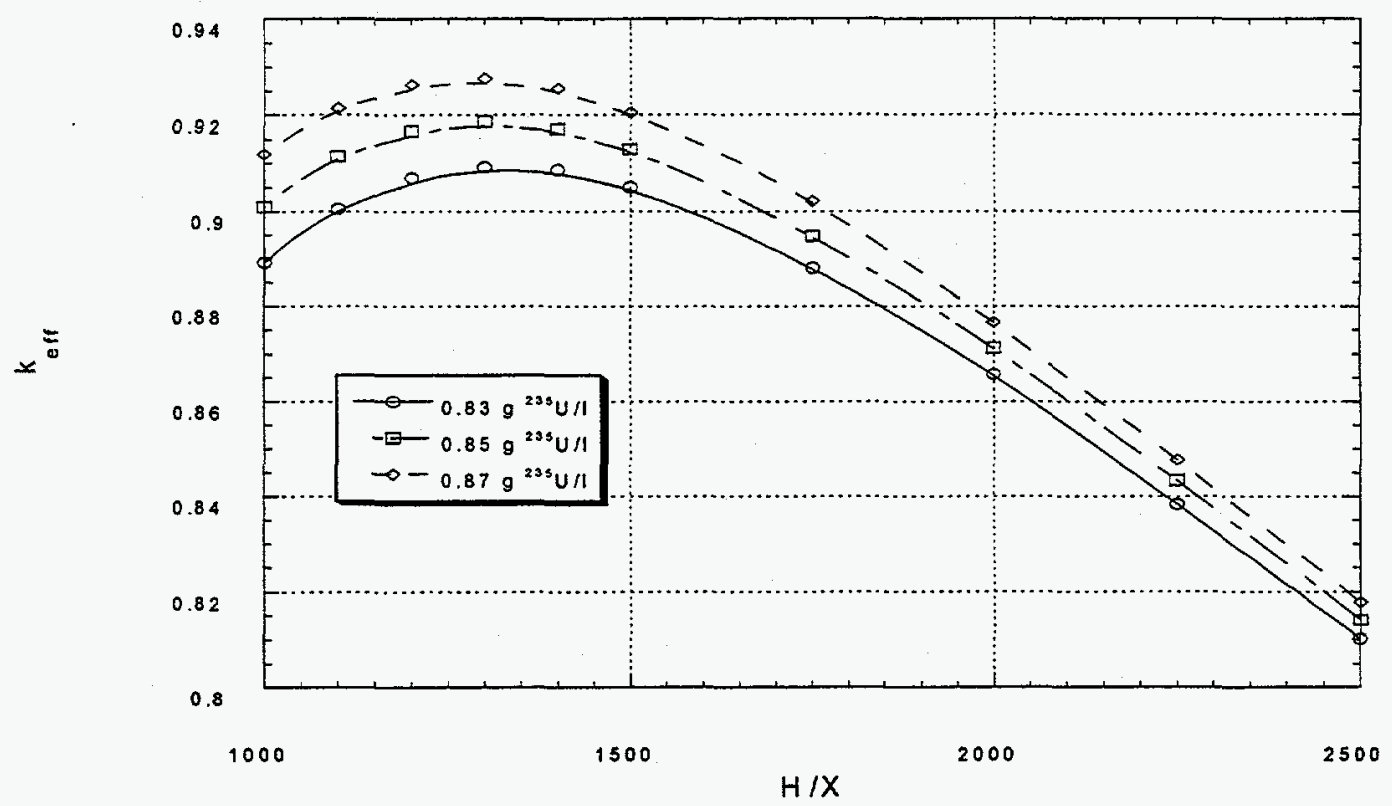

Figure A-4 Water-reflected, five-vehicle volume of homogeneous ${ }^{235} \mathrm{U}$ and $\mathrm{H}_{2} \mathrm{O}$; ${ }^{235} \mathrm{U}$ concentration where $k_{\text {eff }} \sim 0.93$ at optimum $\mathrm{H}^{235} \mathrm{U}$

Table A-3 Array of $27 \times 27 \times 6110$-gal drums on hexagonal pitch

\begin{tabular}{cccc}
\hline & & & $\mathrm{g}^{235} \mathrm{U}$ \\
$\mathrm{H}^{235} \mathrm{U}$ & $\mathrm{g}^{235} \mathrm{U} / \mathrm{L}$ & $0.8912 \pm 0.0007$ & 2166 \\
\hline 2500 & 10.4 & $0.9200 \pm 0.0007^{b}$ & \\
& & $0.8669 \pm 0.0007^{c}$ & \\
& & $0.9145 \pm 0.0008$ & 729 \\
2000 & 3.5 & $0.9209 \pm 0.0010$ & 448 \\
1500 & 2.15 & $0.9191 \pm 0.0012$ & 385 \\
1200 & 1.85 & $1.1955 \pm 0.0014^{b}$ & \\
& & $0.6890 \pm 0.0009^{c}$ & \\
\hline
\end{tabular}

${ }^{\circ}$ Based on 55-gal drum volume.

${ }^{b}$ Drum absent.

'2.4-mm drum body thickness. 
Lastly, an assessment of the subcritical dimensions of individual fully water-reflected spheres of homogeneous mixtures of uranium and water were conducted to explore potential bounding specifications for fissile-material exemptions and general licenses. The critical masses of such water-moderated systems are given in Figure A-5. The minimum critical mass is $614 \mathrm{~g}$ and is located at an $\mathrm{H}^{235} \mathrm{U}$ ratio of 490 and a mixture radius of $14.03 \mathrm{~cm}$. A $5 \%$ margin of subcriticality was selected over a $7 \%$ margin because the mixtures in the critical mass searches are binary (i.e., uranium and water) rather than rnore difficult to validate tertiary systems (e.g., uranium, beryllium, and water).

Similar assessments were done to determine the subcritical dimensions of ${ }^{239} \mathrm{Pu}$ or ${ }^{233} \mathrm{U}$ as individually water-reflected spheres of homogeneous mixtures of ${ }^{235} \mathrm{Pu}$ or ${ }^{233} \mathrm{U}$ and water to explore potential bounding specifications for fissile-material exemptions and general licenses. The critical parameters for these systems are given in Figure A-6 for ${ }^{239} \mathrm{Pu}-\mathrm{H}_{2} \mathrm{O}$ mixtures and in Figure A-7 for ${ }^{233} \mathrm{U}-\mathrm{H}_{2} \mathrm{O}$ mixtures.

The determined ${ }^{239} \mathrm{Pu}$ minimum subcritical $\left(\mathrm{k}_{\text {eff }} \leq 0.95\right)$ mass parameters are $379 \mathrm{~g}{ }^{239} \mathrm{Pu}$ homogeneously mixed with water (resulting in a hydrogen-to- ${ }^{239} \mathrm{Pu}$ atom ratio of about 900 and about $30 \mathrm{~g}{ }^{239} \mathrm{Pu} / \mathrm{L}$ ) as a fully water-reflected 14.5 -cm-radius sphere.

The determined ${ }^{233} \mathrm{U}$ minimum subcritical $\left(\mathrm{k}_{\text {eff }} \leq 0.95\right)$ mass parameters are $437 \mathrm{~g}{ }^{233} \mathrm{U}$ homogeneously mixed with water (resulting in a hydrogen-to- ${ }^{233} \mathrm{U}$ atom ratio of about 900 and about $57 \mathrm{~g}^{233} \mathrm{U} / \mathrm{L}$ ) as a fully water-reflected $12.2-\mathrm{cm}$ radius sphere.

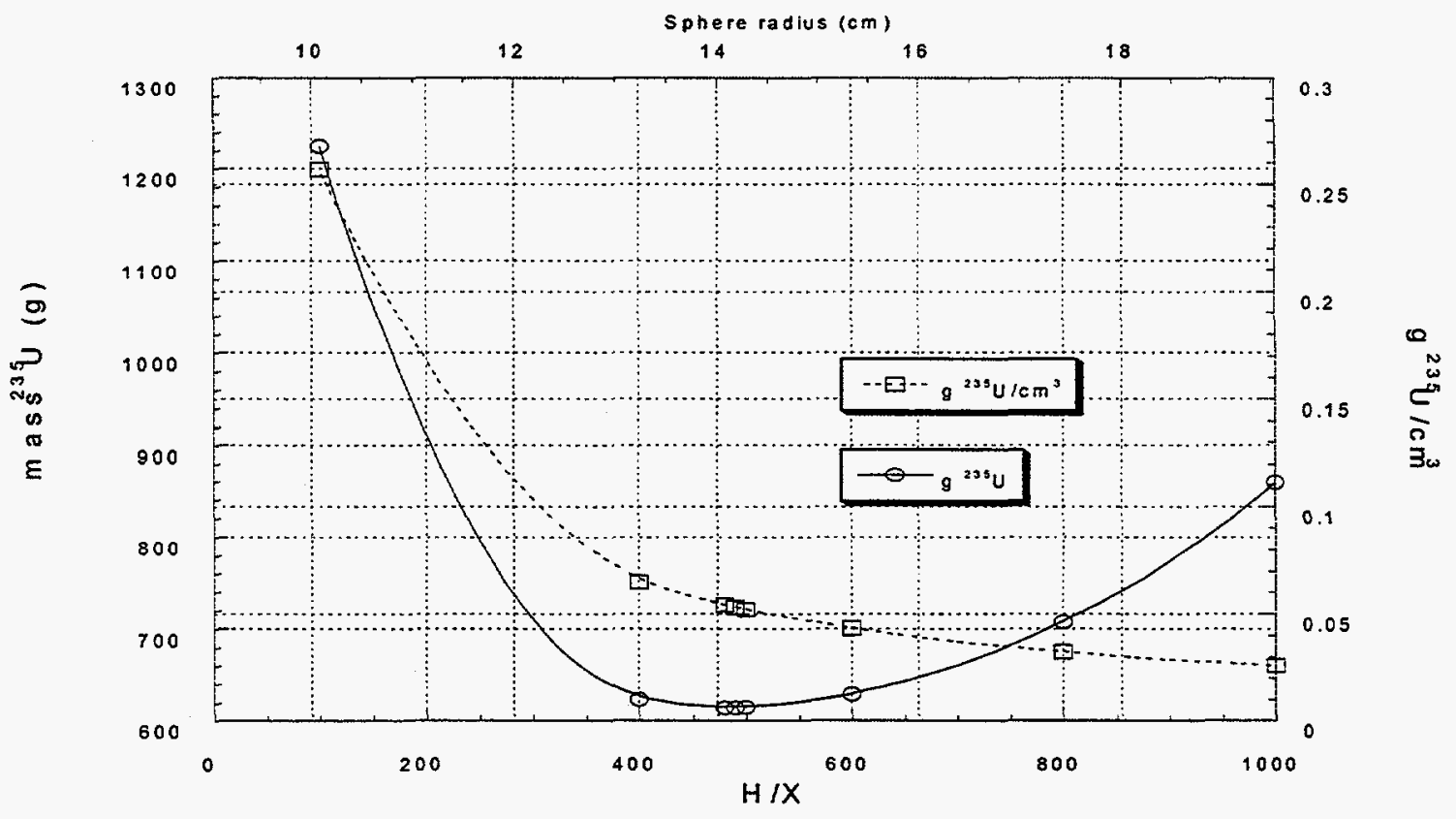

Figure A-5 Critical masses of water-reflected, homogeneous ${ }^{235} \mathrm{U}$ and $\mathrm{H}_{2} \mathrm{O}$ spheres; $\mathrm{k}_{\mathrm{eff}} \sim 0.95$ 


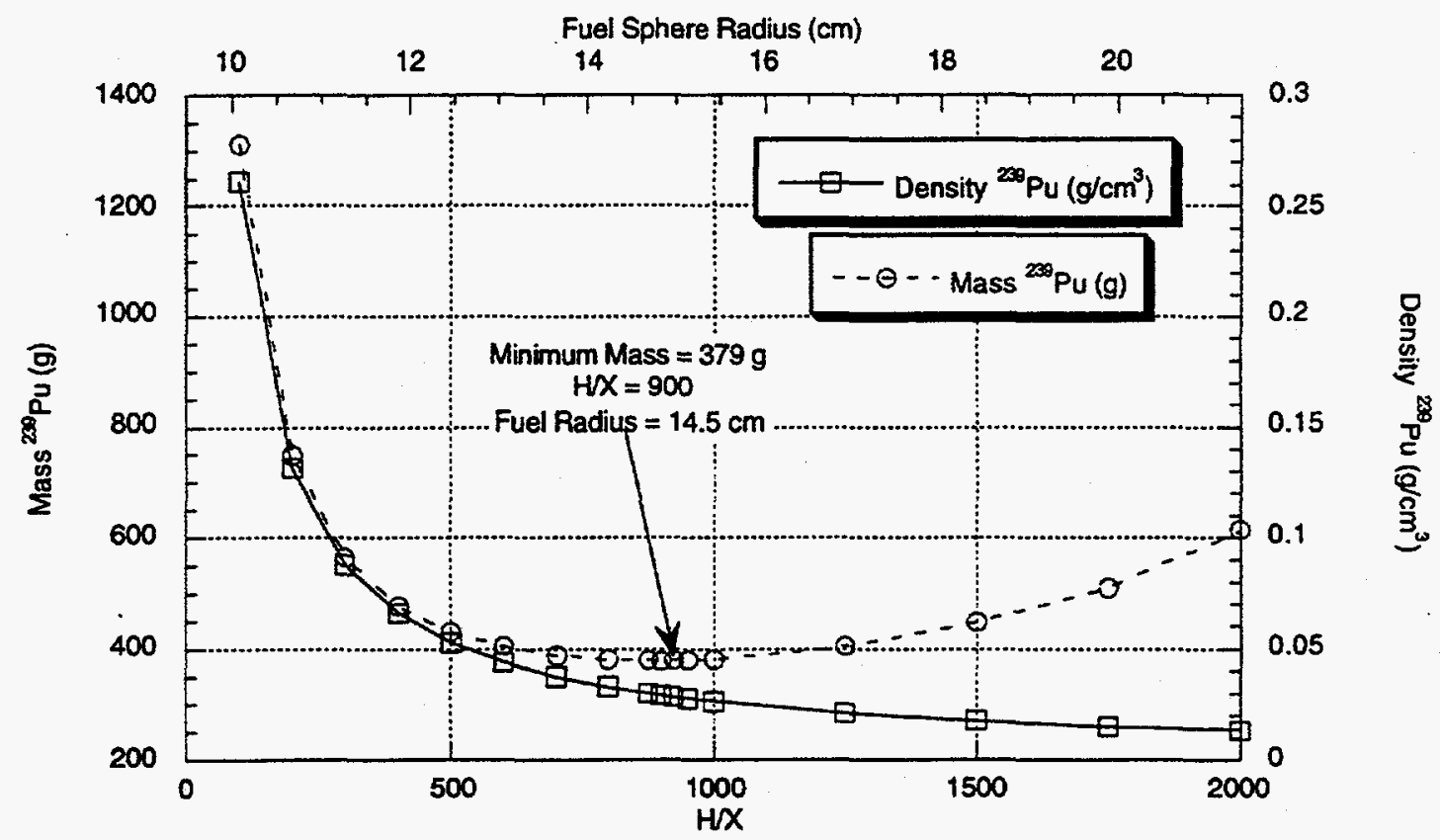

Figure A-6 Fissile masses and densities of water-reflected ${ }^{239} \mathrm{Pu}$ and $\mathrm{H}_{2} \mathrm{O}$ spheres; $\mathbf{k}_{\mathrm{ef}} \approx 0.95$ (radius scale is approximate)

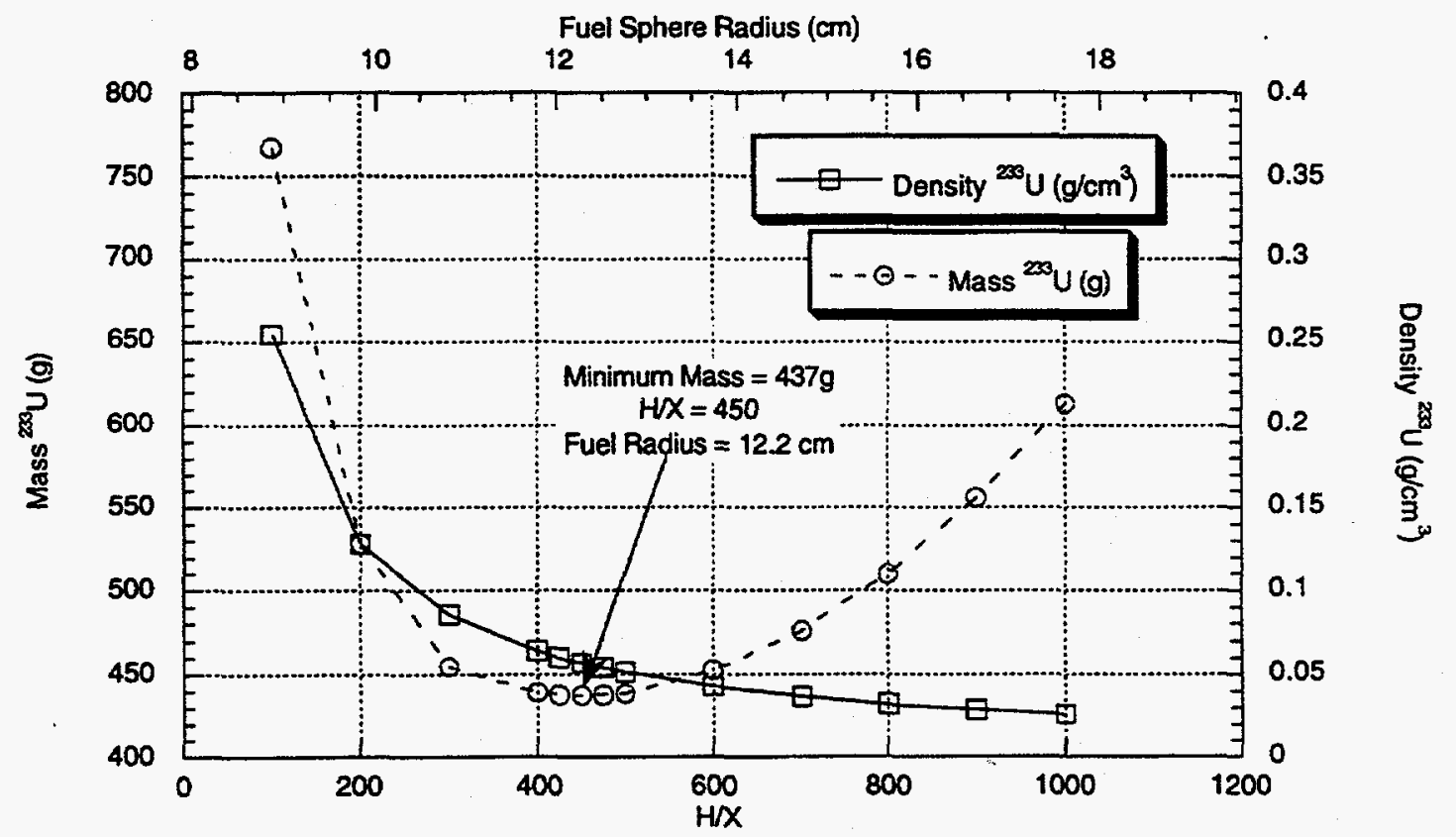

Figure A-7 Fissile masses and densities of water-reflected ${ }^{233} \mathrm{U}$ and $\mathrm{H}_{2} \mathrm{O}$ spheres; $\mathbf{k}_{\mathrm{eff}} \approx 0.95$ (radius scale is approximate) 
An assessment of the critical dimensions of individual fully water-reflected spheres of homogeneous mixtures of U(100) and high-density polyethylene were conducted to explore relative potential bounding specifications for fissile-material exemptions. The critical masses of such polyethylene-moderated systems are given in Figure A-8. The minimum critical mass $\left(\mathrm{k}_{\text {eff }}=1.0\right)$ is about $527 \mathrm{~g} \mathrm{U}(100)$ and occurs at an $\mathrm{H}^{235} \mathrm{U}$ ratio of about 471 with a mixture radius of $12.26 \mathrm{~cm}$. No margin of subcriticality was selected because the purpose of these results was to relate critical fissile mixtures of $U(100)$ with water and polyethylene.

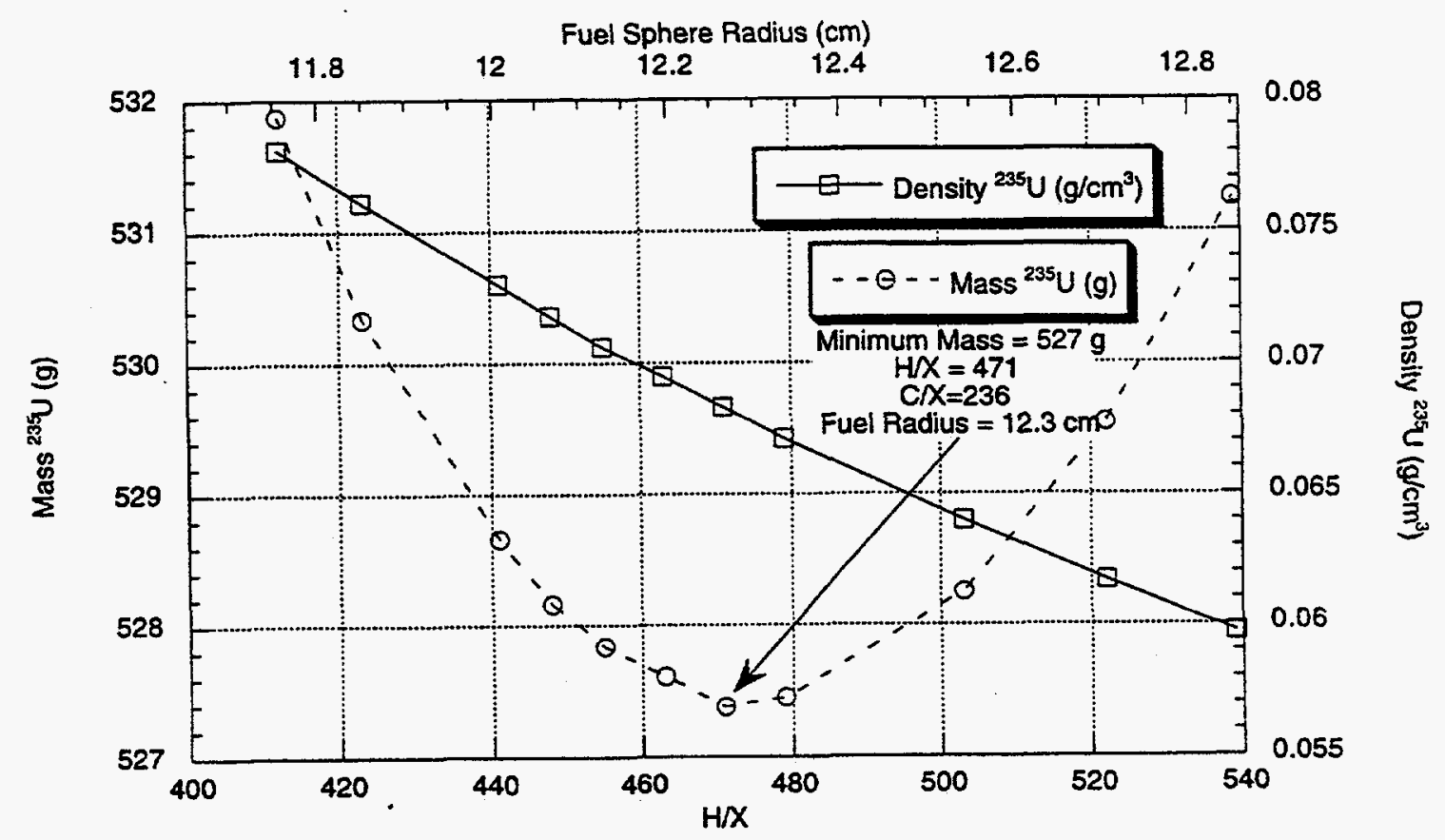

Figure A-8 Critical masses of water-reflected, homogeneous ${ }^{235} \mathrm{U}$ and polyethylene spheres; $k_{\text {eff }} \sim \mathbf{1 . 0 0}$ 


\section{APPENDIX B}

Subcritical Silicon Dioxide Systems 



\section{APPENDIX B}

\section{Subcritical Silicon Dioxide Systems}

The exemption and general-license specifications are limited to considering only the type, mass and form of fissile material, together with the moderator. In this study, $100 \%$-enriched ${ }^{235} \mathrm{U}[\mathrm{U}(100)],{ }^{238} \mathrm{Pu}$ or ${ }^{233} \mathrm{U}$ homogeneously mixed with silicon dioxide $\left(\mathrm{SiO}_{2}\right)$ and water were considered. Silicon dioxide was chosen because of its bounding representation as dirt, glass, or common waste matrix material. The $\mathrm{SiO}_{2}$ was assumed to be at $60 \%$ of theoretical density, or $1.6 \mathrm{~g} / \mathrm{cm}^{3}$, to simulate tamped densities of relatively homogeneous loose dirt that normally has pour densities ranging from $20 \%$ to $30 \%$ of theoretical density. ${ }^{235} \mathrm{U}$ in a homogenous mixture was chosen because the high enrichment is most reactive and for such enrichments homogeneous uranium-moderator mixtures are typically reactive than corresponding heterogeneous uraniummoderator mixtures. Likewise, the ${ }^{239} \mathrm{Pu}$ and ${ }^{233} \mathrm{U}$ studies were assumed to be $100 \mathrm{wt} \%$ to avoid lack of conservatism regarding nonfission isotopes of plutonium or uranium.

Infinite systems of $U(100)$ were analyzed first to determine subcritical atom or mass ratios of various mixtures to define an "exemption for low-level materials" consistent with safety intended to be provided by $\S 71.10(a)$. For an infinite system there is no leakage and the moderator-to-fissile nuclei ratio $\left(\mathrm{Si}^{235} \mathrm{U}\right)$ is the only parameter of interest. The infinite system results for homogeneous ${ }^{235} \mathrm{U}$ and silicon dioxide are given in Table $\mathrm{B}-1$ and plotted in Figure $\mathrm{B}-1$. The $\mathrm{U}(100)$ and $\mathrm{SiO}_{2}$ infinite homogeneous system subcritical neutron multiplication factor is 0.9256 , corresponding to a concentration of $1.33 \mathrm{~g}{ }^{235} \mathrm{U} / \mathrm{L}$ at an $\mathrm{Si}^{235} \mathrm{U}$ of 4700 . The subcritical neutron multiplication factor of 0.93 was selected to provide an adequate margin of subcriticality that is consistent with upper subcritical limits from broad-based historical validation studies.

Table B-1 Infinite homogeneous ${ }^{235} \mathrm{U}$ and $\mathrm{SiO}_{2}$

\begin{tabular}{rc}
\hline $\mathrm{Si}^{235} \mathrm{U}$ & $\mathrm{k}_{\text {inf }}$ \\
\hline 100 & 1.6147 \\
500 & 1.5877 \\
1000 & 1.5031 \\
2000 & 1.3014 \\
3000 & 1.1341 \\
3682 & 1.0378 \\
3917 & 1.0118 \\
4173 & 0.9820 \\
4471 & 0.9493 \\
4700 & 0.9256 \\
4814 & 0.9143 \\
5216 & 0.8763 \\
\hline
\end{tabular}




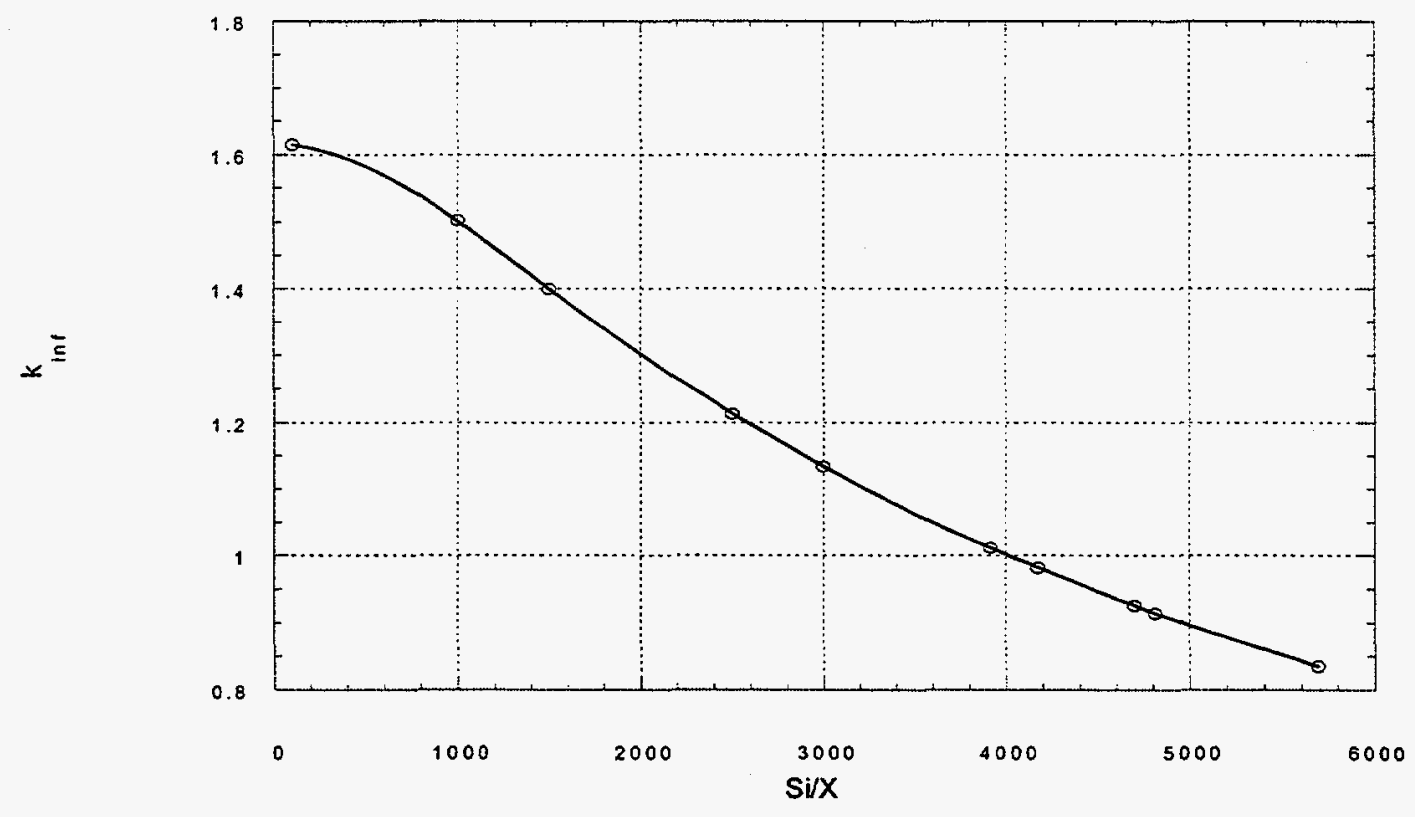

Figure B-1 Infinite homogeneous ${ }^{235} \mathrm{U}$ and $\mathrm{SiO}_{2}\left(1.6 \mathrm{~g} / \mathrm{cm}^{3}\right)$

The subcritical $\mathrm{Si}^{225} \mathrm{U}$ of 4700 for the infinite system calculations provides a good starting point for determining subcritical finite systems of the same mixture. Because of increased leakage, the subcritical $\mathrm{Si}^{235} \mathrm{U}$ for our corresponding finite system is somewhat less than 4700 . The finite system was evaluated as a fully water-reflected sphere of homogeneous uranium at $100 \%$ enrichment, $\mathrm{SiO}_{2}$ at $60 \%$ of theoretical density, and $\mathrm{H}_{2} \mathrm{O}$ at $0 \%$ to $39 \%$ volume fraction of the mixture. The mixture volume is about $584 \mathrm{~m}^{3}$. No container was considered in the calculational models due to the nonconservative introduction of neutron-absorbing materials. The selected volume of $584 \mathrm{~m}^{3}$ is representative of the maximum volume available in five public highway transportation vehicles (i.e., two tandem trailers pulled by a single tractor). The selection of five vehicles [cf. $\$ 71.59(\mathrm{a})(1)]$ was made instead of two [cf. $\$ 71.59(\mathrm{a})(2)]$ to ensure the large volume associated with normal conditions of transport are accommodated, together with changes that might occur under hypothetical accident conditions. The $\mathbf{k}_{\text {eff }}$ values from these finite system calculations are given in Figure B-2 versus ${ }^{235} \mathrm{U}$ concentration for seven water-volume fractions.

The ${ }^{235} \mathrm{U}$ concentrations of Figure B-2 yielding $\mathrm{k}_{\text {eff }}$ values of 0.93 are plotted in Figure B-3 versus their matching $\mathrm{H}^{235} \mathrm{U}$ and $\mathrm{Si}^{235} \mathrm{U}$ ratios. Additional data for combinations of $\mathrm{H}^{235} \mathrm{U}, \mathrm{Si}^{235} \mathrm{U}$, and ${ }^{235} \mathrm{U}$ concentrations that calculate 0.93 have been added to Figure B-3 to give a more complete picture. A sampling of the data in Figure B-3 is given in Table B-2. The five vehicle and 55-gal drum ${ }^{235} \mathrm{U}$ masses in the table are based on the determined ${ }^{235} \mathrm{U}$ concentrations and $584-\mathrm{m}^{3}$ and $208-\mathrm{L}$ volumes. From Figure B-3, one sees that any ${ }^{235} \mathrm{U}$ concentration above the $\mathrm{g}{ }^{235} \mathrm{U} / \mathrm{L}$ curve is above the upper subcritical limit as is any $\mathrm{H}^{235} \mathrm{U}$ below the $\mathrm{H} / \mathrm{X}$ curve. Conversely, any ${ }^{235} \mathrm{U}$ concentration below the $\mathrm{g}{ }^{235} \mathrm{U} / \mathrm{L}$ curve is below the upper subcritical limit as is any $\mathrm{H}^{235} \mathrm{U}$ above the $\mathrm{H} / \mathrm{X}$ curve.

To determine the ${ }^{235} \mathrm{U}$ concentration that is always below the upper subcritical limit, a ${ }^{235} \mathrm{U}$ concentration was selected, optimum $\mathrm{Si}^{235} \mathrm{U}$ and $\mathrm{H}^{235} \mathrm{U}$ ratios were determined for the concentration, and the resulting $\mathrm{k}_{\text {eff }}$ value was compared for closeness to the bounding value of 0.93. A sample of such calculations is presented in Figure B-4. From the figure, $1.05 \mathrm{~g}$ ${ }^{235} \mathrm{U} / \mathrm{L}$ is seen to calculate at a $\mathrm{k}_{\text {eff }}$ of 0.9286 for an optimum $\mathrm{Si}^{235} \mathrm{U}$ of 2421 and an optimum $\mathrm{H}^{235} \mathrm{U}$ of 124 . 


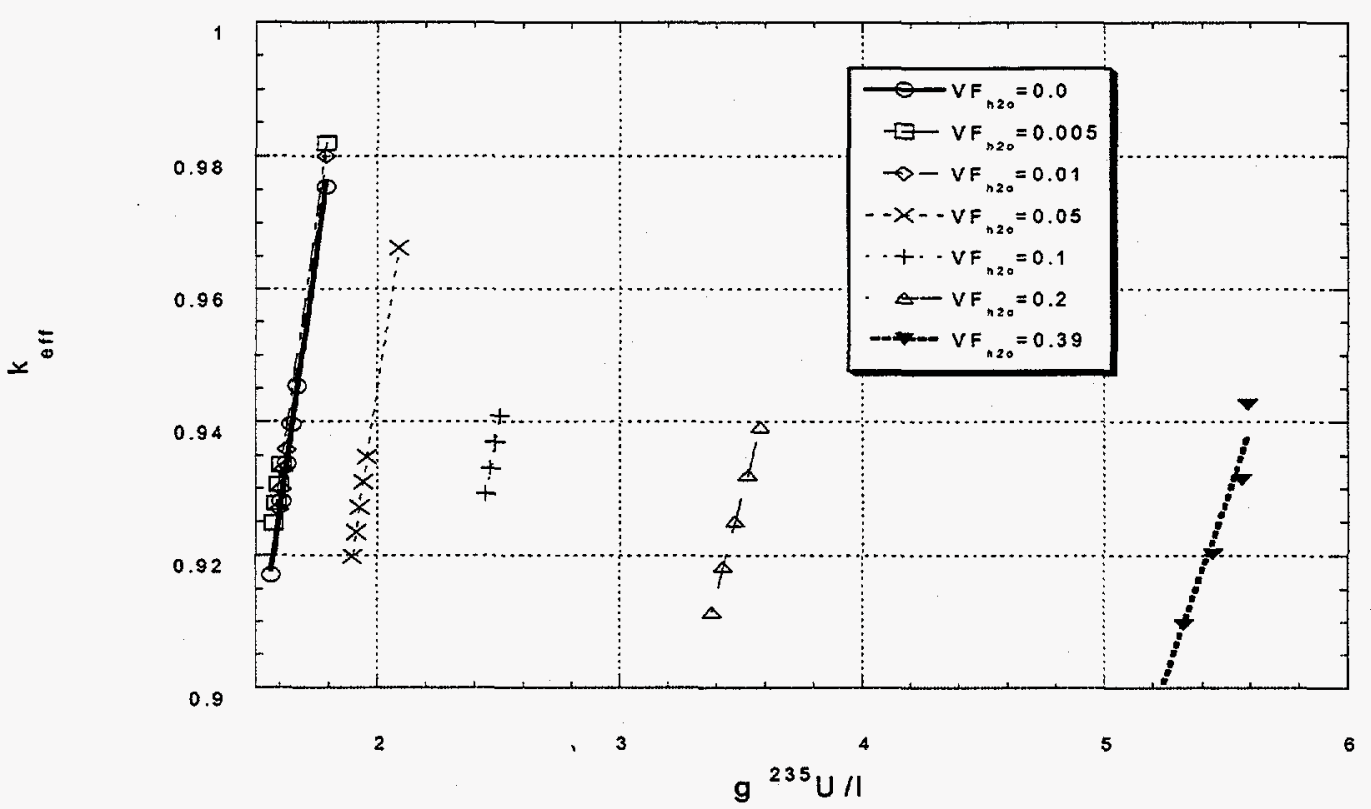

Figure B-2 Water-reflected, five-vehicle volume of homogeneous ${ }^{235} \mathrm{U}, \mathrm{SiO}_{2}\left(1.6 \mathrm{~g} / \mathrm{cm}^{3}\right)$, and $\mathrm{H}_{2} \mathrm{O}$

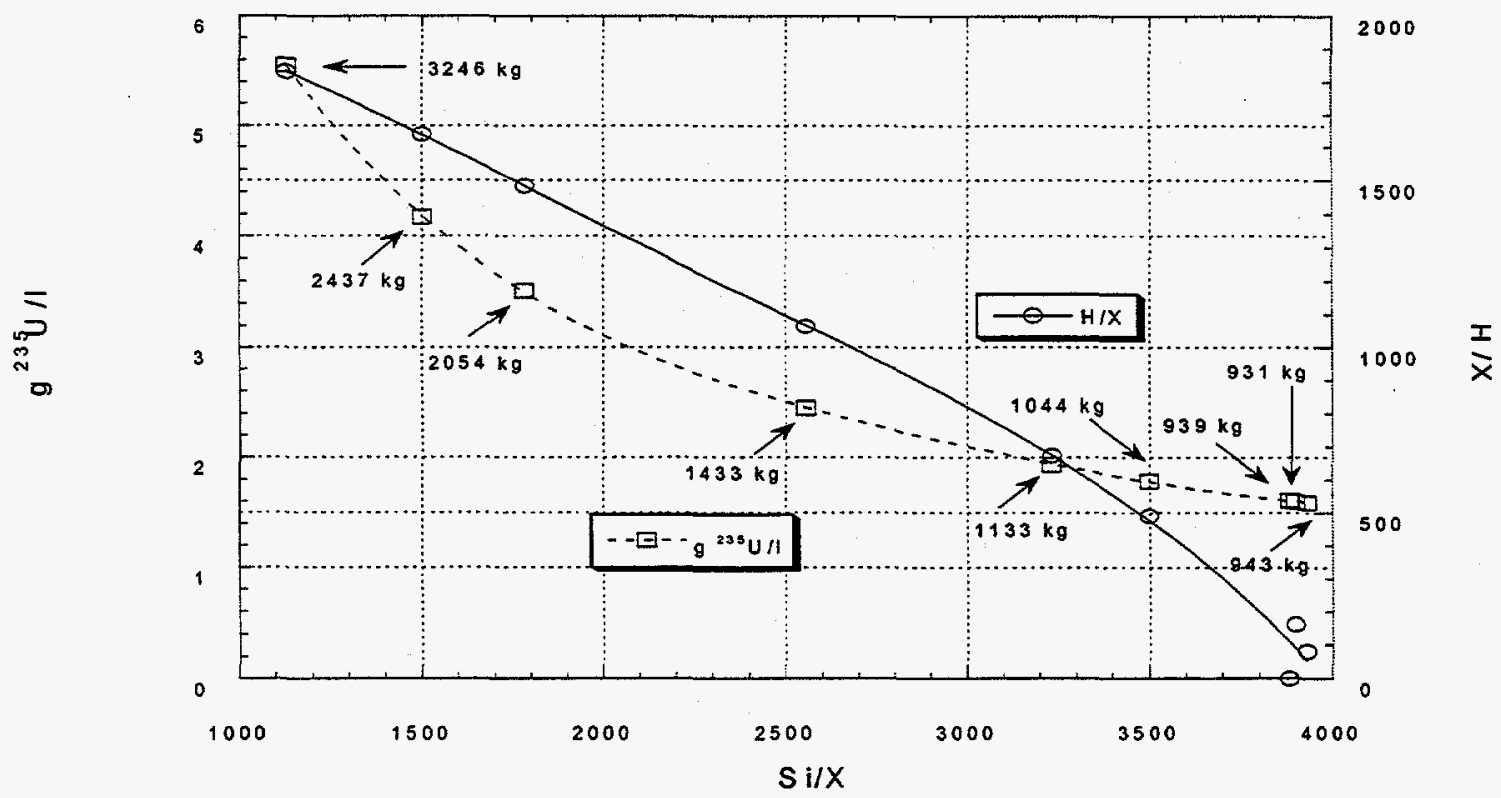

Figure B-3 Water-reflected, five-vehicle volume of homogeneous ${ }^{235} \mathrm{U}, \mathrm{SiO}_{2}\left(1.6 \mathrm{~g} / \mathrm{cm}^{3}\right)$, and $\mathrm{H}_{2} \mathrm{O} ; \mathrm{k}_{\mathrm{eff}} \sim 0.93$ 
Table B-2 Homogeneous ${ }^{235} U$ and silicon dioxide subcritical masses

\begin{tabular}{cccccc}
\hline $\mathrm{g}^{235} \mathrm{U} / \mathrm{L}$ & $\mathrm{Si}^{235} \mathrm{U}$ & $\mathrm{H}^{235} \mathrm{U}$ & $\mathrm{k}_{\text {eff }}$ & $\begin{array}{c}\mathrm{kg}^{235} \mathrm{U} \text { per } \\
\text { five vehicle }\end{array}$ & $\begin{array}{c}\mathrm{g}^{235} \mathrm{U} \text { per } \\
\text { drum }^{a}\end{array}$ \\
\hline 5.5488 & 1128 & 1831 & 0.9359 & 3264 & 1156 \\
4.1727 & 1500 & 1640 & 0.9341 & 2437 & 869 \\
3.5104 & 1783 & 1484 & 0.9346 & 2053 & 731 \\
2.4488 & 2556 & 1064 & 0.9333 & 1432 & 510 \\
1.9366 & 3232 & 673 & 0.9318 & 1133 & 403 \\
1.7883 & 3500 & 490 & 0.9331 & 1044 & 372 \\
1.6119 & 3883 & 0 & 0.9303 & 943 & 335 \\
1.6053 & 3899 & 162 & 0.9304 & 939 & 334 \\
1.5922 & 3931 & 82 & 0.9302 & 931 & 331 \\
\hline
\end{tabular}

${ }^{a}$ Based on 55-gal drum volume.

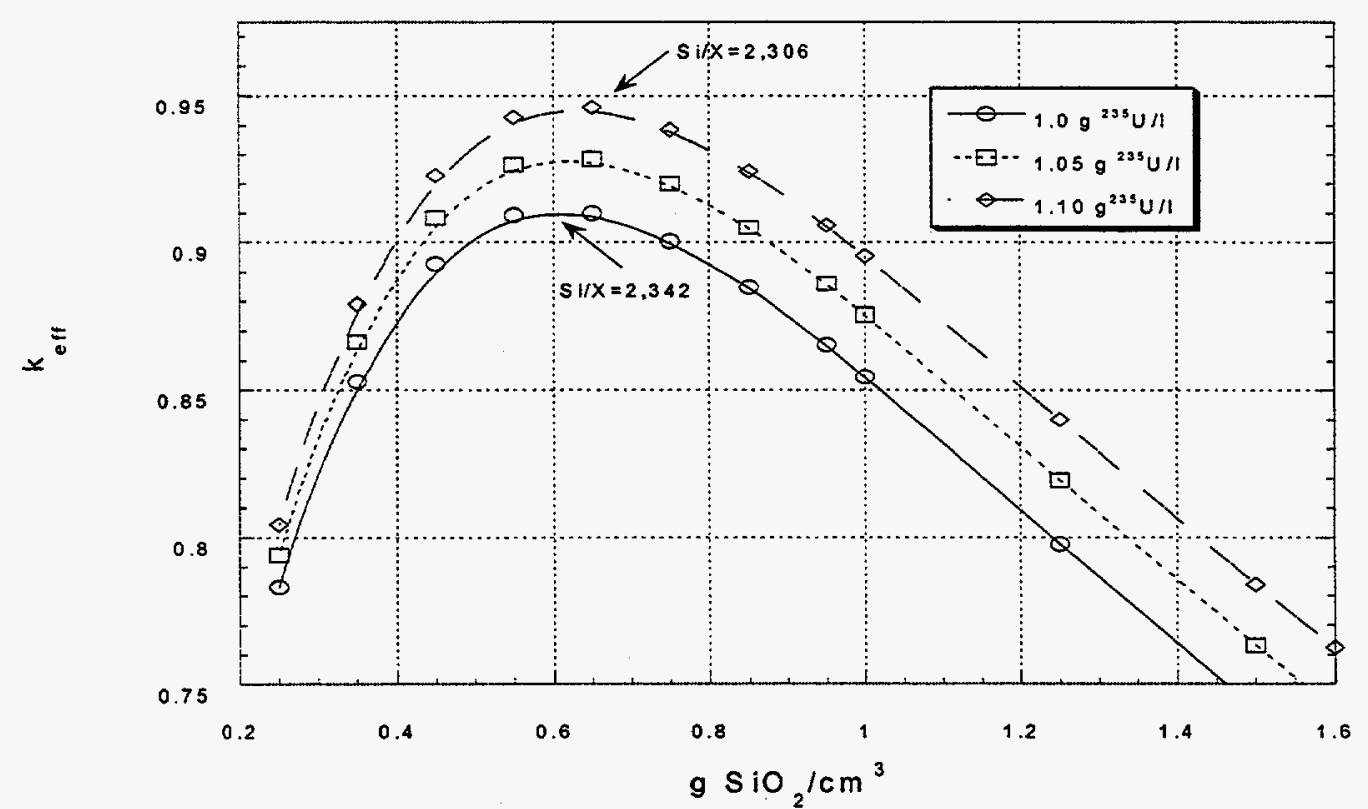

Figure B-4 Water-reflected, five-vehicle volume of homogeneous ${ }^{235} \mathrm{U}, \mathrm{SiO}_{2}$, and $\mathrm{H}_{2} \mathrm{O}$; ${ }^{235} U$ concentration where $k_{\text {eff }}$ at optimum $\mathrm{H}^{235} \mathrm{U}$ and $\mathrm{Si}^{235} \mathrm{U}$ 
In an effort to assign minimum transport indexes to packages for transportation, arrays of drum-type packages were evaluated. Package loadings and materials were considered to determine their effects on the $\mathrm{k}_{\mathrm{eff}}$ of the arrays. The packages analyzed were modeled in a near-cubic (optimal) triangular-pitch (optimal) $27 \times 27 \times 6$ array reflected by $30.48 \mathrm{~cm}$ of water. The total array volume was approximately $584 \mathrm{~m}^{3}$, with $20 \%$ interstitial void between packages. The volume between the drum-type packages was selected as void to maximize the array $k_{\text {eff. }}$ The packages were comprised of uranium-moderator mixture in a 110-gal dnum that was modeled as two joined 55 -gal 20 -gauge $(0.823$-mm body thickness) 316 -stainless steel DOT-17E drums. 316-Stainless steel was picked because it contained the minimum quantity of neutron-absorbing material. The 110-gal package was selected to minimize the quantity of steel mass to fissile-material mass; however, the tabulated mass of fissile material per drum is provided for the volume of 55-gal drums, a more common drum-type container used by industry.

Table B-3 presents results of the drum-array calculations. Each drum-type package contains a homogenous mixture of ${ }^{235} \mathrm{U}$, $1.60 \mathrm{~g} \mathrm{SiO}_{2} / \mathrm{cm}^{3}$, and $0.005 \mathrm{~g} \mathrm{H}_{2} \mathrm{O} / \mathrm{cm}^{3}$. For each $\mathrm{Si}^{235} \mathrm{U}$ ratio, the maximum subcritical ${ }^{235} \mathrm{U}$ concentration is given for the minimum drum-body thickness; this calculation is less than the $7 \%$ margin of subcriticality. For the maximum and minimum analyzed $\mathrm{H}^{235} \mathrm{U}$ ratios, the effect on $\mathrm{k}_{\text {eff }}$ from increasing the drum wall thickness by a factor of $\sim 3$ or completely removing drum material were examined. The given ${ }^{235} \mathrm{U}$ mass that is permissible per drum is based on the subcritical ${ }^{235} \mathrm{U}$ concentration at a given $\mathrm{Si}^{235} \mathrm{U}$ and a $208-\mathrm{L}$ drum volume for the minimum drum-body thickness only.

Lastly, an assessment of the subcritical dimension of an individually water-reflected homogeneous mixture of uranium and silicon dioxide was conducted to explore potential bounding specifications for fissile-material exemptions and general licenses. The critical masses of such silicon dioxide-moderated systems are given in Figure B-5. The minimum critical mass is $147 \mathrm{~kg}$ and is located at an $\mathrm{Si}^{235} \mathrm{U}$ ratio of 1150 and a mixture radius of $186.5 \mathrm{~cm}$. A $5 \%$ margin of subcriticality was selected over a $7 \%$ margin because the mixtures in the critical mass searches are binary (i.e., uranium and $\mathrm{SiO}_{2}$ ) rather than more difficult to validate tertiary (e.g., uranium, water, and $\mathrm{SiO}_{2}$ ) systems.

Table B-3 Array of $27 \times 27 \times 6110$-gal drums on hexagonal pitch

\begin{tabular}{|c|c|c|c|}
\hline $\mathrm{Si}^{235} \mathrm{U}$ & $\mathrm{g}^{235} \mathrm{U} / \mathrm{L}$ & $\mathbf{k}_{\text {eff }}$ & $\begin{array}{c}\mathrm{g}^{235} \mathrm{U} \\
\text { per drum }\end{array}$ \\
\hline \multirow[t]{3}{*}{4000} & 1.56 & $0.7098 \pm 0.0013$ & 325 \\
\hline & & $0.9347 \pm 0.0017^{b}$ & \\
\hline & & $0.5265 \pm 0.0010^{c}$ & \\
\hline 2608 & 2.4 & $0.9073 \pm 0.0018$ & 500 \\
\hline 2503 & 2.5 & $0.9213 \pm 0.0019$ & 520 \\
\hline \multirow[t]{3}{*}{2318} & 2.7 & $0.9634 \pm 0.0019$ & 563 \\
\hline & & $1.1793 \pm 0.0024^{b}$ & \\
\hline & & $0.7411 \pm 0.0015^{c}$ & \\
\hline
\end{tabular}

${ }^{a}$ Based on 55-gal drum volume.

${ }^{b}$ Drum absent.

2.4-mm drum-body thickness. 


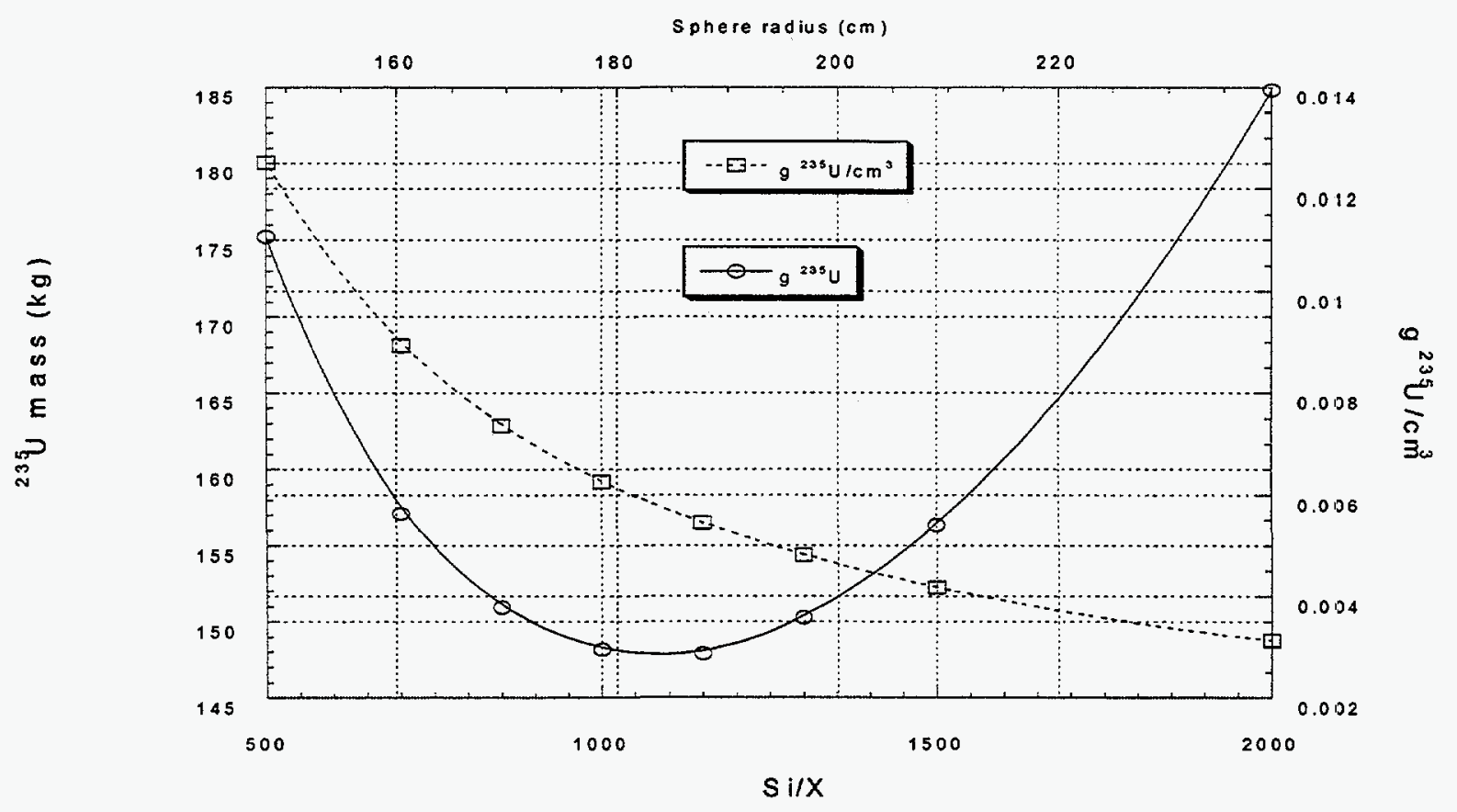

Figure B-5 Critical masses of water-reflected, homogeneous ${ }^{235} \mathrm{U}$ and $\mathrm{SiO}_{2}\left(1.6 \mathrm{~g} / \mathrm{cm}^{3}\right)$ spheres; $\mathrm{k}_{\mathrm{eff}} \sim 0.95$

Similar assessments were done to determine the subcritical dimensions of ${ }^{239} \mathrm{Pu}$ or ${ }^{233} \mathrm{U}$ as individually water-reflected spheres of homogeneous mixtures of ${ }^{239} \mathrm{Pu}$ or ${ }^{233} \mathrm{U}$ and to explore potential bounding specifications for fissile-material exemptions and general licenses. The critical parameters for these systems are provided as follows.

The determined ${ }^{239} \mathrm{Pu}$ minimum subcritical $\left(\mathrm{k}_{\mathrm{eff}} \leq 0.95\right)$ mass parameters are $72,688 \mathrm{~g}{ }^{239} \mathrm{Pu}$ homogeneously mixed with water (resulting in a silicon-to- ${ }^{230} \mathrm{Pu}$ atom ratio of about 2900 and about $2.2 \mathrm{~g}{ }^{239} \mathrm{Pu} / \mathrm{L}$ ) as a fully water-reflected 199.2-cm radius sphere. The results of the parameter survey are provided in Figure B-6.

The determined ${ }^{233} \mathrm{U}$ minimum subcritical $\left(\mathrm{k}_{\text {eff }} \leq 0.95\right)$ mass parameters are $61,616 \mathrm{~g}{ }^{233} \mathrm{U}$ homogeneously mixed with water (resulting in a silicon-to- ${ }^{233} \mathrm{U}$ atom ratio of about 1100 and about $5.6 \mathrm{~g}{ }^{233} \mathrm{U} / \mathrm{L}$ ) as a fully water-reflected $132.6 \mathrm{~cm}$ radius sphere. The results of the parameter survey are provided in Figure B-7. 


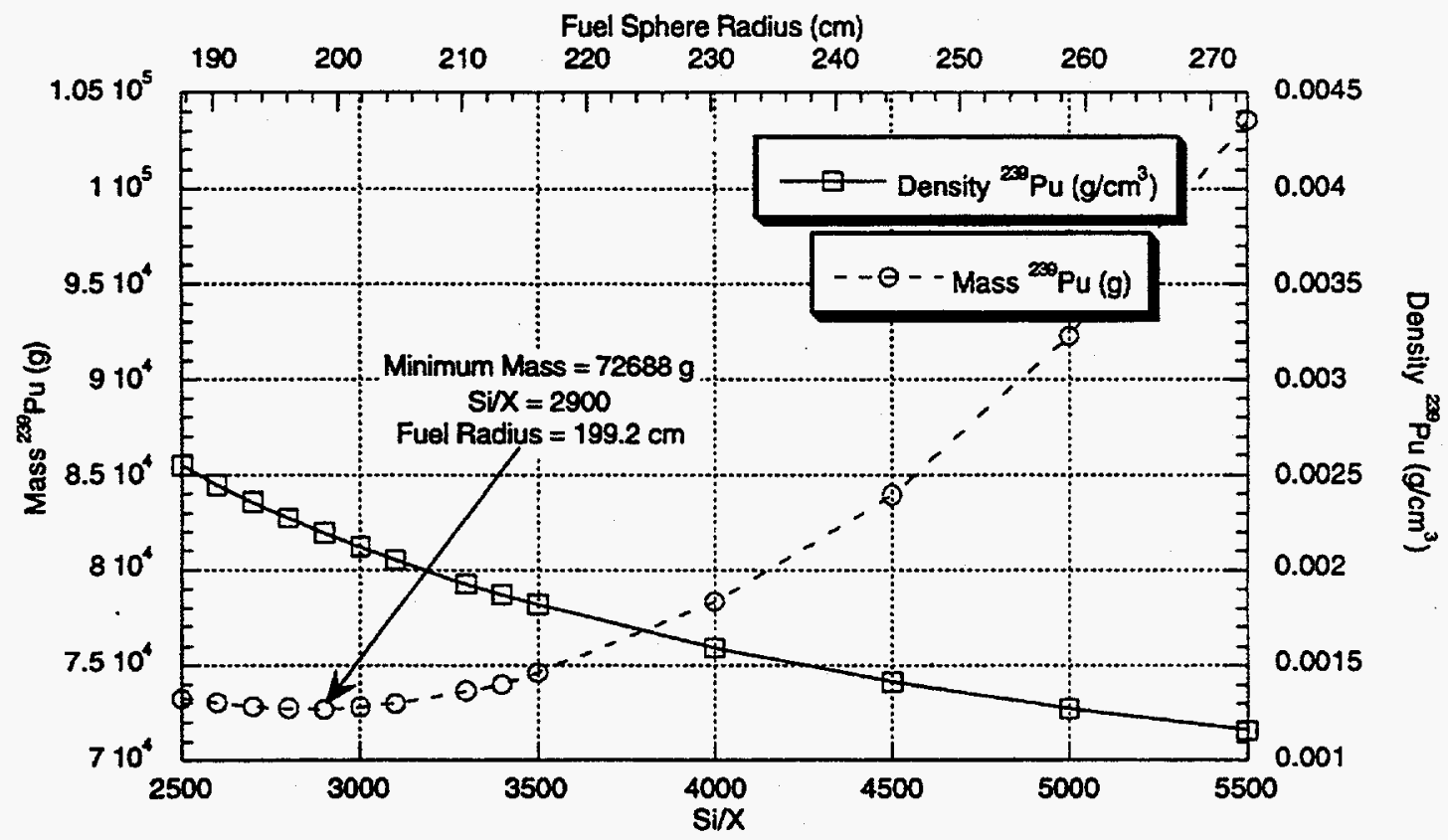

Figure B-6 Fissile masses and densities of water-reflected ${ }^{239} \mathrm{Pu}$ and Si spheres; $\mathrm{k}_{\mathrm{eff}} \approx 0.95$ (radius scale is approximate)

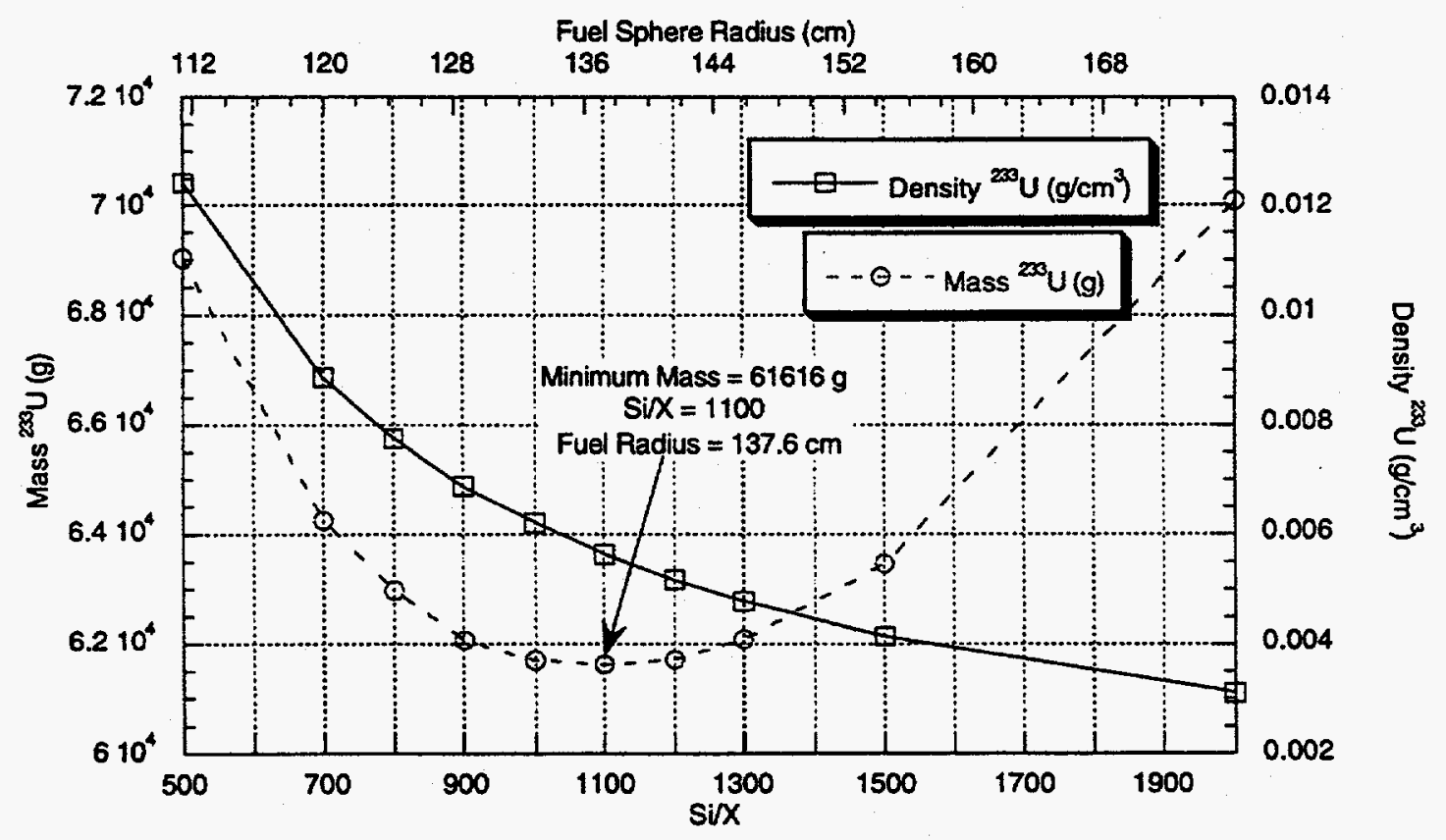

Figure B-7 Fissile masses and densities of water-reflected ${ }^{233} \mathrm{U}$ and Si spheres; $k_{\text {eff }} \approx 0.95$ (radius scale is approximate) 



\section{APPENDIX C}

Subcritical Carbon Systems 



\section{APPENDIX C}

\section{Subcritical Carbon Systems}

The exemption and general-license specifications are limited to considering only the type, mass and form of fissile material, together with the moderator. In this study, $100 \%$-enriched ${ }^{235} \mathrm{U}[\mathrm{U}(100)],{ }^{239} \mathrm{Pu}$ or ${ }^{233} \mathrm{U}$ homogeneously mixed with carbon and water were considered. The carbon was assumed to be at $60 \%$ of theoretical density, or $1.26 \mathrm{~g} / \mathrm{cm}^{3}$. ${ }^{235} \mathrm{U}$ in a homogenous mixture was chosen because the high enrichment is most reactive and for such enrichments homogeneous uranium-moderator mixtures are typically more reactive than corresponding heterogeneous uranium-moderator mixtures. Likewise, the ${ }^{239} \mathrm{Pu}$ and ${ }^{233} \mathrm{U}$ studies were assumed to be $100 \mathrm{wt} \%$ to avoid lack of conservatism regarding nonfission isotopes of plutonium or uranium.

Infinite systems of $U(100)$ were analyzed first to determine subcritical atom or mass ratios of various mixtures to define an "exemption for low-level materials" consistent with safety intended to be provided by $\S 71.10(\mathrm{a})$. For an infinite system there is no leakage and the moderator-to-fissile nuclei ratio $\left(\mathrm{C}^{235} \mathrm{U}\right)$ is the only parameter of interest. The infinite system results for homogeneous $U(100)$ and carbon are given in Table $C-1$ and plotted in Figure $C-1$. The $U(100)$ and carbon infinite homogeneous system subcritical neutron multiplication factor is 0.9304 , corresponding to a concentration of $0.171 \mathrm{~g}^{235} \mathrm{U} / \mathrm{L}$ at a $\mathrm{C}^{235} \mathrm{U}$ of $2.4 \times 10^{5}$. The fissile material concentration is lower than ordinary water because the parasitic absorption by carbon is significantly less than that of hydrogen. The subcritical neutron multiplication factor of 0.93 was selected to provide an adequate margin of subcriticality that is consistent with upper subcritical limits from broad-based historical validation studies.

Table C-1 Infinite homogeneous ${ }^{235} \mathrm{U}$ and carbon

\begin{tabular}{rc}
\hline $\mathrm{C} /{ }^{235} \mathrm{U}$ & $\mathbf{k}_{\text {inf }}$ \\
\hline 100 & 1.6931 \\
500 & 1.7252 \\
1,000 & 1.8136 \\
2,500 & 1.9107 \\
5,000 & 1.9409 \\
10,000 & 1.9250 \\
50,000 & 1.6376 \\
100,000 & 1.3656 \\
200,000 & 1.0237 \\
235,000 & 0.9411 \\
240,000 & 0.9304 \\
250,000 & 0.9096 \\
\hline
\end{tabular}

The subcritical $\mathrm{C}^{235} \mathrm{U}$ of $2.4 \times 10^{5}$ for the infinite system calculations provides a good starting point for determining subcritical finite systems of the same mixture. Because of increased leakage, the subcritical $\mathrm{C}^{235} \mathrm{U}$ for our corresponding finite system is somewhat less than $2.4 \times 10^{5}$. The finite system was evaluated as a fully water-reflected sphere of homogeneous uranium at $100 \%$ enrichment, carbon at $60 \%$ of theoretical density, and $\mathrm{H}_{2} \mathrm{O}$ at $0 \%$ to $39 \%$ volume fraction of the mixture. The mixture volume is about $584 \mathrm{~m}^{3}$. No container was considered in the calculational models due to the nonconservative introduction of neutron-absorbing materials. The selected volume of $584 \mathrm{~m}^{3}$ is representative of the maximum volume available in five public highway transportation vehicles (i.e., two tandem trailers pulled by a single tractor). The 


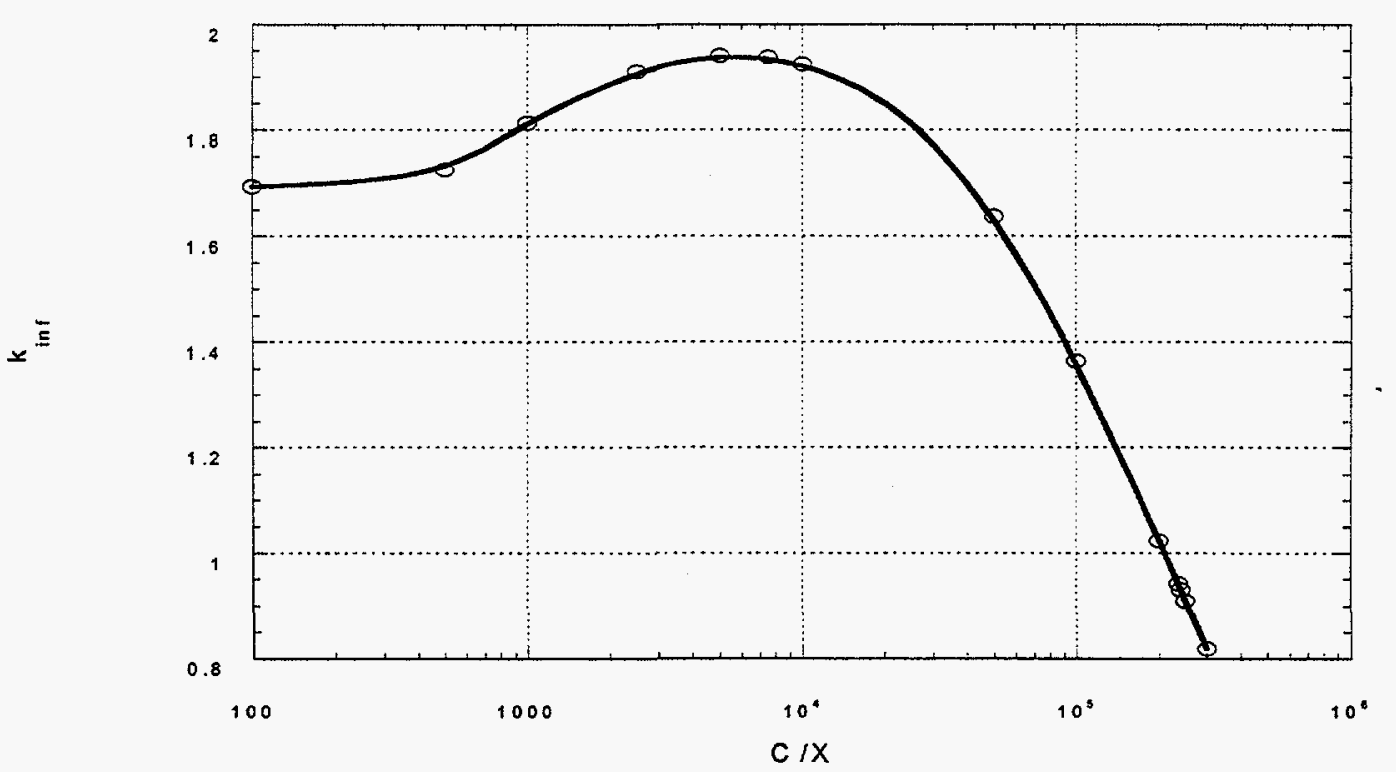

Figure C-1 Infinite homogeneous ${ }^{235} \mathrm{U}$ and carbon

selection of five vehicles [cf. $\$ 71.59$ (a)(1)] was made instead of two [cf. $\$ 71.59(a)(2)]$ to ensure the large volume associated with normal conditions of transport are accommodated, together with changes that might occur under hypothetical accident conditions. The $\mathrm{k}_{\text {eff }}$ values from these finite system calculations are given in Figure $\mathrm{C}-2$ versus ${ }^{235} \mathrm{U}$ concentration for seven water volume fractions. Note that the most reactive system is dry (i.e., $H^{235} \mathrm{U}=0$ ) up to a ${ }^{235} \mathrm{U}$ concentration of $9.92 \mathrm{~g} / \mathrm{cm}^{3}$.

The ${ }^{235} \mathrm{U}$ concentrations of Figure $\mathrm{C}-2$, yielding $\mathrm{k}_{\text {eff }}$ values of 0.93 , are plotted in Figure $\mathrm{C}-3$ versus their matching $\mathrm{H}^{235} \mathrm{U}$ and $\mathrm{C} /{ }^{235} \mathrm{U}$ ratios. Additional data for combinations of $\mathrm{H}{ }^{235} \mathrm{U}, \mathrm{C} /{ }^{235} \mathrm{U}$, and ${ }^{235} \mathrm{U}$ concentrations that calculate 0.93 have been added to Figure $\mathrm{C}-3$ to give a more complete picture. A sampling of the data in Figure C-3 is given in Table C-2. The fivevehicle and 55-gal drum ${ }^{235} \mathrm{U}$ masses in the table are based on the determined ${ }^{235} \mathrm{U}$ concentrations and $584-\mathrm{m}^{3}$ and $208-\mathrm{L}$ volumes. From Figure $\mathrm{C}-3$, one sees that any ${ }^{235} \mathrm{U}$ concentration above the $\mathrm{g}{ }^{235} \mathrm{U} / \mathrm{L}$ curve is above the upper subcritical limit as is any $\mathrm{H} /{ }^{235} \mathrm{U}$ below the $\mathrm{H} / \mathrm{X}$ curve. Conversely, any ${ }^{235} \mathrm{U}$ concentration below the $\mathrm{g}{ }^{235} \mathrm{U} / \mathrm{L}$ curve is below the supper subcritical limit as is any $\mathrm{H}^{235} \mathrm{U}$ above the $\mathrm{H} / \mathrm{X}$ curve.

To determine the ${ }^{235} \mathrm{U}$ concentration that is always below the upper subcritical limit, a ${ }^{235} \mathrm{U}$ concentration was selected, optimum $\mathrm{C}^{235} \mathrm{U}$ and $\mathrm{H}^{235} \mathrm{U}$ ratios were determined for the concentration, and the resulting $\mathrm{k}_{\text {eff }}$ value was compared for closeness to the bounding value of 0.93. A sample of such calculations are presented in Figure C-4. From the figure, $0.1030 \mathrm{~g}^{235} \mathrm{U} / \mathrm{L}$ is seen to calculate at a $\mathrm{k}_{\text {eff }}$ of 0.9239 for an optimum $\mathrm{C}^{235} \mathrm{U}$ of 132,994 and an optimum $\mathrm{H}^{235} \mathrm{U}$ of 0 (see Figure C-2).

In an effort to assign minimum transport indexes to packages for transportation, arrays of drum-type packages were evaluated. Package loadings and materials were considered to determine their effects on the $k_{\text {eff }}$ of the arrays. The packages analyzed were modeled in a near-cubic (optimal) triangular pitch (optimal) $27 \times 27 \times 6$ array reflected by $30.48 \mathrm{~cm}$ of water. The total array volume was approximately $584 \mathrm{~m}^{3}$, with $\sim 20 \%$ interstitial void between packages. The volume between the 


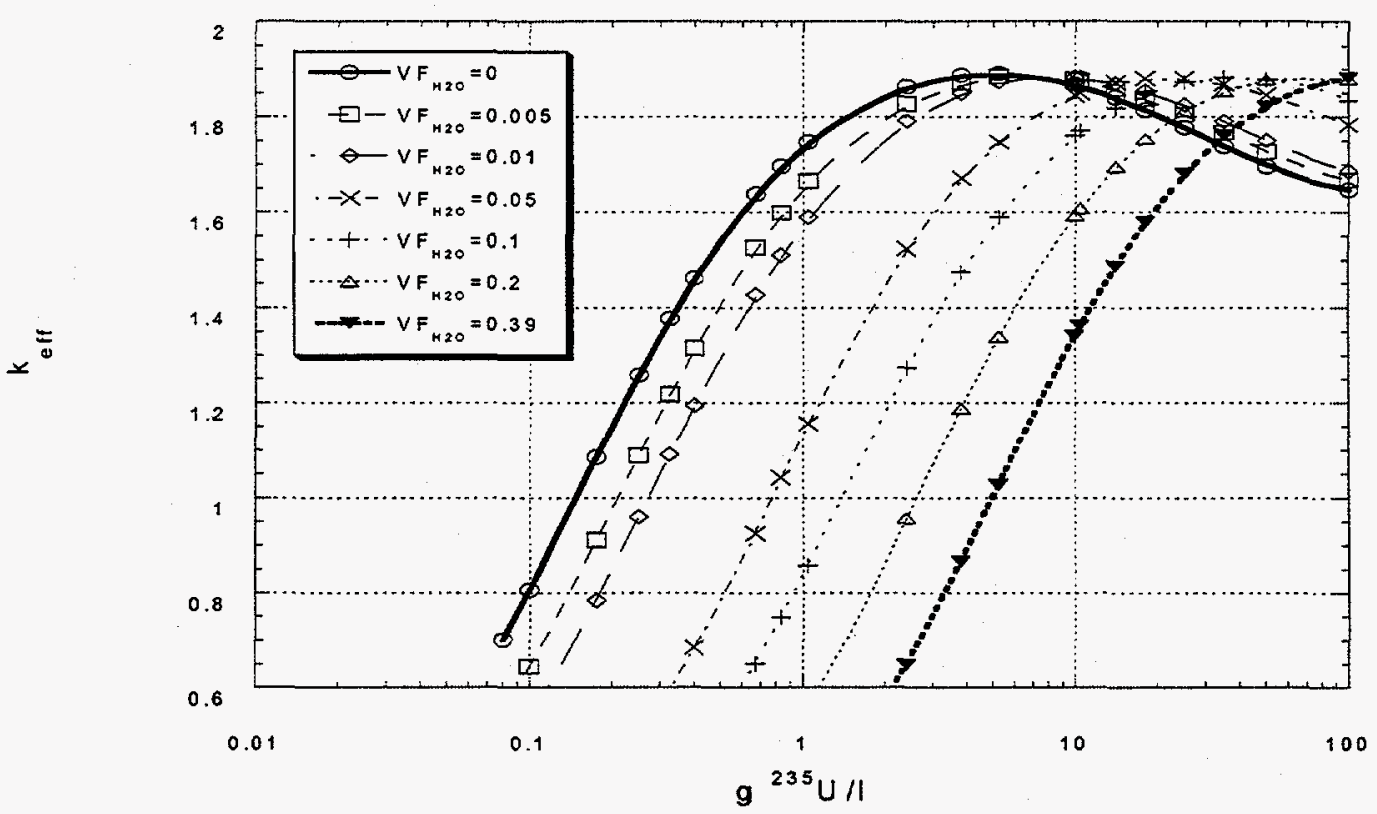

Figure C-2 Water-reflected, five-vehicle volume of homogeneous ${ }^{235} \mathrm{U}$, carbon $\left(1.26 \mathrm{~g} / \mathrm{cm}^{3}\right)$, and $\mathrm{H}_{2} \mathrm{O}$

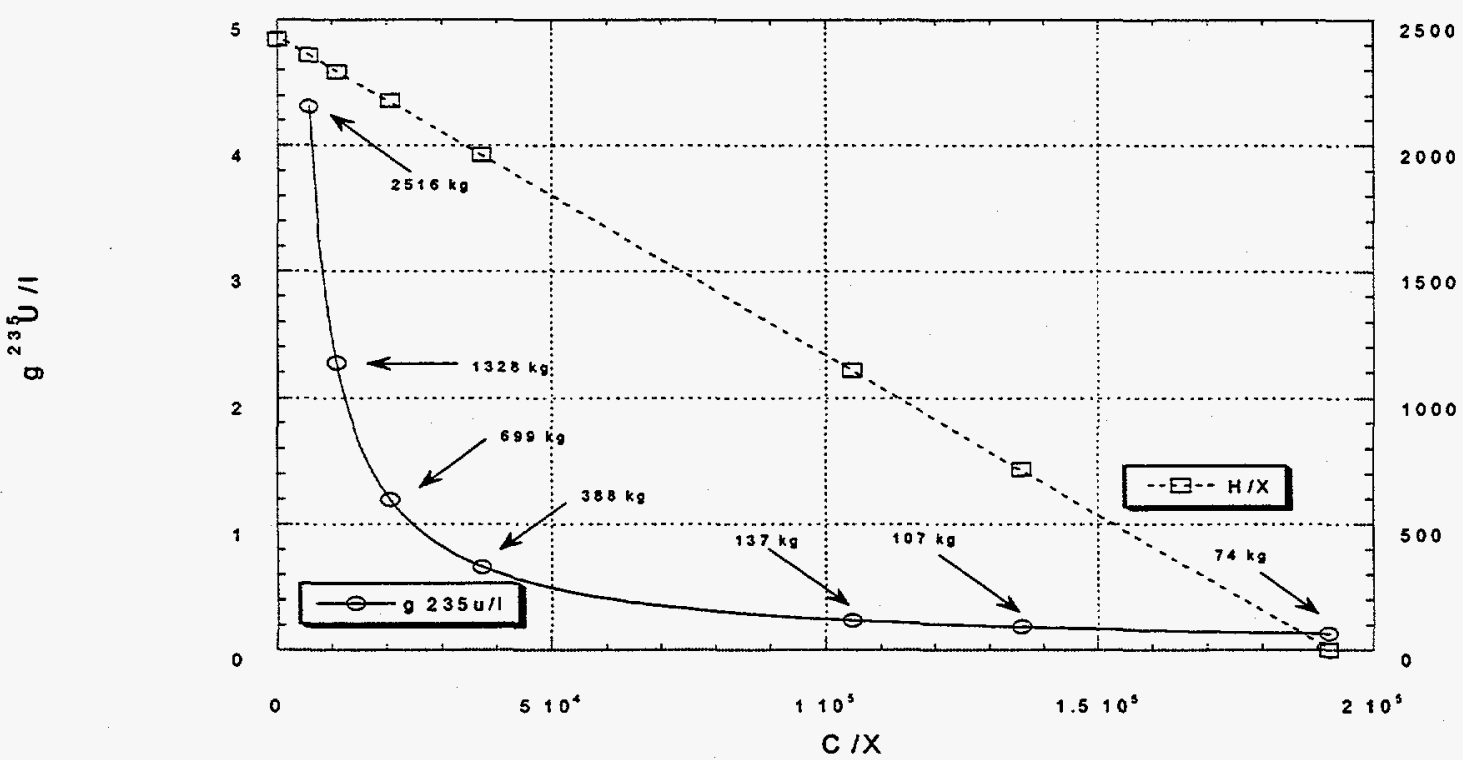

Figure C-3 Water-reflected, five-vehicle volume of homogeneous ${ }^{235} \mathrm{U}$, carbon $\left(1.26 \mathrm{~g} / \mathrm{cm}^{3}\right)$, and $\mathrm{H}_{2} \mathrm{O} ; \mathrm{k}_{\mathrm{eff}} \sim 0.93$ 
Table C-2 Homogeneous ${ }^{235} \mathrm{U}$, carbon, and water subcritical masses

\begin{tabular}{crcccc}
\hline \multicolumn{1}{c}{$\mathrm{g}^{235} \mathrm{U} / \mathrm{L}$} & $\mathrm{C}^{235} \mathrm{U}$ & $\mathrm{H}^{235} \mathrm{U}$ & $\mathrm{k}_{\text {eff }}$ & $\begin{array}{c}\mathrm{kg}^{235} \mathrm{U} \text { per } \\
\text { five vehicle }\end{array}$ & $\begin{array}{c}\mathrm{g}^{235} \mathrm{U} \text { per } \\
\text { drum }^{a}\end{array}$ \\
\hline 10.7 & 0 & 2422 & 0.9303 & 6284 & 2241 \\
4.3069 & 5,725 & 2360 & 0.9296 & 2515 & 897 \\
2.2734 & 10,846 & 2293 & 0.9302 & 1327 & 473 \\
1.1963 & 20,611 & 2178 & 0.9287 & 698 & 249 \\
0.6636 & 37,155 & 1964 & 0.9300 & 387 & 138 \\
0.2354 & 104,749 & 1107 & 0.9297 & 137 & 49.0 \\
0.1815 & 135,852 & 718 & 0.9288 & 106 & 37.8 \\
0.1274 & 193,512 & 0 & 0.9259 & 74.4 & 26.5 \\
\hline
\end{tabular}

${ }^{a}$ Based on 55-gal drum volume.

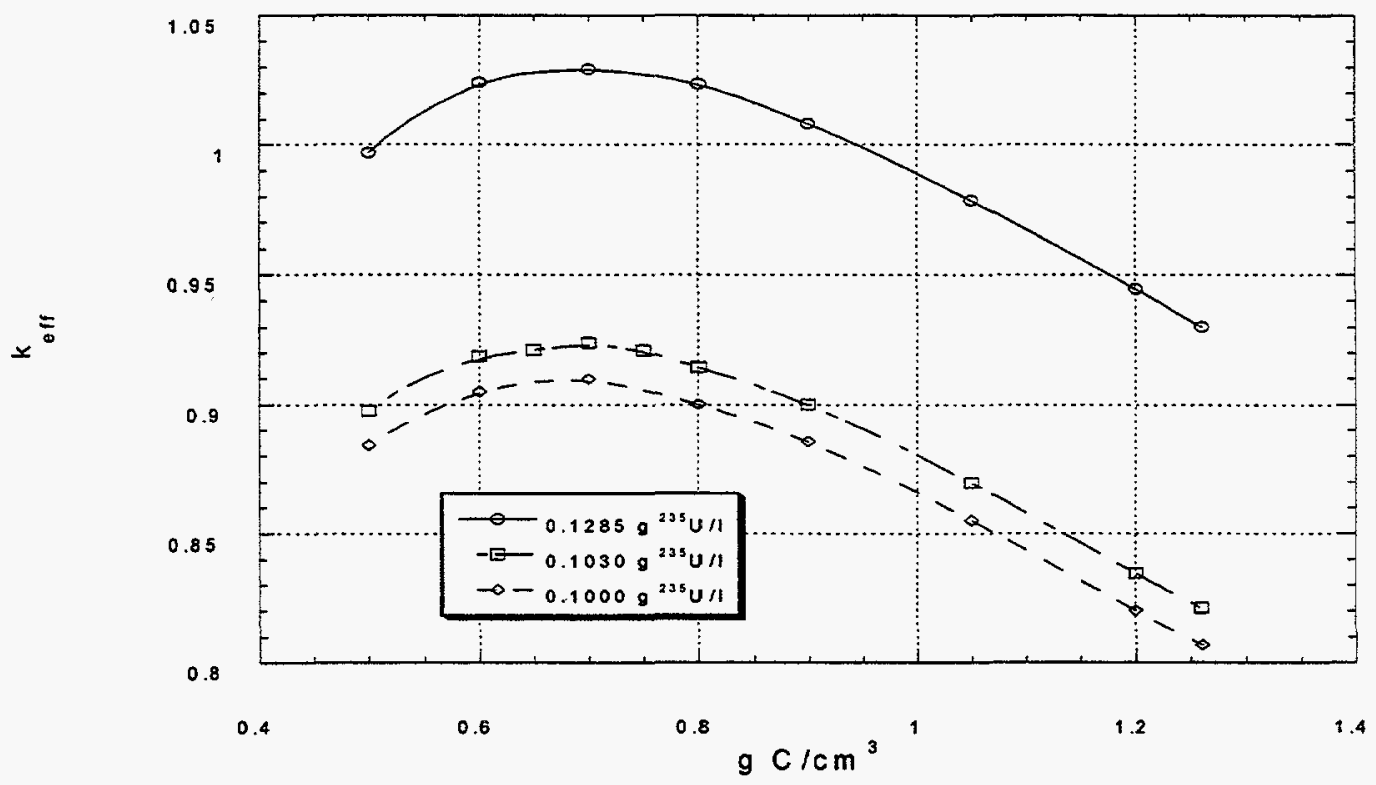

Figure C-4 Water-reflected, five-vehicle volume of homogeneous ${ }^{235} \mathrm{U}$, carbon, and $\mathrm{H}_{2} \mathrm{O}$; ${ }^{235} U$ concentration where $k_{\text {ef }}$ at optimum $H / X$ and $C / X$ 
drum-type packages was selected as void to maximize the array $\mathrm{k}_{\text {eff }}$. The packages were comprised of uranium-moderator mixture in a 110-gal drum that was modeled as two joined 55-gal, 20-gauge (0.823-mm body thickness) 316 -stainless steel DOT-17E drums. 316-Stainless steel was picked because it contained the minimum quantity of neutron-absorbing material. The 110-gal package was selected to minimize the quantity of steel mass to fissile-material mass; however, the tabulated mass of fissile material per drum is provided for the volume of 55-gal drums, a more common drum-type container used by industry.

Table $\mathrm{C}-3$ presents results of the drum-array calculations. Each drum-type package contains a homogenous mixture of ${ }^{235} \mathrm{U}$, $1.26 \mathrm{~g} \mathrm{C} / \mathrm{cm}^{3}$, and water. For each $\mathrm{C}^{235} \mathrm{U}$ ratio, the maximum subcritical ${ }^{235} \mathrm{U}$ concentration is given for the minimum drum body thickness; this calculation is less than the 7\% margin of subcriticality. For the maximum and minimum analyzed $\mathrm{H}^{235} \mathrm{U}$ ratios, the effect on $\mathrm{k}_{\text {eff }}$ from increasing the drum-wall thickness by a factor of $\sim 3$ or completely removing drum material were examined. The given ${ }^{235} \mathrm{U}$ mass that is permissible per drum is based on the subcritical ${ }^{235} \mathrm{U}$ concentration at a given $\mathrm{C}^{235} \mathrm{U}$ and a 208 -L-drum volume for the minimum drum-body thickness only.

Lastly, an assessment of the subcritical dimension of an individually water-reflected homogeneous mixture of uranium and carbon were conducted to explore potential bounding specifications for fissile-material exemptions and general licenses. The critical masses of such carbon-moderated systems are given in Figure C-5. The minimum critical mass is $2,187 \mathrm{~g}$ and is located at an $\mathrm{C}^{235} \mathrm{U}$ ratio of 25,000 and a mixture radius of $68.2 \mathrm{~cm}$. A $5 \%$ margin of subcriticality was selected over a $7 \%$ margin because the mixtures in the critical mass searches are binary (i.e., uranium and carbon) rather than more difficult to validate tertiary (e.g., uranium, water, and carbon) systems.

Similar assessments were done to determine the subcritical dimensions of ${ }^{230} \mathrm{Pu}$ or ${ }^{233} \mathrm{U}$ as individually water-reflected spheres of homogeneous mixtures of ${ }^{239} \mathrm{Pu}$ or ${ }^{233} \mathrm{U}$ and to explore potential bounding specifications for fissile-material exemptions and general licenses. The critical parameters for these systems are provided as follows.

Table C-3 Array of $27 \times 27 \times 6110$-gal drums on hexagonal pitch

\begin{tabular}{ccccc}
\hline & & & & $\mathrm{g}^{235} \mathrm{U}$ \\
$\mathrm{C}{ }^{235} \mathrm{U}$ & $\mathrm{H}^{235} \mathrm{U}$ & $\mathrm{g}^{235} \mathrm{U} / \mathrm{L}$ & $\mathrm{k}_{\text {eff }}$ & 185 \\
\hline 27,704 & 0 & 0.89 & $0.9306 \pm 0.0020$ & \\
& & & $1.7582 \pm 0.0025^{b}$ & \\
& & & $0.5841 \pm 0.0016^{c}$ & \\
17,867 & 1,000 & 1.38 & $0.9289 \pm 0.0016$ & 287 \\
12,146 & 1,500 & 2.03 & $0.9259 \pm 0.0014$ & 422 \\
6,274 & 2,000 & 3.93 & $0.9284 \pm 0.0014$ & 818 \\
& & & $1.0160 \pm 0.0013^{b}$ & \\
& & & $0.8541 \pm 0.0012^{c}$ & \\
\hline
\end{tabular}

${ }^{\circ}$ Based on 55-gal drum volume.

${ }^{b}$ Drum absent.

2.4-mm-drum-body thickness. 


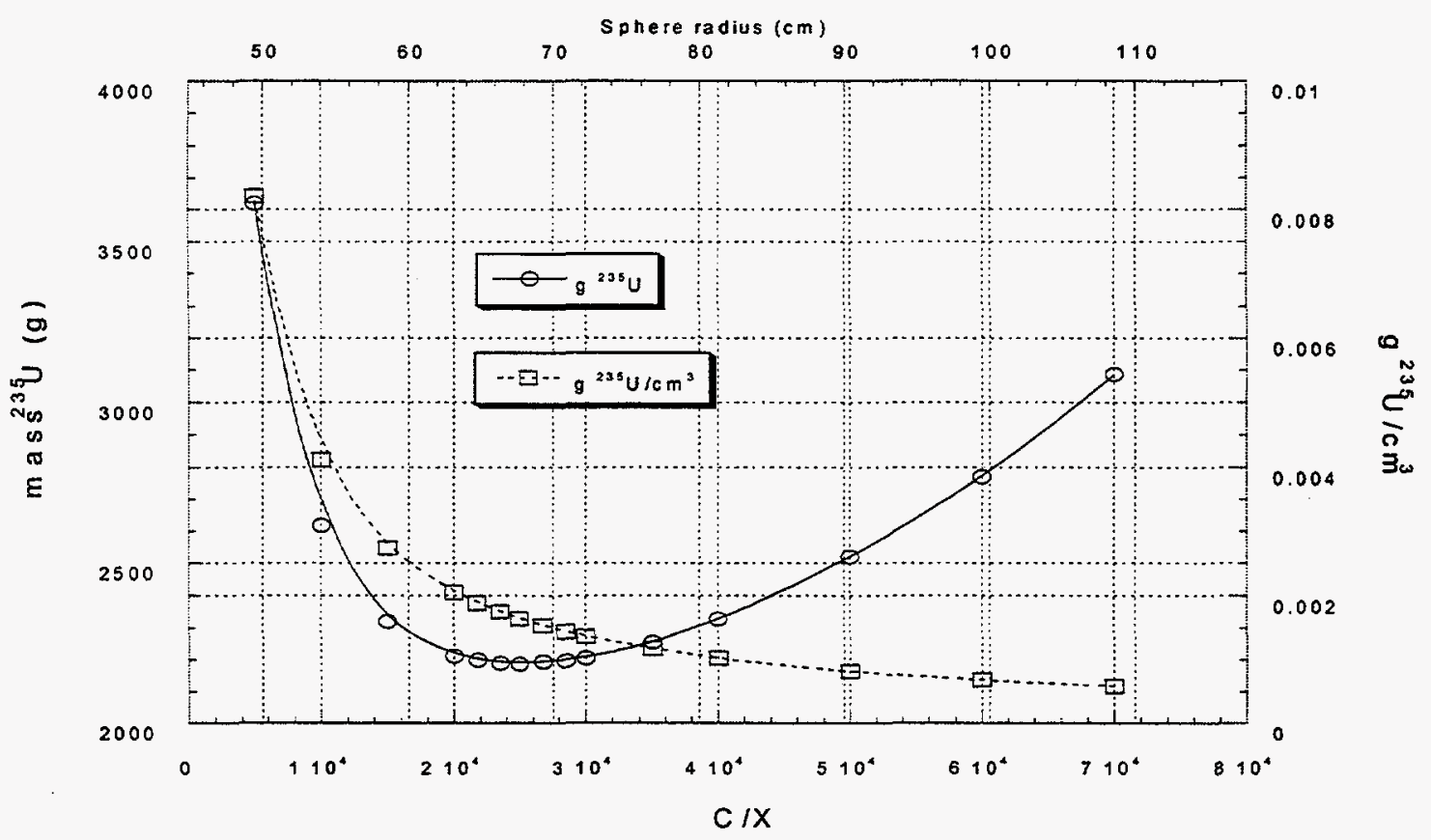

Figure C-5 Critical masses of water-reflected, homogeneous ${ }^{235} \mathrm{U}$ and carbon $\left(1.26 \mathrm{~g} / \mathrm{cm}^{3}\right)$ spheres; $k_{\mathrm{eff}} \sim 0.95$

The determined ${ }^{239} \mathrm{Pu}$ minimum subcritical $\left(\mathrm{k}_{\text {eff }} \leq 0.95\right)$ mass parameters are $1,212 \mathrm{~g}{ }^{239} \mathrm{Pu}$ homogeneously mixed with water (resulting in a carbon-to- ${ }^{230} \mathrm{Pu}$-atom ratio of about 44,000 and about $0.95 \mathrm{~g}{ }^{239} \mathrm{Pu} / \mathrm{L}$ ) as a fully water-reflected 67.3-cm-radius sphere. The results of the parameter survey are provided in Figure C-6.

The determined ${ }^{233} \mathrm{U}$ minimum subcritical $\left(\mathrm{k}_{\text {eff }} \leq 0.95\right)$ mass parameters are $1,722 \mathrm{~g}{ }^{233} \mathrm{U}$ homogeneously mixed with water (resulting in a carbon-to- ${ }^{233} \mathrm{U}$-atom ratio of about 22,000 and about $1.9 \mathrm{~g}{ }^{233} \mathrm{U} / \mathrm{L}$ ) as a fully water reflected $60.54-\mathrm{cm}$-radius sphere. The results of the parameter survey are provided in Figure C-7. 


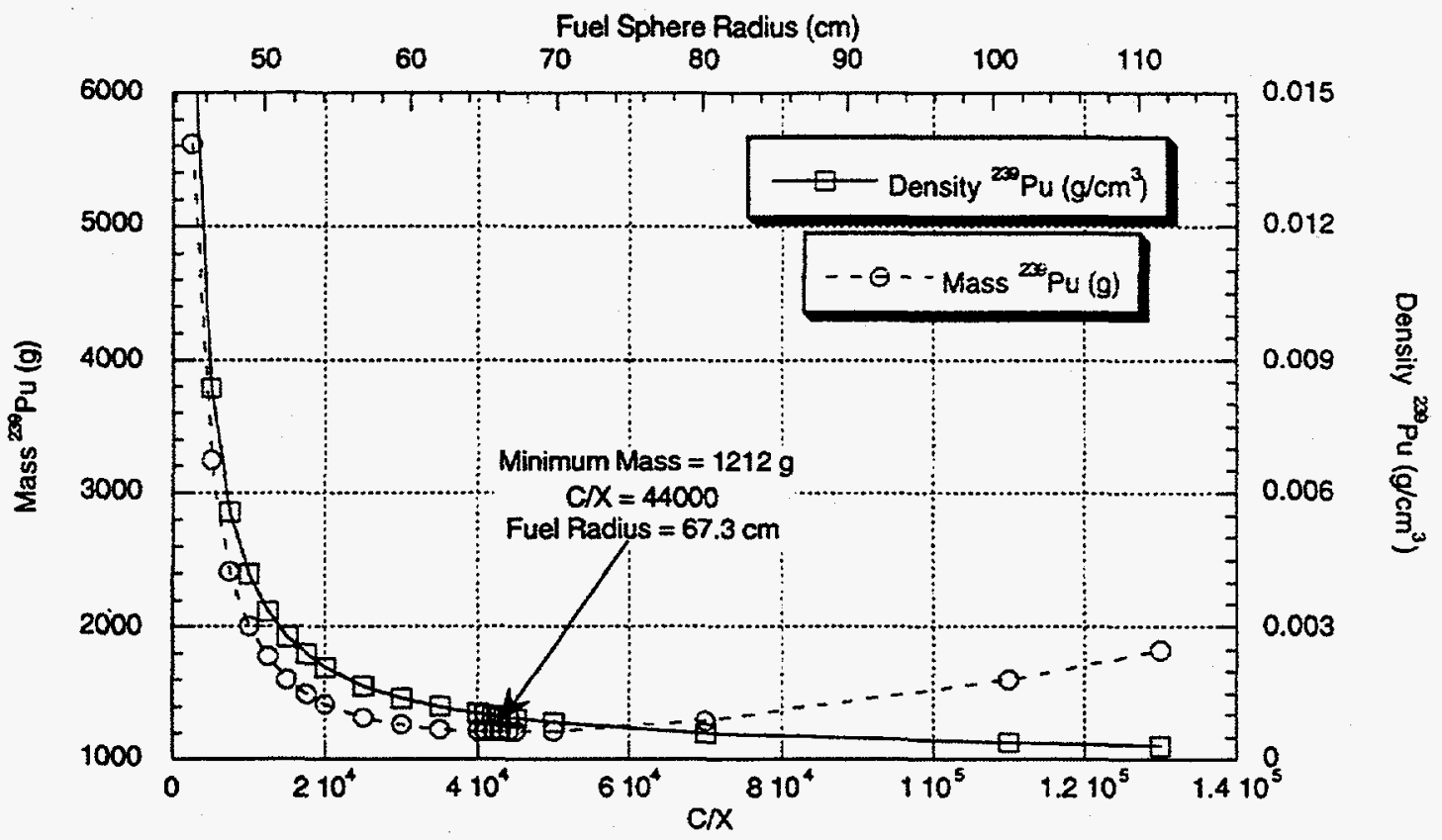

Figure $\dot{C}-6$ Fissile masses and densities of water-reflected ${ }^{239} \mathrm{Pu}$ and $\mathrm{C}$ spheres; $\mathrm{k}_{\mathrm{eff}} \approx 0.95$ (radius scale is approximate)

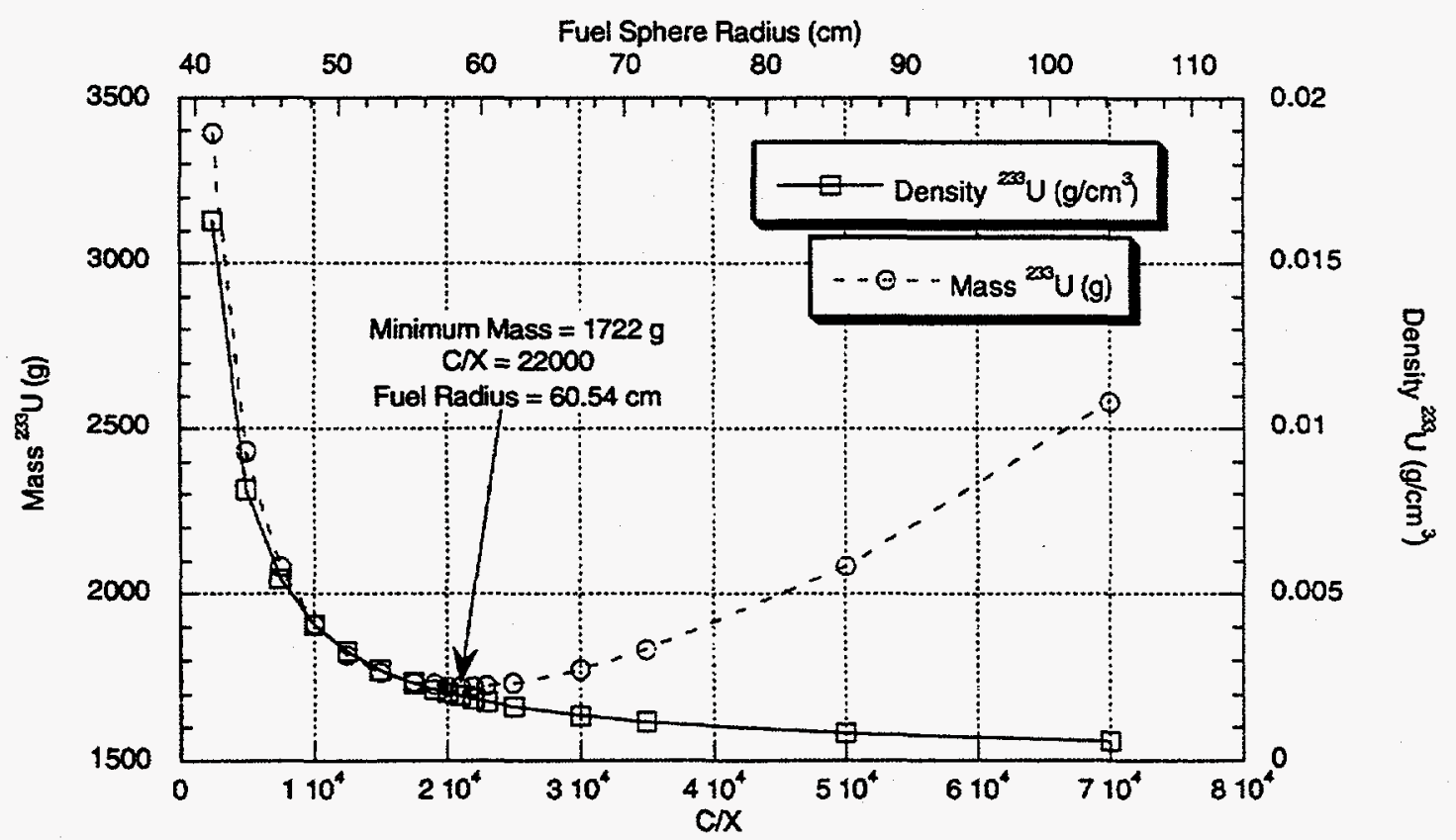

Figure C-7 Fissile masses and densities of water-reflected ${ }^{233} \mathrm{U}$ and $\mathrm{C}$ spheres; $\mathrm{k}_{\mathrm{eff}} \approx 0.95$ (radius scale is approximate) 



\section{APPENDIX D}

Subcritical Beryllium Systems 



\section{APPENDIX D}

\section{Subcritical Beryllium Systems}

The exemption and general-license specifications are limited to considering only the type, mass and form of fissile material, together with the moderator. In this study, $100 \%$-enriched ${ }^{235} \mathrm{U}[\mathrm{U}(100)],{ }^{239} \mathrm{Pu}$ or ${ }^{233} \mathrm{U}$ homogeneously mixed with beryllium and water were considered. The beryllium was assumed to be at $60 \%$ of theoretical density, or $1.11 \mathrm{~g} / \mathrm{cm}^{3}$. ${ }^{235} \mathrm{U}$ in a homogenous mixture was chosen because the high enrichment is most reactive and for such enrichments homogeneous uranium-moderator mixtures are typically more reactive than corresponding heterogeneous uraniummoderator mixtures. Likewise, the ${ }^{239} \mathrm{Pu}$ and ${ }^{233} \mathrm{U}$ studies were assumed to be $100 \mathrm{wt} \%$ to avoid lack of conservatism regarding nonfission isotopes of plutonium or uranium.

Infinite systems were analyzed first to determine subcritical atom or mass ratios of various mixtures to define an "exemption for low-level materials" consistent with safety intended to be provided by $\$ 71.10$ (a). For an infinite system there is no leakage and the moderator-to-fissile nuclei ratio $\left(C{ }^{235} \mathrm{U}\right)$ is the only parameter of interest. The infinite system results for homogeneous ${ }^{235} \mathrm{U}$ and beryllium are given in Table $\mathrm{D}-1$ and plotted in Figure $\mathrm{D}-1$. The ${ }^{235} \mathrm{U}$ and beryllium infinite homogeneous system subcritical neutron multiplication factor is 0.9339 , corresponding to a concentration of $0.508 \mathrm{~g}{ }^{235} \mathrm{U} / \mathrm{L}$ at a $\mathrm{Be}^{235} \mathrm{U}$ of $9.5 \times 10^{4}$. The fissile material concentration is lower than ordinary water because the parasitic absorption by beryllium is significantly less than that of hydrogen. The subcritical neutron multiplication factor of 0.93 was selected to provide an adequate margin of subcriticality that is consistent with upper subcritical limits from broad-based historical validation studies.

The subcritical $\mathrm{Be} /{ }^{235} \mathrm{U}$ of $9.5 \times 10^{4}$ for the infinite system calculations provides a good starting point for determining subcritical finite systems of the same mixture. Due to increased leakage, the subcritical $\mathrm{Be}^{235} \mathrm{U}$ for our corresponding finitesystem is somewhat less than $9.5 \times 10^{4}$. The finite system was evaluated as a fully water-reflected sphere of homogeneous uranium at $100 \%$ enrichment, beryllium at $60 \%$ of theoretical density, and $\mathrm{H}_{2} \mathrm{O}$ at $0 \%$ to $39 \%$ volume fraction of the mixture. The mixture volume is about $584 \mathrm{~m}^{3}$. No container was considered in the calculational models due to the nonconservative introduction of neutron-absorbing materials. The selected volume of $584 \mathrm{~m}^{3}$ is representative of the maximum volume available in five public highway transportation vehicles (i.e., two tandem trailers pulled by a single tractor). The selection of five vehicles [cf. $\$ 71.59(\mathrm{a})(1)]$ was made instead of two [cf. $\$ 71.59(\mathrm{a})(2)]$ to ensure the large volume associated with normal conditions of transport are accommodated, together with changes that might occur under

Table D-1 Infinite homogeneous ${ }^{235} \mathrm{U}$ and beryllium

\begin{tabular}{rc}
\hline $\mathrm{Be}^{235} \mathrm{U}$ & $\mathrm{k}_{\text {inf }}$ \\
\hline 100 & 1.8087 \\
500 & 1.9557 \\
1,000 & 2.0285 \\
2,500 & 2.0602 \\
5,000 & 2.0205 \\
10,000 & 1.9092 \\
50,000 & 1.2824 \\
95,000 & 0.9339 \\
110,000 & 0.8563 \\
130,000 & 0.7709 \\
\hline
\end{tabular}




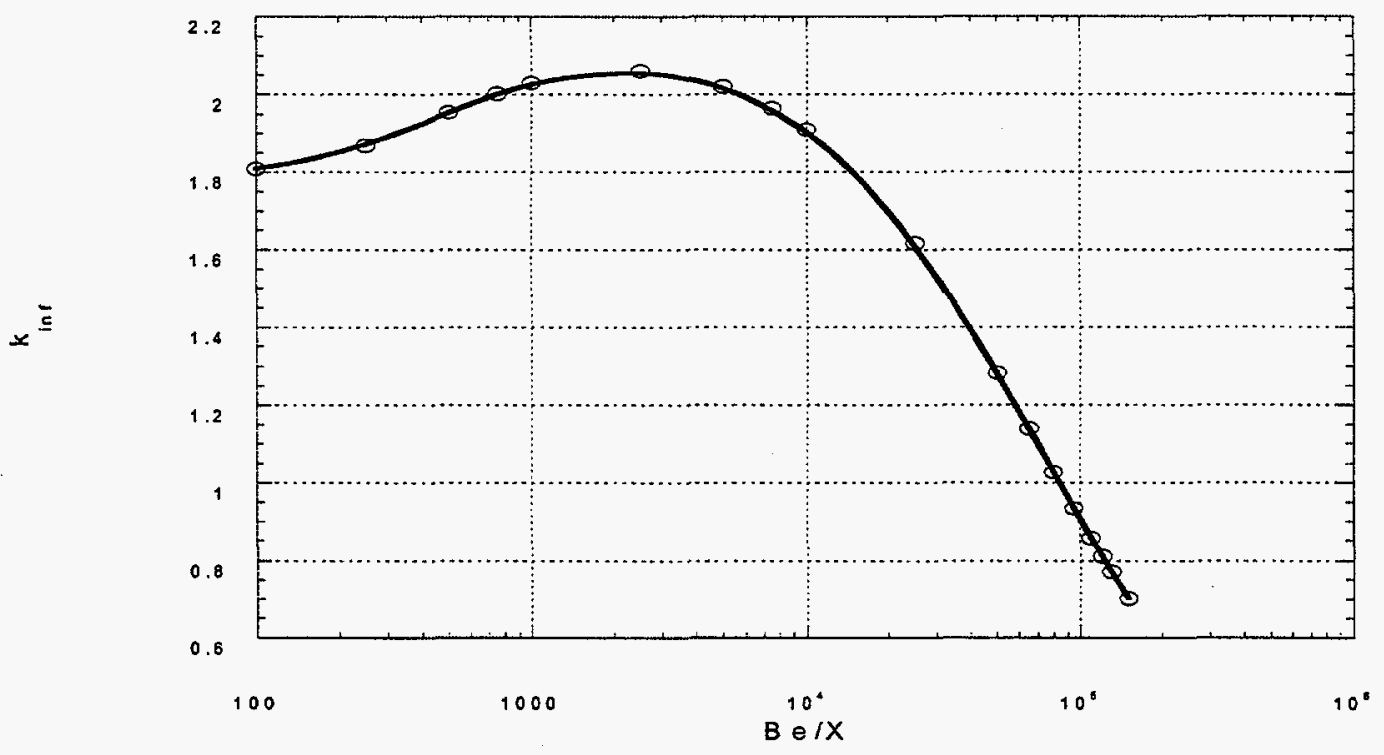

Figure D-1 Infinite homogeneous ${ }^{235} \mathrm{U}$ and beryllium

hypothetical accident conditions. The $\mathrm{k}_{\text {eff }}$ values from these finite-system calculations are given in Figure D-2 versus ${ }^{235} \mathrm{U}$ concentration for seven water-volume fractions. Please note the sensitivity of $k_{\text {eff }}$ to extremely small changes in ${ }^{235} \mathrm{U}$ concentration.

The ${ }^{235} \mathrm{U}$ concentrations of Figure $\mathrm{D}-2$, yielding $\mathrm{k}_{\text {eff }}$ values of 0.93 , are plotted in Figure $\mathrm{D}-3$ versus their matching $\mathrm{H}^{235} \mathrm{U}$ and $\mathrm{Be}^{235} \mathrm{U}$ ratios. Additional data for combinations of $\mathrm{H}^{235} \mathrm{U}, \mathrm{Be} /{ }^{235} \mathrm{U}$, and ${ }^{235} \mathrm{U}$ concentrations that calculate 0.93 have been added to Figure D-3 to give a more complete picture. A sampling of the data in Figure D-3 is given in Table D-2. The fivevehicle and 55-gal drum ${ }^{235} \mathrm{U}$ masses in the table are based on the determined ${ }^{235} \mathrm{U}$ concentrations and 584- $\mathrm{m}^{3}$ and $208-\mathrm{L}$ volumes. From Figure D-3, one sees that any ${ }^{235} \mathrm{U}$ concentration above the $\mathrm{g}{ }^{235} \mathrm{U} / \mathrm{L}$ curve is above the upper subcritical limit as is any $\mathrm{H}^{235} \mathrm{U}$ below the $\mathrm{H} / \mathrm{X}$ curve. Conversely, any ${ }^{235} \mathrm{U}$ concentration below the $\mathrm{g}{ }^{235} \mathrm{U} / \mathrm{L}$ curve is below the upper subcritical limit as is any $\mathrm{H}^{235} \mathrm{U}$ above the $\mathrm{H} / \mathrm{X}$ curve.

To determine the ${ }^{235} \mathrm{U}$ concentration that is always below the upper subcritical limit, a ${ }^{235} \mathrm{U}$ concentration was selected, optimum $\mathrm{Be}^{235} \mathrm{U}$ and $\mathrm{H}^{235} \mathrm{U}$ ratios were determined for the concentration, and the resulting $\mathrm{k}_{\text {eff }}$ value was compared for closeness to the bounding value of 0.93 . Samples of such calculations are presented in Figure D- 4 . From the figure, $0.14 \mathrm{~g}$ ${ }^{235} \mathrm{U} / \mathrm{L}$ is seen to calculate at a $\mathrm{k}_{\text {eff }}$ of 0.9169 for an optimum $B \mathrm{Be}^{235} \mathrm{U}$ of 52,161 and an optimum $\mathrm{H}^{235} \mathrm{U}$ of 0 . 


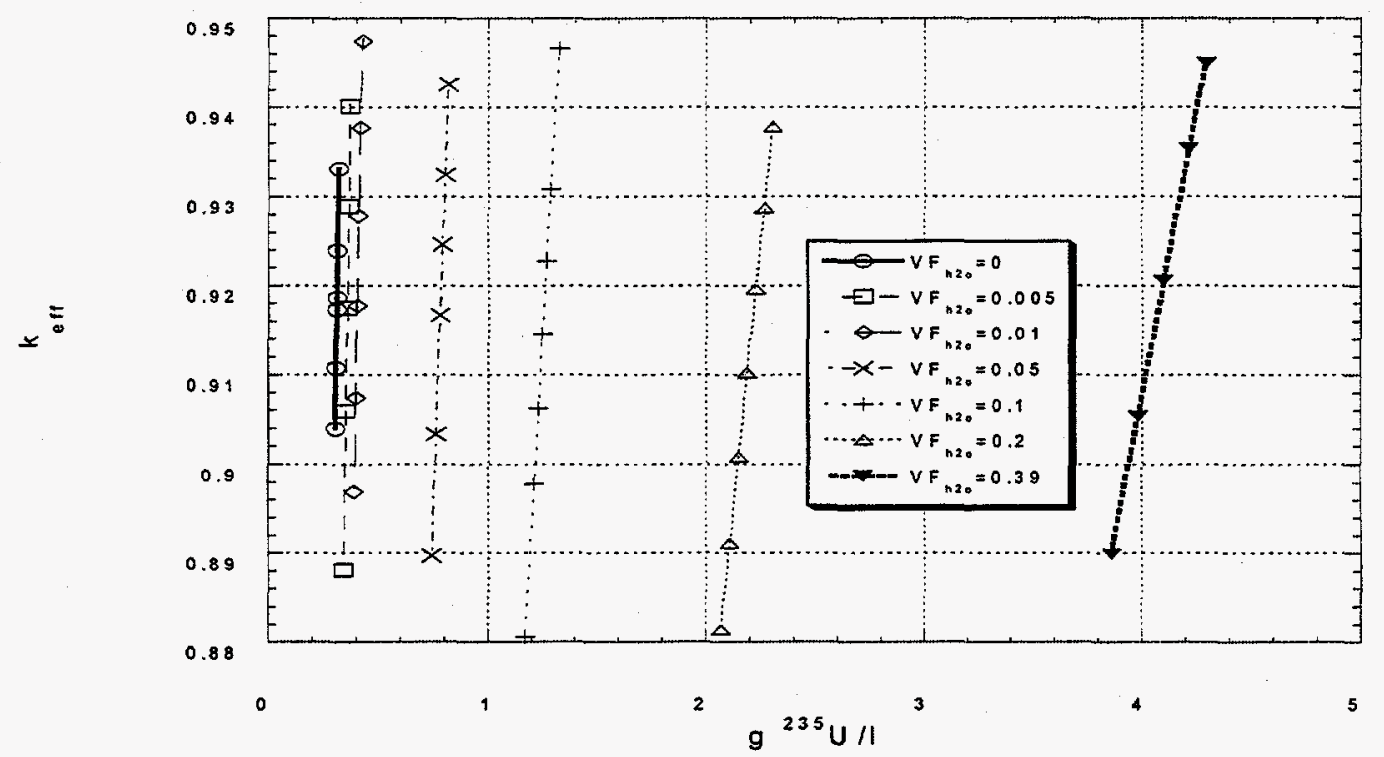

Figure D-2 Water-reflected, five-vehicle volume of homogeneous ${ }^{235} \mathrm{U}$, beryllium $\left(1.11 \mathrm{~g} / \mathrm{cm}^{3}\right)$, and $\mathrm{H}_{2} \mathrm{O}$

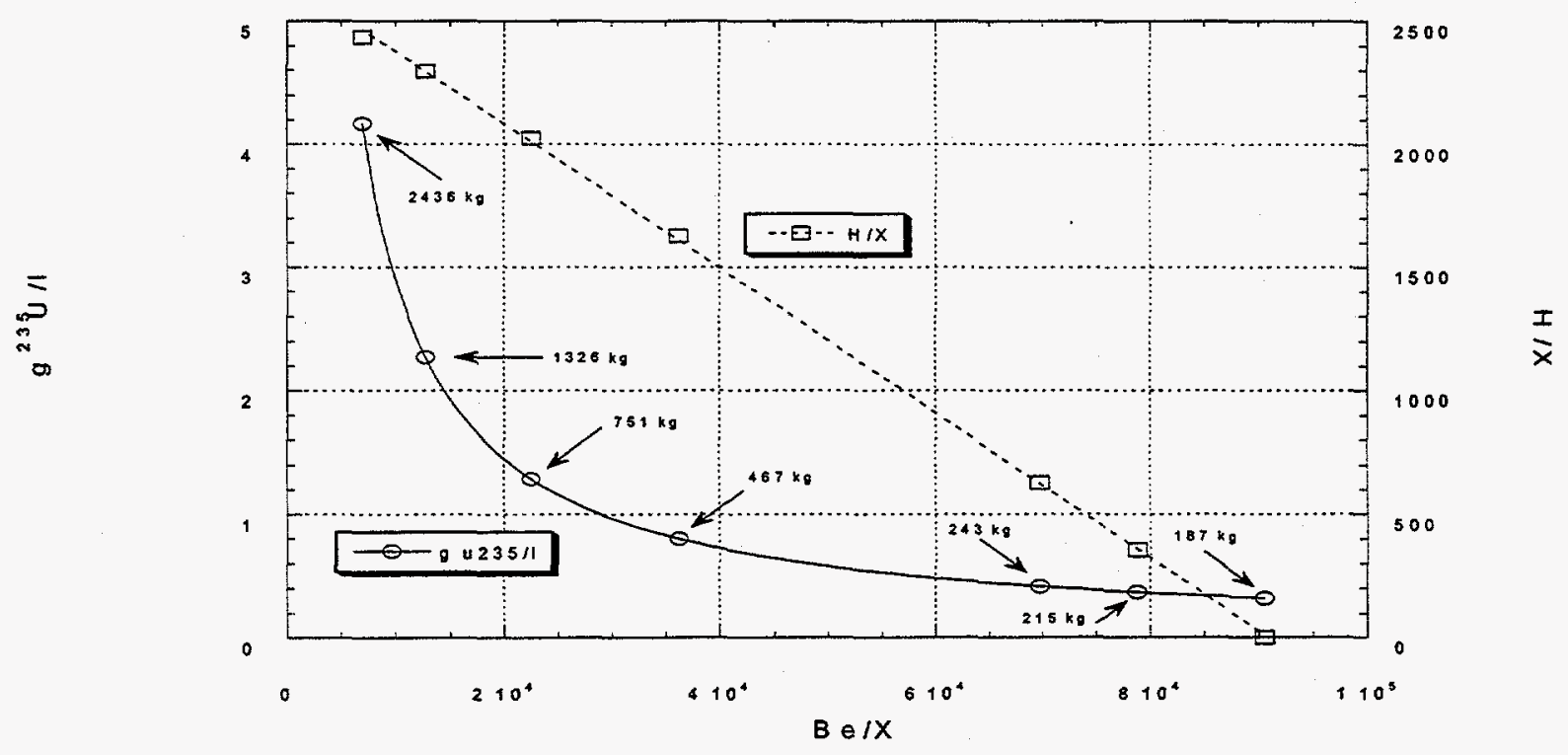

Figure D-3 Water-reflected, five-vehicle volume of homogeneous ${ }^{235} \mathrm{U}$, beryllium $\left(1.11 \mathrm{~g} / \mathrm{cm}^{3}\right)$, and $\mathrm{H}_{2} \mathrm{O}$; $k_{\text {eff }} \sim 0.93$ 
Table D-2 Homogeneous ${ }^{235} \mathrm{U}$, beryllium, and water subcritical masses

\begin{tabular}{lrcccc}
\hline $\mathrm{g}^{235} \mathrm{U} / \mathrm{L}$ & $\mathrm{Be}^{235} \mathrm{U}$ & $\mathrm{H}^{235} \mathrm{U}$ & \multicolumn{1}{c}{$\mathrm{k}_{\text {eff }}$} & $\begin{array}{c}\mathrm{kg}^{235} \mathrm{U} \text { per } \\
\text { five vehicle }\end{array}$ & $\begin{array}{c}\mathrm{g}^{235} \mathrm{U} \text { per } \\
\text { drum }\end{array}$ \\
\hline 10.7 & 0 & 2425 & 0.9303 & 6271 & 2236 \\
4.1705 & 6,941 & 2440 & 0.9300 & 2436 & 868 \\
2.2695 & 12,756 & 2299 & 0.9300 & 1327 & 472 \\
1.2858 & 22,515 & 2029 & 0.9299 & 751 & 267 \\
0.8003 & 36,176 & 1628 & 0.9299 & 467 & 166 \\
0.4153 & 69,708 & 627 & 0.9298 & 243 & 86.5 \\
0.3715 & 77,929 & 351 & 0.9355 & 217 & 76.5 \\
0.3198 & 90,520 & 0 & 0.9300 & 74.4 & 66.6 \\
\hline
\end{tabular}

"Based on 55-gal drum volume.

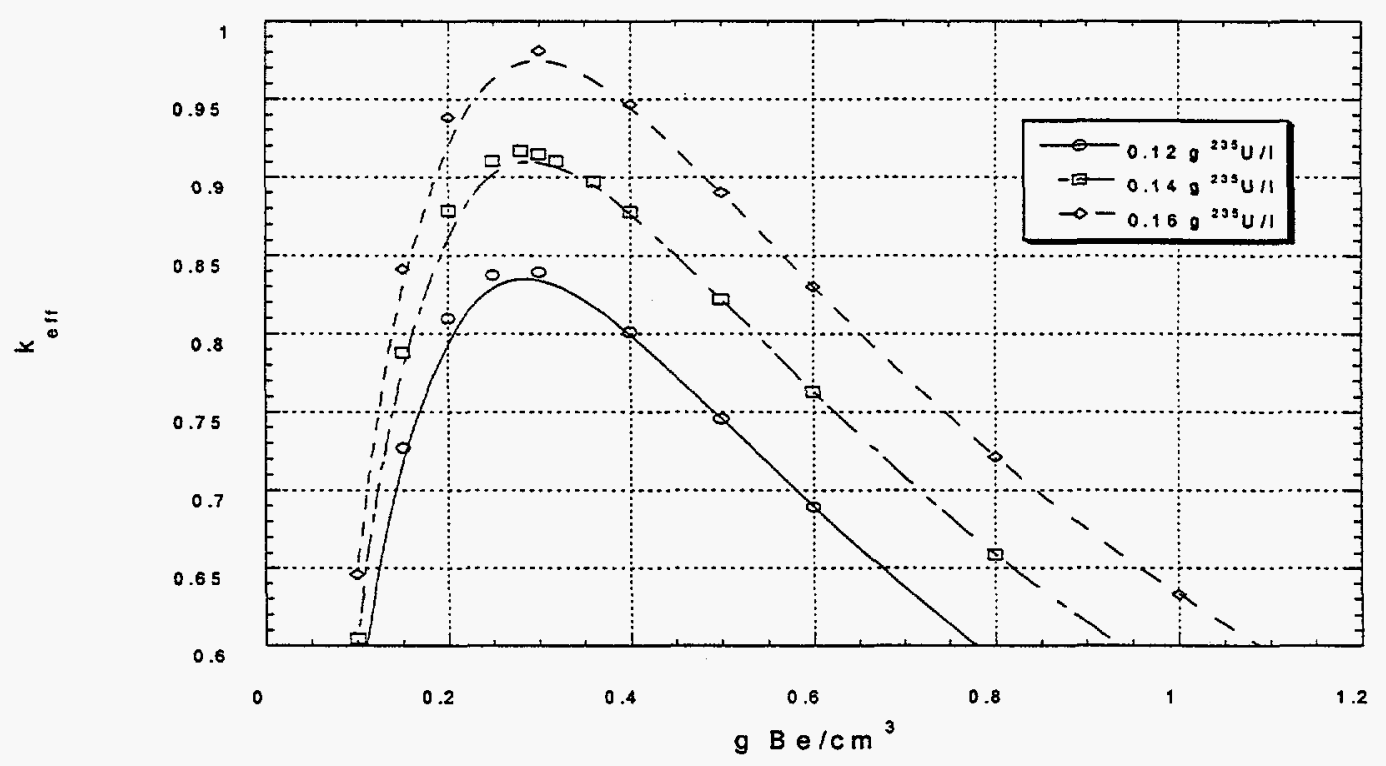

Figure D-4 Water-reflected, five-vehicle volume of homogeneous ${ }^{235} \mathrm{U}$, beryllium, and $\mathrm{H}_{2} \mathrm{O}$; ${ }^{235} \mathrm{U}$ concentration where $\mathrm{k}_{\text {eff }}$ at optimum $\mathrm{H}^{235} \mathrm{U}$ and $\mathrm{Be} /{ }^{235} \mathrm{U}$ 
In an effort to assign minimum transport indexes to packages for transportation, arrays of drum-type packages were evaluated. Package loadings and materials were considered to determine their effects on the $\mathrm{k}_{\mathrm{eff}}$ of the arrays. The packages analyzed were modeled in a near-cubic (optimal) triangular-pitch (optimal) $27 \times 27 \times 6$ array reflected by $30.48 \mathrm{~cm}$ of water. The total array volume was approximately $584 \mathrm{~m}^{3}$, with $\sim 20 \%$ interstitial void between packages. The volume between the drum-type packages was selected as void to maximize the array $\mathrm{k}_{\text {eff }}$. The packages were comprised of uranium-moderator mixture in a 110-gal drum that was modeled as two joined 55-gal, 20-gauge (0.823-mm body thickness) 316-stainless steel DOT-17E drums. 316-Stainless steel was picked because it contained the minimum quantity of neutron-absorbing material. The 110-gal package was selected to minimize the quantity of steel mass to fissile-material mass; however, the tabulated mass of fissile material per drum is provided for the volume of 55-gal drums, a more common drum-type container used by industry.

Table D-3 presents results of the drum-array calculations. Each drum-type package contains a homogenous mixture of ${ }^{235} \mathrm{U}$, $1.11 \mathrm{~g} \mathrm{Be} / \mathrm{cm}^{3}$, and water. For each $\mathrm{Be}^{235} \mathrm{U}$ ratio, the maximum subcritical ${ }^{235} \mathrm{U}$ concentration is given for the minimum drum-body thickness; this calculation is less than the $7 \%$ margin of subcriticality. For the maximum and minimum effects on $\mathrm{k}_{\text {eff }}$ from increasing the drum-wall thickness by a factor of $\sim 3$ or completely removing drum material were examined. The given ${ }^{235} \mathrm{U}$ mass that is permissible per drum is based on the subcritical ${ }^{235} \mathrm{U}$ concentration at a given $\mathrm{Be} /{ }^{235} \mathrm{U}$ and a 208-L-drum volume for the minimum drum-body thickness only.

Lastly, an assessment of the subcritical dimension of an individually water-reflected homogeneous mixture of uranium and beryllium were conducted to explore potential bounding specifications for fissile-material exemptions and general licenses. The critical masses of such beryllium-moderated systems are given in Figure D-5. The minimum critical mass is $765 \mathrm{~g}$ and is located at an $\mathrm{Be}^{235} \mathrm{U}$ ratio of 12,000 and a mixture radius of $35.6 \mathrm{~cm}$. A $5 \%$ margin of subcriticality was selected over a $7 \%$ margin because the mixtures in the critical mass searches are binary (i.e., uranium and beryllium) rather than more difficult to validate tertiary (e.g., uranium, water, and beryllium) systems.

Similar assessments were done to determine the subcritical dimensions of ${ }^{239} \mathrm{Pu}$ or ${ }^{233} \mathrm{U}$ as individually water-reflected spheres of homogeneous mixtures of ${ }^{239} \mathrm{Pu}$ or ${ }^{233} \mathrm{U}$ and to explore potential bounding specifications for fissile-material exemptions and general licenses. The critical parameters for these systems are provided as follows.

The determined ${ }^{239} \mathrm{Pu}$ minimum subcritical $\left(\mathrm{k}_{\text {eff }} \leq 0.95\right)$ mass parameters are $424 \mathrm{~g}{ }^{239} \mathrm{Pu}$ homogeneously mixed with water (resulting in a beryllium-to- ${ }^{230} \mathrm{Pu}$ atom ratio of about 21,000 and about $2.3 \mathrm{~g}{ }^{239} \mathrm{Pu} / \mathrm{L}$ ) as a fully water-reflected $35.1-\mathrm{cm}$ radius sphere. The results of the parameter survey are provided in Figure D-6.

The determined ${ }^{233} \mathrm{U}$ minimum subcritical $\left(\mathrm{k}_{\text {eff }} \leq 0.95\right)$ mass parameters are $605 \mathrm{~g}{ }^{233} \mathrm{U}$ homogeneously mixed with water (resulting in a beryllium-to- ${ }^{233} \mathrm{U}$ atom ratio of about 10,000 and about $4.8 \mathrm{~g}^{233} \mathrm{U} / \mathrm{L}$ ) as a fully water-reflected 31.1 -cm-radius sphere. The results of the parameter survey are provided in Figure D-7. 
Table D-3 Array of $27 \times 27 \times 6110$-gal drums on hexagonal pitch

\begin{tabular}{rrrcc}
\hline & & & & $\mathrm{g}^{235} \mathrm{U}$ \\
$\mathrm{Be} / 235$ & $\mathrm{H}^{235} \mathrm{U}$ & $\mathrm{g}^{235} \mathrm{U} / \mathrm{L}$ & $0.9223 \pm 0.0020$ & 190 \\
\hline 31,638 & 0 & 0.915 & $1.5146 \pm 0.0027^{b}$ & \\
& & & $0.6415 \pm 0.0016^{c}$ & \\
& & & $0.9229 \bullet 0.0017$ & 287 \\
20,752 & 1000 & 1.395 & $0.9220 \pm 0.0015$ & 400 \\
15,078 & 1500 & 1.920 & $0.9249 \pm 0.0015$ & 664 \\
9,075 & 2000 & 3.190 & $1.0280 \bullet 0.0016^{b}$ & \\
& & & $0.8512 \pm 0.0018^{c}$ & \\
\hline
\end{tabular}

${ }^{a}$ Based on 55 -gal drum volume.

${ }^{b}$ Drum absent.

2.4-mm drum-body thickness.

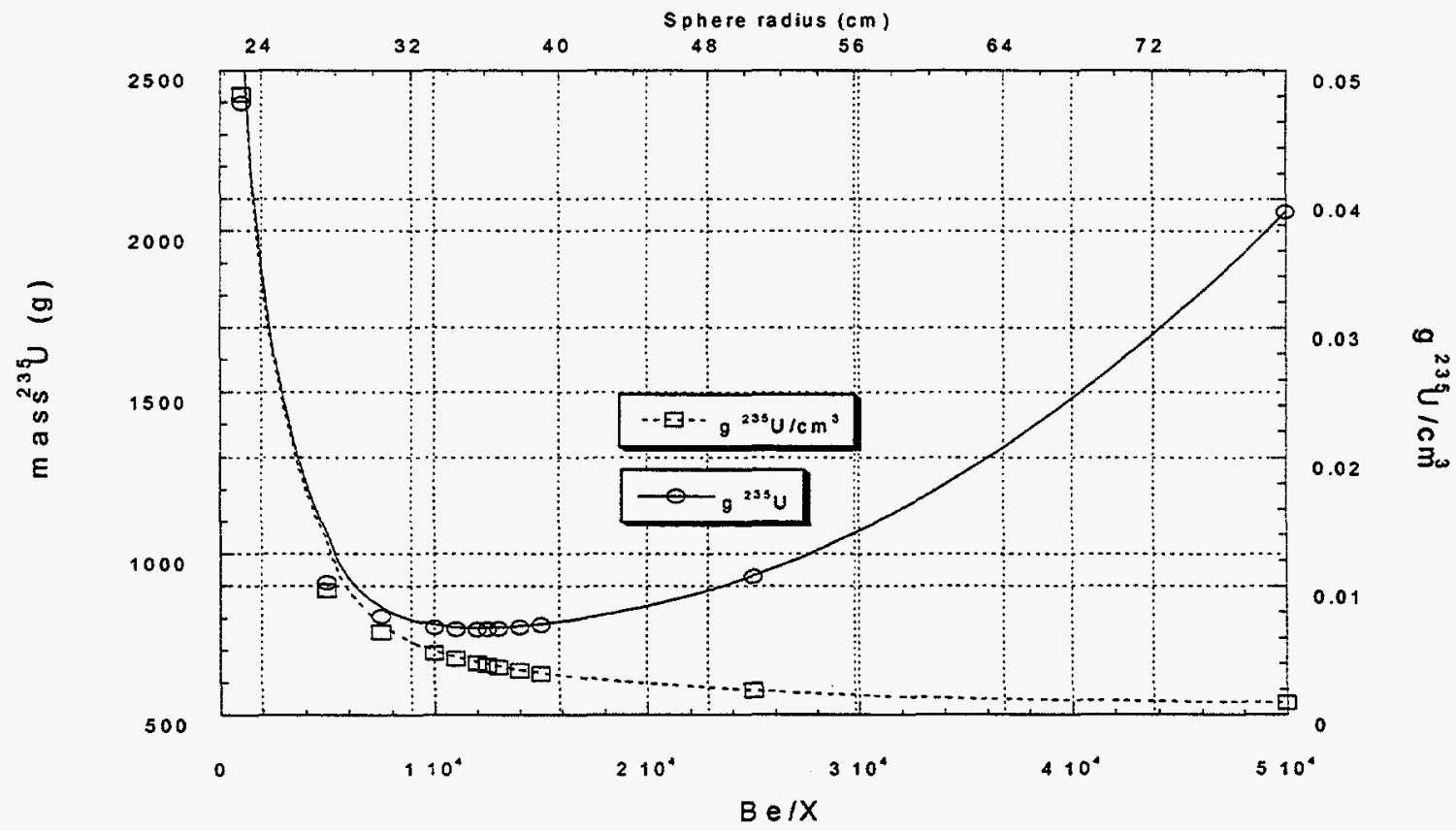

Figure D-5 Critical masses of water-reflected, homogeneous ${ }^{235} \mathrm{U}$ and beryllium $\left(1.11 \mathrm{~g} / \mathrm{cm}^{3}\right)$ spheres; $k_{\text {eff }} \sim 0.95$ 


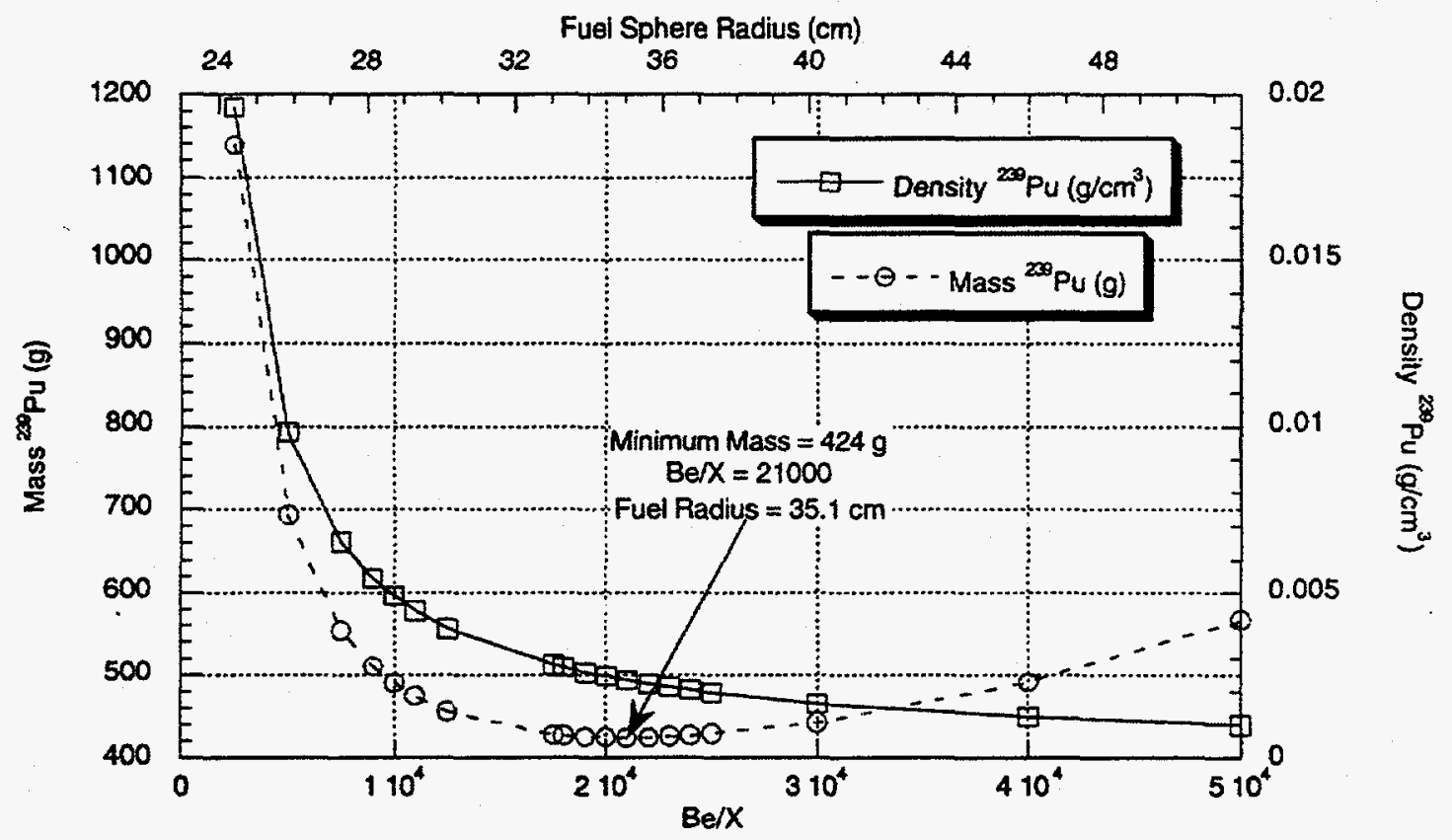

Figure D-6 Fissile masses and densities of water-reflected ${ }^{239} \mathrm{Pu}$ and Be spheres; $\mathrm{k}_{\mathrm{eff}} \approx 0.95$ (radius scale is approximate)

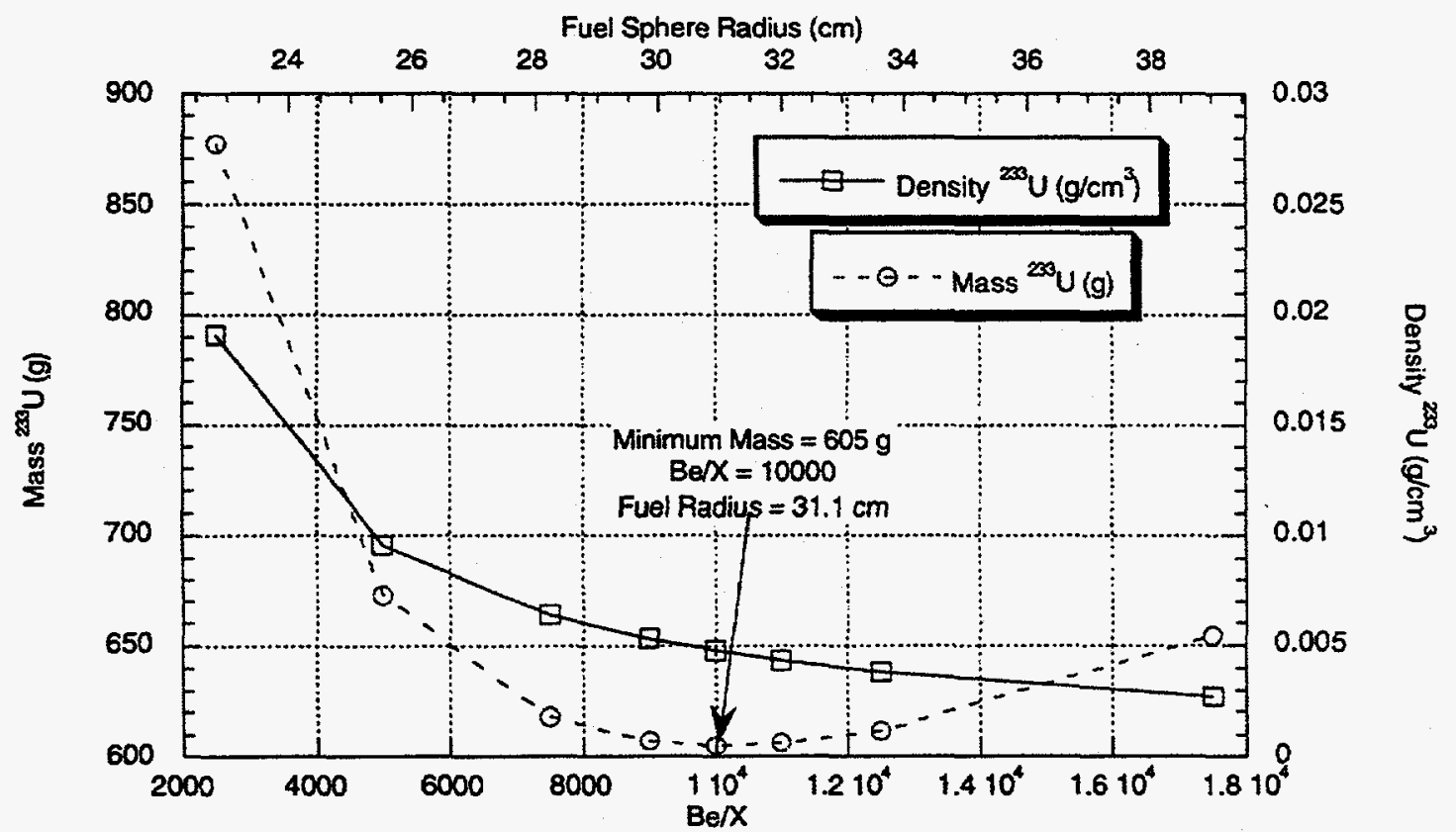

Figure D-7 Fissile masses and densities of water-reflected ${ }^{233} \mathrm{U}$ and Be spheres; $\mathrm{k}_{\mathrm{eff}} \approx 0.95$ (radius scale is approximate) 



\section{APPENDIX E}

Subcritical Heavy-Water Systems 


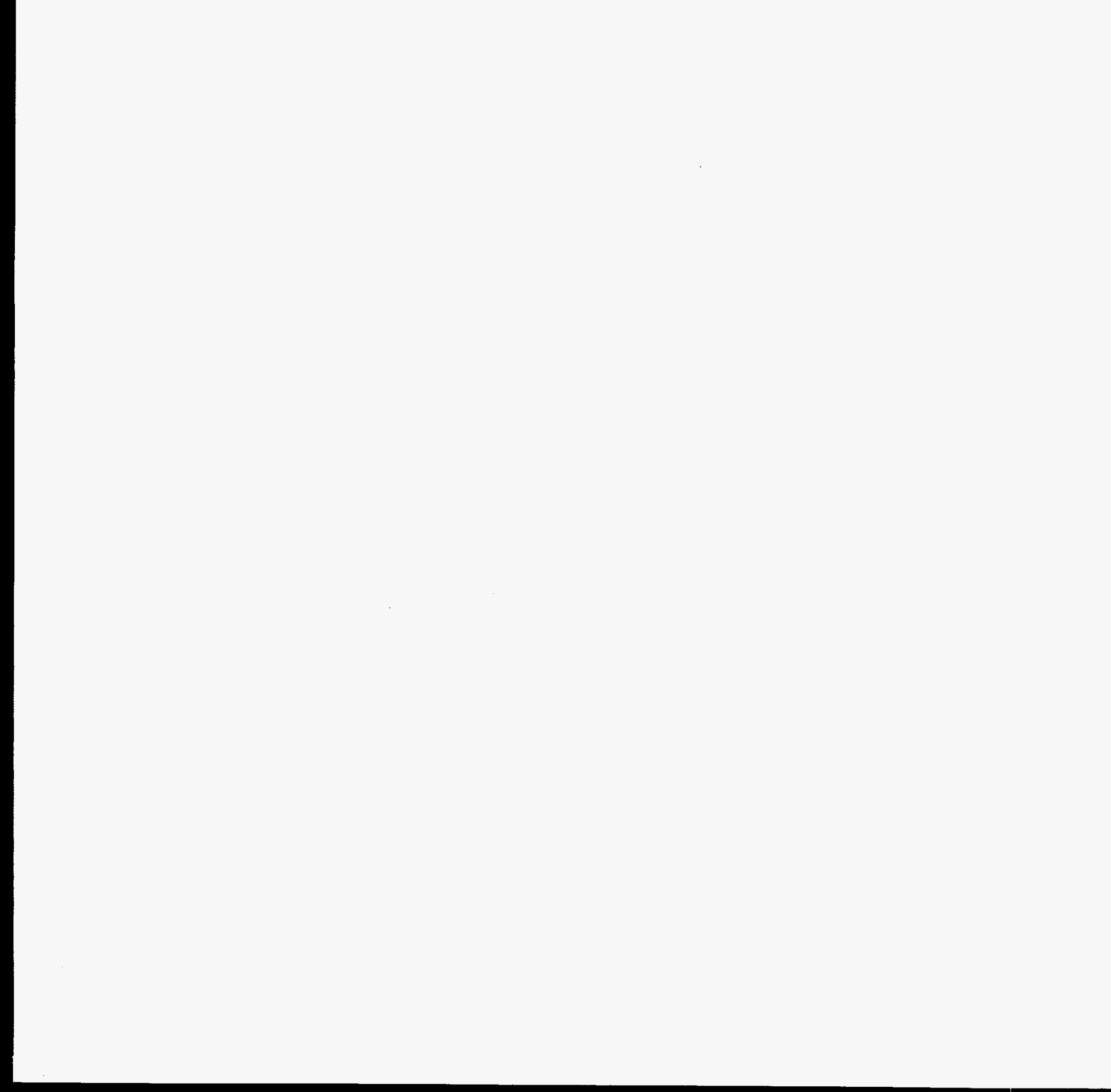




\section{APPENDIX E}

\section{Subcritical Heavy-Water Systems}

The exemption and general-license specifications are limited to considering only the type, mass and form of fissile material, together with the moderator. In this study, $100 \%$-enriched ${ }^{235} \mathrm{U}[\mathrm{U}(100)],{ }^{239} \mathrm{Pu}$ or ${ }^{233} \mathrm{U}$ homogeneously mixed with heavy water $\left(\mathrm{D}_{2} \mathrm{O}\right)$ and water were considered. The $\mathrm{D}_{2} \mathrm{O}$ was assumed to be at $60 \%$ of theoretical density, or $0.6632 \mathrm{~g} / \mathrm{cm}^{3}$. $U(100)$ in a homogenous mixture was chosen because the high enrichment is most reactive and for such enrichments homogeneous uranium-moderator mixtures are typically more reactive than corresponding heterogeneous uranium-moderator mixtures. Likewise, the ${ }^{239} \mathrm{Pu}$ and ${ }^{233} \mathrm{U}$ studies were assumed to be $100 \mathrm{wt} \%$ to avoid lack of conservatism regarding nonfission isotopes of plutonium or uranium.

Infinite systems were analyzed first to determine subcritical atom or mass ratios of various mixtures to define an "exemption for low-level materials" consistent with safety intended to be provided by $\$ 71.10(a)$. For an infinite system there is no leakage and the moderator-to-fissile nuclei ratio $\left(D /{ }^{235} \mathrm{U}\right)$ is the only parameter of interest. The infinite system results for homogeneous $\mathrm{U}(100)$ and $\mathrm{D}_{2} \mathrm{O}$ are given in Table E-1 and plotted in Figure E-1. The U(100) and $\mathrm{D}_{2} \mathrm{O}$ infinite homogeneous system subcritical neutron multiplication factor is 0.9289 , corresponding to a concentration of $0.0192 \mathrm{~g}{ }^{235} \mathrm{U} / \mathrm{L}$ at a D/255 $\mathrm{U}$ of $1.35 \times 10^{6}$. The fissile material concentration is lower than ordinary water because the parasitic absorption by heavy water is significantly less than that of hydrogen. The subcritical neutron multiplication factor of 0.93 was selected to provide an adequate margin of subcriticality that is consistent with upper subcritical limits from broad-based historical validation studies.

Table E-1 Infinite homogeneous ${ }^{235} \mathrm{U}$ and heavy water

\begin{tabular}{rc}
\hline $\mathrm{D} /{ }^{235} \mathrm{U}$ & $\mathrm{k}_{\text {inf }}$ \\
\hline 100 & 1.7713 \\
500 & 1.9446 \\
1,000 & 1.9958 \\
2,500 & 2.0322 \\
5,000 & 2.0423 \\
10,000 & 2.0408 \\
50,000 & 1.9760 \\
500,000 & 1.4217 \\
$1,000,000$ & 1.0836 \\
$1,300,000$ & 0.9484 \\
$1,350,000$ & 0.9289 \\
$1,400,000$ & 0.9103 \\
\hline
\end{tabular}




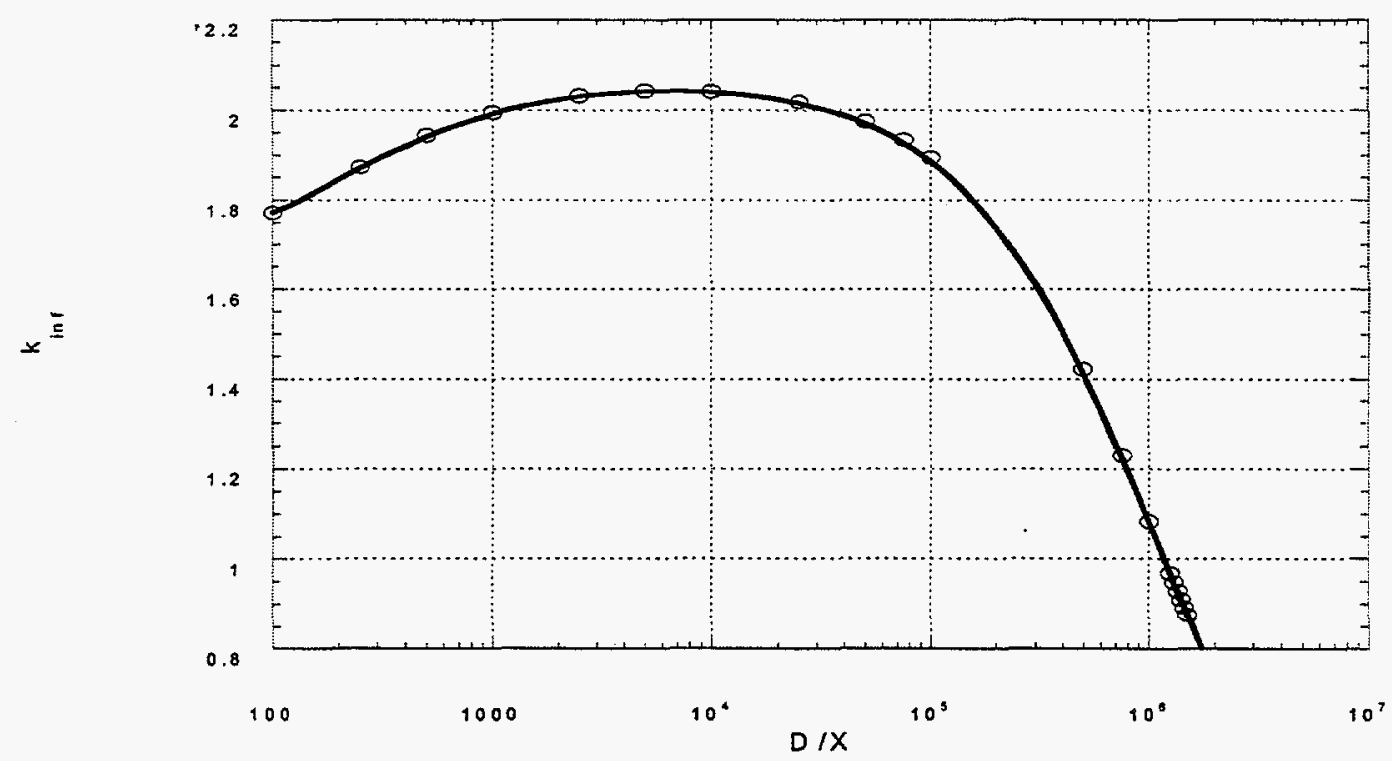

Figure E-1 Infinite homogeneous ${ }^{235} \mathrm{U}$ and $\mathrm{D}_{2} \mathrm{O}$

The subcritical $\mathrm{D} /{ }^{235} \mathrm{U}$ of $1.35 \times 10^{6}$ for the infinite system calculations provides a good starting point for determining subcritical finite systems of the same mixture. Due to increased leakage, the subcritical $D / 235 \mathrm{U}$ for our corresponding finite system is somewhat less than $1.35 \times 10^{6}$. The finite system was evaluated as a fully water-reflected sphere of homogeneous uranium at $100 \%$ enrichment, $\mathrm{D}_{2} \mathrm{O}$ at $60 \%$ of theoretical density, and $\mathrm{H}_{2} \mathrm{O}$ at $0 \%$ to $39 \%$ volume fraction of the mixture. The mixture volume is about $584 \mathrm{~m}^{3}$. No container was considered in the calculational models due to the nonconservative introduction of neutron-absorbing materials. The selected volume of $584 \mathrm{~m}^{3}$ is representative of the maximum volume available in five public highway transportation vehicles (i.e., two tandem trailers pulled by a single tractor). The selection of five vehicles [cf. $\$ 71.59(\mathrm{a})(1)$ ] was made instead of two [cf. $\$ 71.59(\mathrm{a})(2)]$ to ensure the large volume associated with normal conditions of transport are accommodated, together with changes that might occur under hypothetical accident conditions. The $k_{\text {eff }}$ values from these finite-system calculations are given in Figure E-2 versus ${ }^{23} U$ concentration for seven water-volume fractions. Please note the sensitivity of $k_{\text {eff }}$ to infinitesimal changes in ${ }^{235} U$ concentration.

The ${ }^{235} \mathrm{U}$ concentrations of Figure E-2, yielding $\mathrm{k}_{\text {eff }}$ values of 0.93 , are plotted in Figure $\mathrm{E}-3$ versus their matching $\mathrm{H}^{235} \mathrm{U}$ and $\mathrm{D} /{ }^{235} \mathrm{U}$ ratios. Additional data for combinations of $\mathrm{H}^{235} \mathrm{U}, \mathrm{D} /{ }^{235} \mathrm{U}$, and ${ }^{235} \mathrm{U}$ concentrations that calculate 0.93 lave been added to Figure E-3 to give a more complete picture. A sampling of the data in Figure E-3 is given in Table E-2. The fivevehicle and 55 -gal drum ${ }^{235} \mathrm{U}$ masses in the table are based on the determined ${ }^{235} \mathrm{U}$ concentrations and $584-\mathrm{m}^{3}$ and $208-\mathrm{L}$ volumes. From Figure $\mathrm{E}-3$, one sees that any ${ }^{235} \mathrm{U}$ concentration above the $\mathrm{g}{ }^{235} \mathrm{U} / \mathrm{L}$ curve is above the upper 


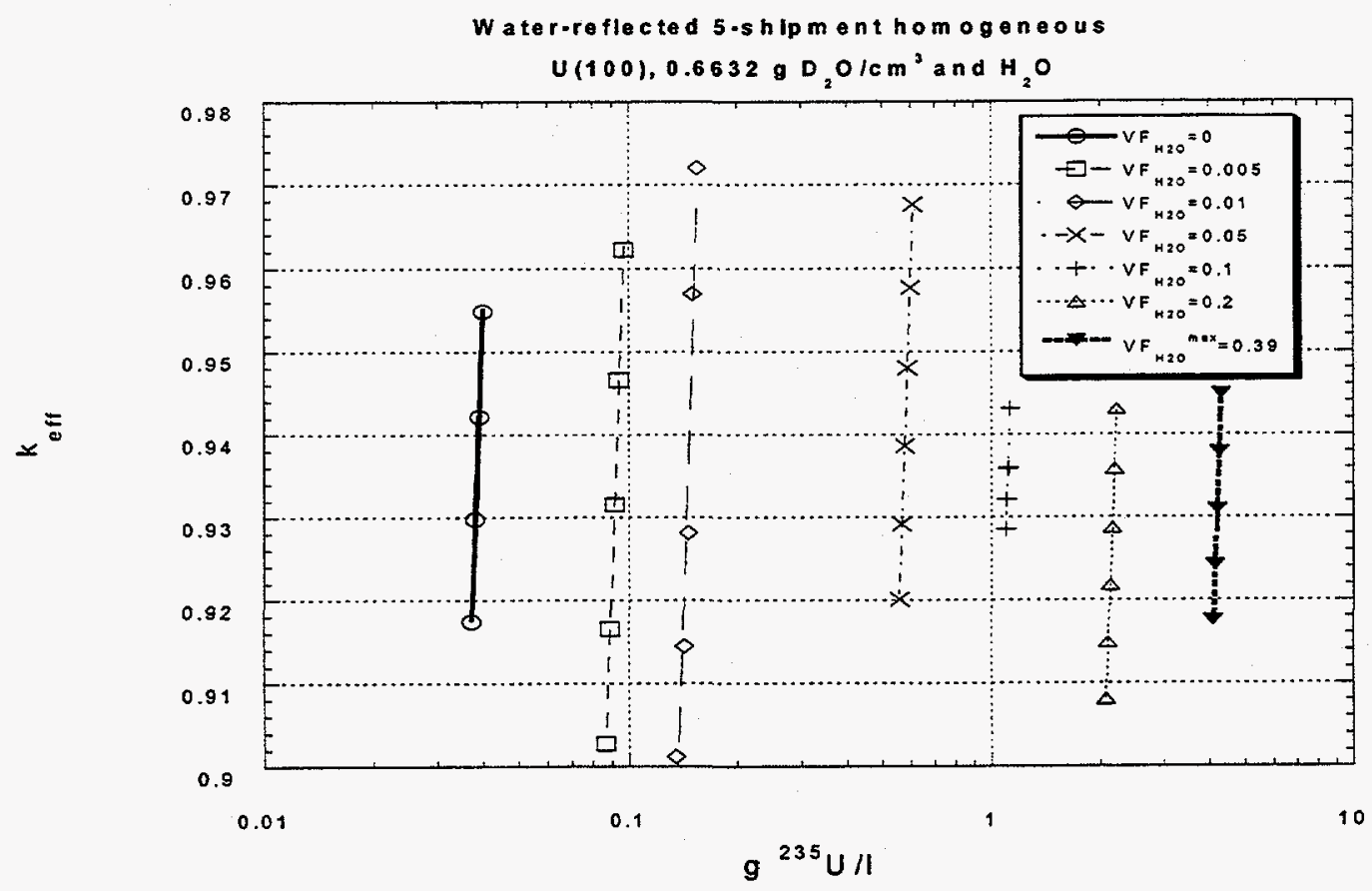

Figure E-2 Water-reflected, five-vehicle volume of homogeneous ${ }^{235} \mathrm{U}$, $\mathrm{D}_{2} \mathrm{O}\left(0.6632 \mathrm{~g} / \mathrm{cm}^{3}\right)$, and $\mathrm{H}_{2} \mathrm{O}$

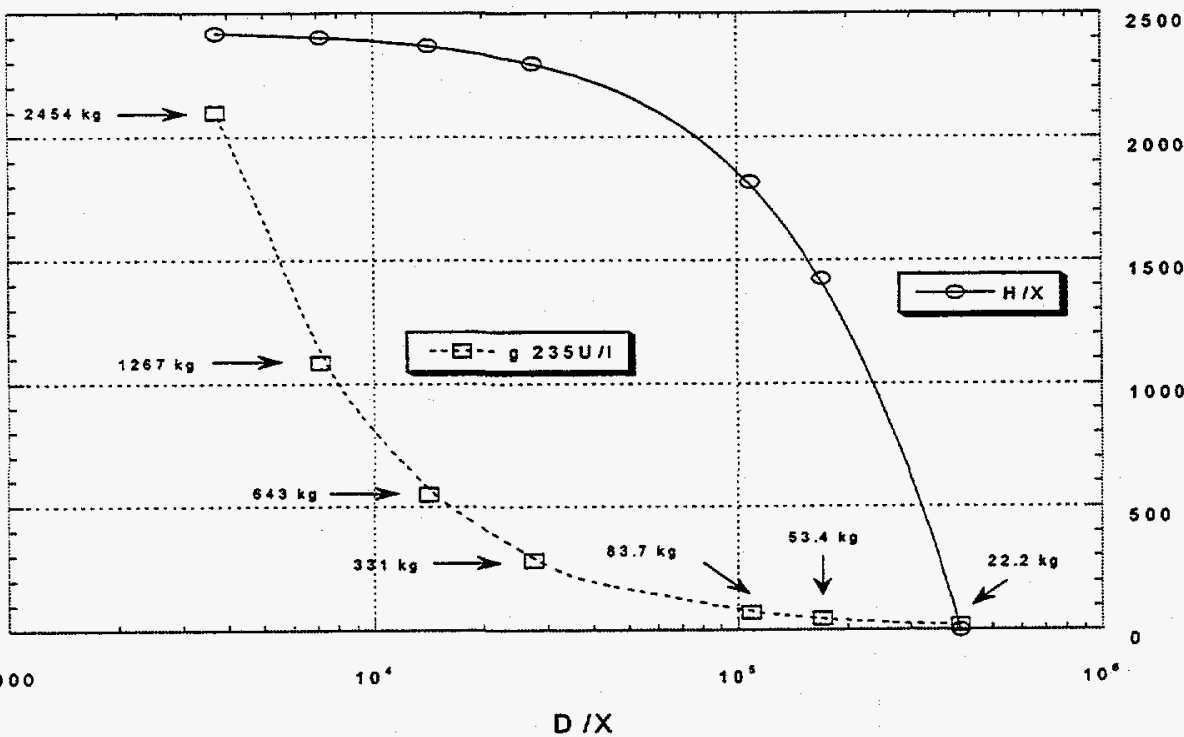

Figure E-3 Water-reflected, five-vehicle volume of homogeneous ${ }^{235} \mathbf{U}$, $\mathrm{D}_{2} \mathrm{O}\left(0.6632 \mathrm{~g} / \mathrm{cm}^{3}\right)$, and $\mathrm{H}_{2} \mathrm{O} ; \mathrm{k}_{\mathrm{eff}} \sim 0.93$ 
Table E-2 Homogeneous ${ }^{235} \mathrm{U}$, heavy water, and water subcritical masses

\begin{tabular}{lrcccc}
\hline $\mathrm{g}^{235} \mathrm{U} / \mathrm{L}$ & $\mathrm{D} /{ }^{235} \mathrm{U}$ & $\mathrm{H}^{235} \mathrm{U}$ & $\mathrm{k}_{\text {eff }}$ & $\begin{array}{c}\mathrm{kg}^{235} \mathrm{U} \text { per } \\
\text { five vehicle }\end{array}$ & $\begin{array}{c}\mathrm{g}^{235} \mathrm{U} \text { per } \\
\text { drum }^{a}\end{array}$ \\
\hline 10.4 & 0 & 2410 & 0.9319 & 6074 & 2165 \\
4.2019 & 3,706 & 2418 & 0.9301 & 2454 & 87.5 \\
2.1691 & 7,180 & 2402 & 0.9301 & 1266 & 451 \\
1.1002 & 14,157 & 2368 & 0.9302 & 642 & 229 \\
0.5672 & 27,455 & 2296 & 0.9301 & 331 & 118 \\
0.1433 & 108,676 & 1818 & 0.9297 & 83.6 & 29.8 \\
0.0914 & 17,340 & 1425 & 0.9305 & 53.3 & 19.0 \\
0.0380 & 409,550 & 0 & 0.9300 & 22 & 8 \\
\hline
\end{tabular}

${ }^{\circ}$ Based on 55-gal drum volume.

subcritical limit as is any $\mathrm{H}^{235} \mathrm{U}$ below the $\mathrm{H} / \mathrm{X}$ curve. Conversely, any ${ }^{235} \mathrm{U}$ concentration below the $\mathrm{g}{ }^{235} \mathrm{U} / \mathrm{L}$ curve is below the upper subcritical limit as is any $\mathrm{H}^{235} \mathrm{U}$ above the $\mathrm{H} / \mathrm{X}$ curve.

To determine the ${ }^{235} \mathrm{U}$ concentration that is always below the upper subcritical limit, a ${ }^{235} \mathrm{U}$ concentration was selected, optimum $\mathrm{D} /{ }^{235} \mathrm{U}$ and $\mathrm{H}^{235} \mathrm{U}$ ratios were determined for the concentration, and the resulting $\mathrm{k}_{\text {eff }}$ value was compared for closeness to the bounding value of 0.93 . A sample of such calculations are presented in Figure E-4. From the figure, $0.0393 \mathrm{~g}^{235} \mathrm{U} / \mathrm{L}$ is seen to calculate at a $\mathrm{k}_{\text {eff }}$ of 0.9169 for an optimum $\mathrm{D} /{ }^{235} \mathrm{U}$ of $3.963 \times 10^{5}$ and an optimum $\mathrm{H} / /^{235} \mathrm{U}$ of 0 .

In an effort to assign minimum transport indexes to packages for transportation, arrays of drum-type packages were evaluated. Package loadings and materials were considered to determine their affect on the $k_{\text {eff }}$ of the arrays. The packages analyzed were modeled in a near-cubic (optimal) triangular-pitch (optimal) $27 \times 27 \times 6$ array reflected by $30.48 \mathrm{~cm}$ of water. The total array volume was approximately $584 \mathrm{~m}^{3}$, with $\sim 20 \%$ interstitial void between packages. The volume between the drum-type packages was selected as void to maximize the array $k_{\text {eff }}$. The packages were comprised of uranium-moderator mixture in a 110-gal drum that was modeled as two joined 55-gal, 20-gauge (0.823-mm body thickness), 316-stainless steel DOT-17E dnums. 316-Stainless steel was picked because it contained the minimum quantity of neutron-absorbing material. The 110-gal package was selected to minimize the quantity of steel mass to fissile-material mass; however, the tabulated mass of fissile material per drum is provided for the volume of 55-gal drums, a more common drum-type container used by industry.

Table E-3 presents results of the drum-array calculations. Each drum-type package contains an homogenous mixture of ${ }^{235} \mathrm{U}$, $0.6632 \mathrm{~g} \mathrm{D}_{2} \mathrm{O} / \mathrm{cm}^{3}$, and water. For each $\mathrm{D}^{235} \mathrm{U}$ ratio, the maximum subcritical ${ }^{235} \mathrm{U}$ concentration is given for the minimum drum-body thickness; this calculation is less than the $7 \%$ margin of subcriticality. For the maximum and minimum analyzed $\mathrm{H}^{235} \mathrm{U}$ ratios, the effects on $\mathrm{k}_{\text {eff }}$ from increasing the drum-wall thickness by a factor of $\sim 3$ or completely removing drum material were examined. The given ${ }^{235} \mathrm{U}$ mass that is permissible per drum is based on the subcritical ${ }^{235} \mathrm{U}$ concentration at a given $\mathrm{D} /{ }^{235} \mathrm{U}$ and a 208 - $\mathrm{L}$-drum volume for the minimum drum-body thickness only. 


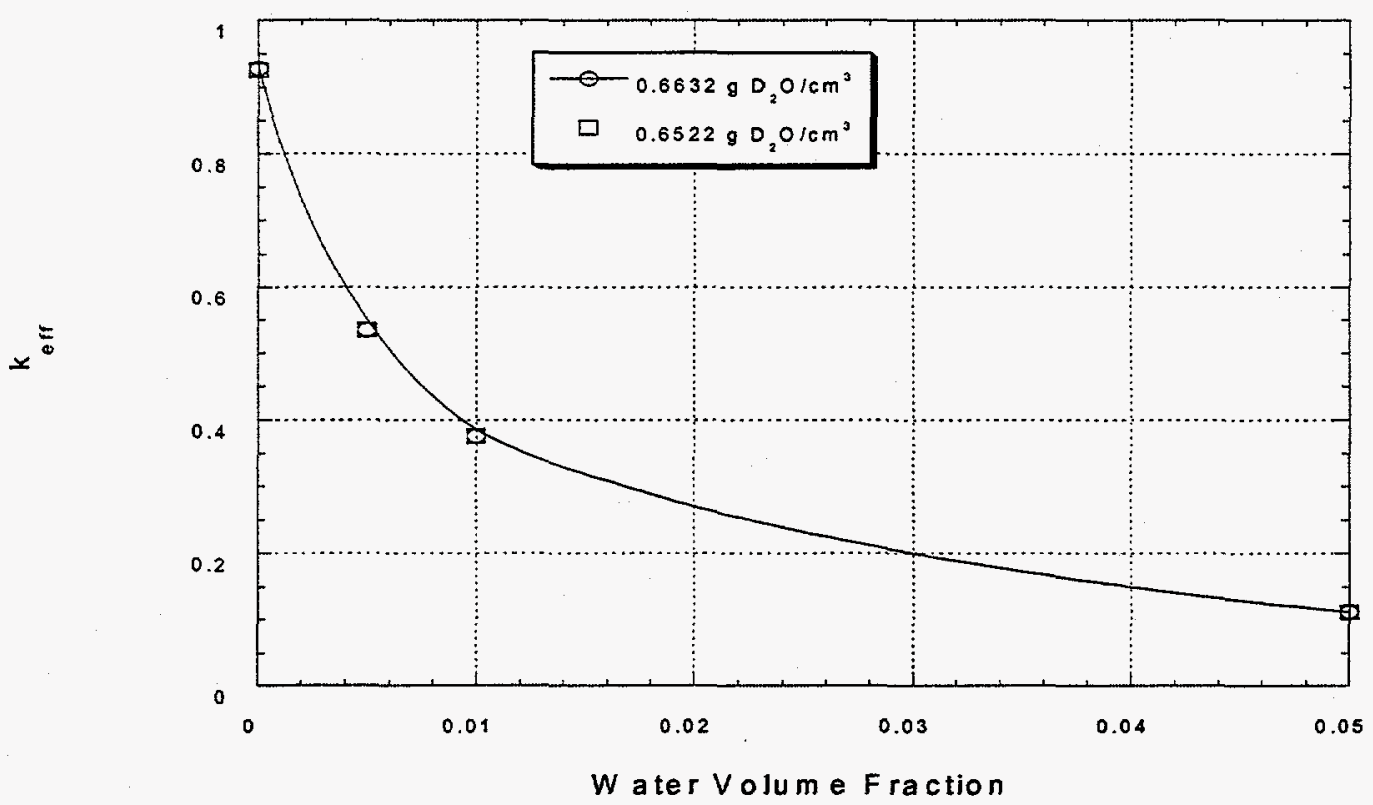

Figure E-4 Water-reflected, five-vehicle volume of homogeneous ${ }^{235} \mathrm{U}, \mathrm{D}_{2} \mathrm{O}$, and $\mathrm{H}_{2} \mathrm{O}$; ${ }^{235} \mathrm{U}$ concentration where $\mathrm{k}_{\text {eff }}$ at optimum $\mathrm{H}^{235} \mathrm{U}$ and $\mathrm{D} /{ }^{235} \mathrm{U}$

Table E-3 Array of $27 \times 27 \times 6110$-gal drums on hexagonal pitch

\begin{tabular}{ccccc}
\hline $\mathrm{D}{ }^{235} \mathrm{U}$ & $\mathrm{H}^{235} \mathrm{U}$ & $\mathrm{g}^{235} \mathrm{U} / \mathrm{L}$ & $\mathrm{k}_{\text {eff }}$ & $\begin{array}{c}\mathrm{g}^{235} \mathrm{U} \\
\text { per drum }\end{array}$ \\
\hline 20,096 & 0 & 0.775 & $0.9289 \pm 0.0019$ & 161 \\
& & & $1.9709 \pm 0.0034^{b}$ & \\
& & & $0.5587 \pm 0.0016^{c}$ & \\
14,158 & 1,000 & 1.20 & $0.9214 \pm 0.0017$ & 250 \\
8,652 & 1,500 & 1.80 & $0.9320 \pm 0.0017$ & 375 \\
4,326 & 2,000 & 3.60 & $0.9279 \pm 0.0013$ & 750 \\
& & & $1.0280 \pm 0.0014^{b}$ & \\
& & & $0.8466 \pm 0.0015^{c}$ & \\
\hline
\end{tabular}

${ }^{a}$ Based on 55-gal drum volume.

brum absent.

2.4-mm-drum-body thickness. 
Lastly, an assessment of the subcritical dimension of an individually water-reflected homogeneous mixture of uranium and heavy water were conducted to explore potential bounding specifications for fissile-material exemptions and general licenses. The critical masses of such $\mathrm{D}_{2} \mathrm{O}$-moderated systems are given in Figure E-5. The minimum critical mass is $1044 \mathrm{~g}$ and is located at an $\mathrm{D}^{235} \mathrm{U}$ ratio of about 7,500 and a mixture radius of $45.8 \mathrm{~cm}$. A $5 \%$ margin of subcriticality was selected over a $7 \%$ margin because the mixtures in the critical mass searches are binary (i.e., uranium and heavy water) rather than more difficult to validate tertiary (e.g., uranium, water, and heavy-water) systems.

Similar assessments were done to determine the subcritical dimensions of ${ }^{239} \mathrm{Pu}$ or ${ }^{233} \mathrm{U}$ as individually water-reflected spheres of homogeneous mixtures of ${ }^{239} \mathrm{Pu}$ or ${ }^{233} \mathrm{U}$ and to explore potential bounding specifications for fissile-material exemptions and general licenses. The critical parameters for these systems are provided as follows.

The determined ${ }^{239} \mathrm{Pu}$ minimum subcritical $\left(\mathrm{k}_{\text {eff }} \leq 0.95\right)$ mass parameters are $602 \mathrm{~g}{ }^{239} \mathrm{Pu}$ homogeneously mixed with water (resulting in a deuterium-to- ${ }^{230} \mathrm{Pu}$ atom ratio of about 15,000 and about $1.8 \mathrm{~g}{ }^{239} \mathrm{Pu} / \mathrm{L}$ ) as a fully water-reflected 43.4-cmradius sphere. The results of the parameter survey are provided in Figure E-6.

The determined ${ }^{233} \mathrm{U}$ minimum subcritical $\left(\mathrm{k}_{\text {eff }} \leq 0.95\right)$ mass parameters are $851 \mathrm{~g}{ }^{233} \mathrm{U}$ homogeneously mixed with water (resulting in a deuterium-to- ${ }^{233} \mathrm{U}$ atom ratio of about 6,000 and about $4.3 \mathrm{~g}^{233} \mathrm{U} / \mathrm{L}$ ) as a fully water-reflected 31.1 -cm-radius sphere. The results of the parameter survey are provided in Figure E-7.

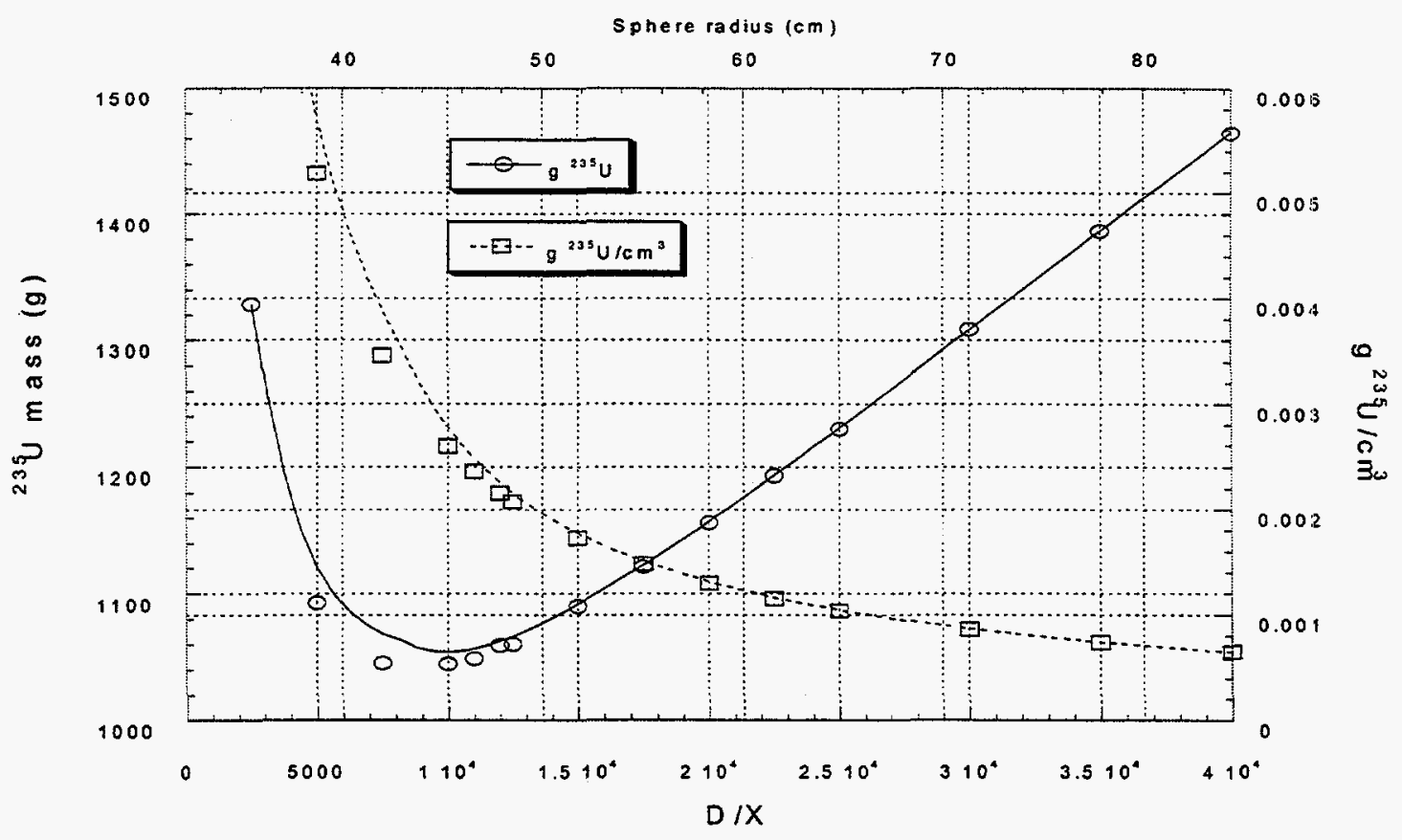

Figure E-5 Critical masses of water-reflected, homogeneous ${ }^{235} \mathrm{U}$ and $D_{2} O\left(0.6632 \mathrm{~g} / \mathrm{cm}^{3}\right)$ spheres; $k_{\text {eff }} \sim 0.95$ 


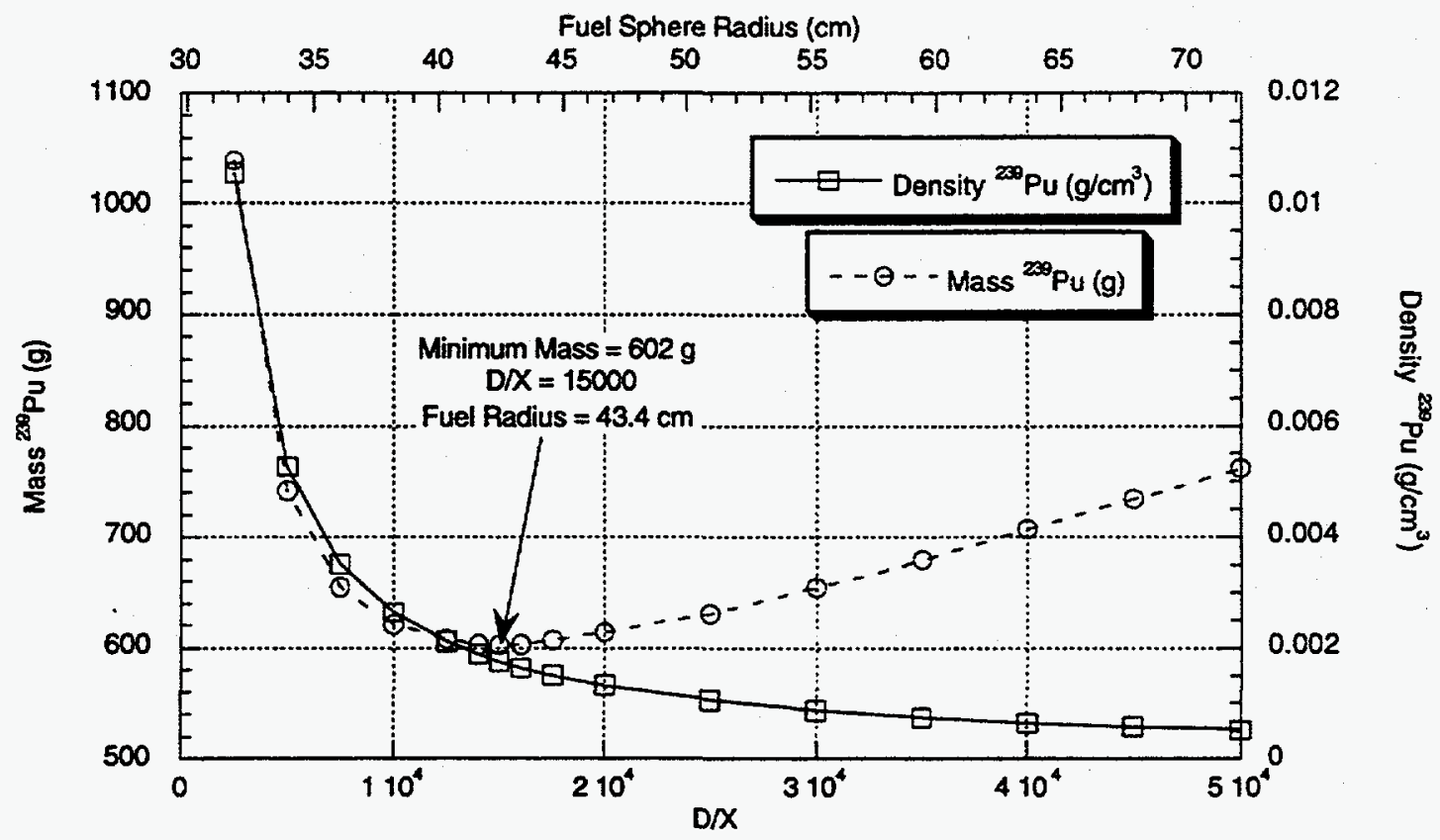

Figure E-6 Fissile masses and densities of water-reflected ${ }^{239} \mathrm{Pu}$ and $\mathrm{D}_{2} \mathrm{O}$ spheres; $\mathrm{k}_{\text {eff }} \approx 0.95$ (radius scale is approximate)

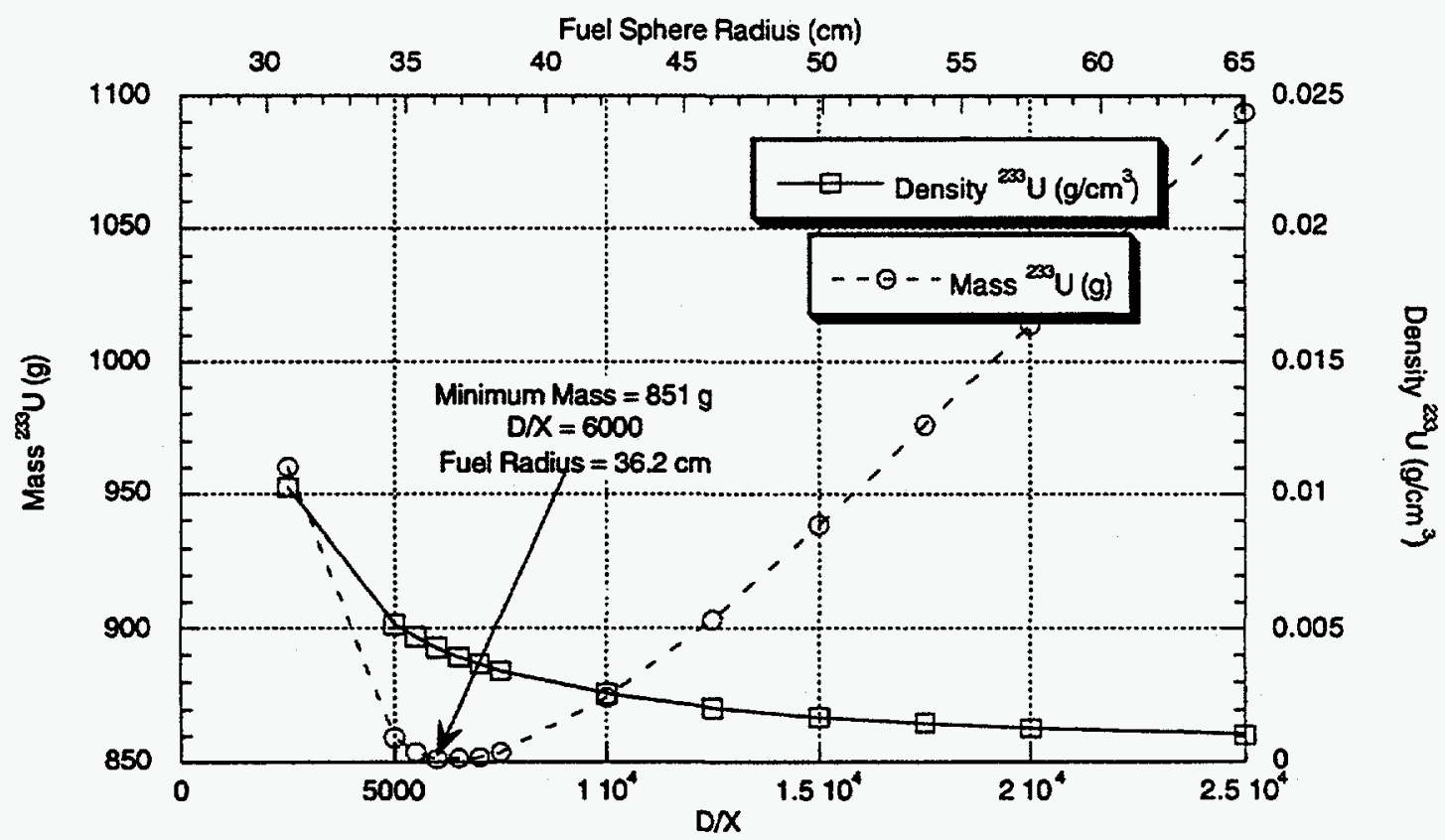

Figure E-7 Fissile masses and densities of water-reflected ${ }^{233} \mathrm{U}$ and $\mathrm{D}_{2} \mathrm{O}$ spheres; $\mathrm{k}_{\text {eff }} \approx 0.95$ (radius scale is approximate) 



\section{APPENDIX F}

Discussion of Radioactivity Exemption Limit of $70 \mathrm{~Bq} / \mathrm{g}(0.002 \mu \mathrm{Ci} / \mathrm{g})$

Applied to Fissile-Material Systems 



\section{APPENDIX F}

\section{Discussion of Radioactivity Exemption Limit of $70 \mathrm{~Bq} / \mathrm{g}(0.002 \mu \mathrm{Ci} / \mathrm{g})$ Applied to Fissile-Material Systems}

Consider the exemption limit of $70 \mathrm{~Bq} / \mathrm{g}$ in the current $10 \mathrm{CFR} 71$ requirement $(\$ 71.10)$ and the 1985 Edition of the IAEA Regulations. ${ }^{235} \mathrm{U}$ has a specific activity of $8 \times 10^{4} \mathrm{~Bq} / \mathrm{g}$; thus, there can be $8.75 \times 10^{-4} \mathrm{~g}$ of ${ }^{235} \mathrm{U}$ per $\mathrm{g}$ of material and remain below the $70 \mathrm{~Bq} / \mathrm{g}$ limit (assuming the material radioactivity is all from ${ }^{235} \mathrm{U}$ ). Figure $\mathrm{F}-1$ is taken from Figure 45 of LA-10860-MS and has a set of unreflected U(93) critical-mass curves as a function of U(93) volume fraction in five different moderators: $\mathrm{BeO}$, beryllium, graphite, $\mathrm{D}_{2} \mathrm{O}$, and water. With the specified ${ }^{235} \mathrm{U}$ mass fraction as a limit, the critical-mass curves from LA-10860-MS were used to develop Table F-1 below.

The first column of Table F-1 lists the selected material interpreted to have the characteristics needed to create a critical system at very low mass fractions. The second column lists the density of the material as provided in the figure of criticalmass curves. (For consistency with the critical data shown, the densities listed in the figure were used throughout. Note the density specified in the figure for ${ }^{235} \mathrm{U}$ is $17.53 \mathrm{~g} / \mathrm{cm}^{3}$.) The uranium volume fraction associated with the limiting uranium mass fraction $\left(8.75 \times 10^{-4}\right)$ is obtained by multiplying the mass fraction by a ratio of the material density to the uranium density (e.g., 2.86/17.53 for BeO). Using this volume fraction and Figure F-1, one can obtain (often with necessary extrapolation) a critical mass of $U(93)$ associated with the volume fraction. This critical-mass value is provided for each moderator material. The volume of material needed to accumulate the critical mass is determined by dividing the critical mass by the limiting uranium mass fraction $\left(8.75 \times 10^{-4}\right)$ and multiplying by the material density. The critical concentration can be obtained from the mass fraction and the material density and be compared to the fissile exemption value of $5 \mathrm{~g}$ per $10 \mathrm{~L}\left(5 \times 10^{-4} \mathrm{~g} / \mathrm{cm}^{3}\right)$ to quickly confirm that the mass fraction associated with $70 \mathrm{~Bq} / \mathrm{g}$ converts to a concentration that would not be allowable under the fissile exemption constraint. (However, a study of the figure would indicate that a value less than $70 \mathrm{~Bq} / \mathrm{g}$ could provide a critical-mass concentration that is less than the fissile-exemption limit.)

For the $\mathrm{BeO}$ system, the $800-\mathrm{L}$ volume is only about $28 \mathrm{ft}^{3}$. A reflected system would provide lower critical-mass values and thus lower material volumes. Although still not a very practical system (due to the scarcity of large amounts of these materials), these situations provide a potential "loophole" in the regulations.

The figure is also a valuable aid to an understanding of these systems. Water systems cannot be made critical below a volume fraction of about $7 \times 10^{-4}$. However, the lack of neutron absorption for the remaining materials means that the limiting volume fraction (minimum critical mass) is at a much lower value. Finally, assuming enriched uranium and the higher associated activities (due to ${ }^{234} \mathrm{U}$, see Table A-3 of 10 CFR 71) would yield much lower volume fractions than shown in Table F-1. 


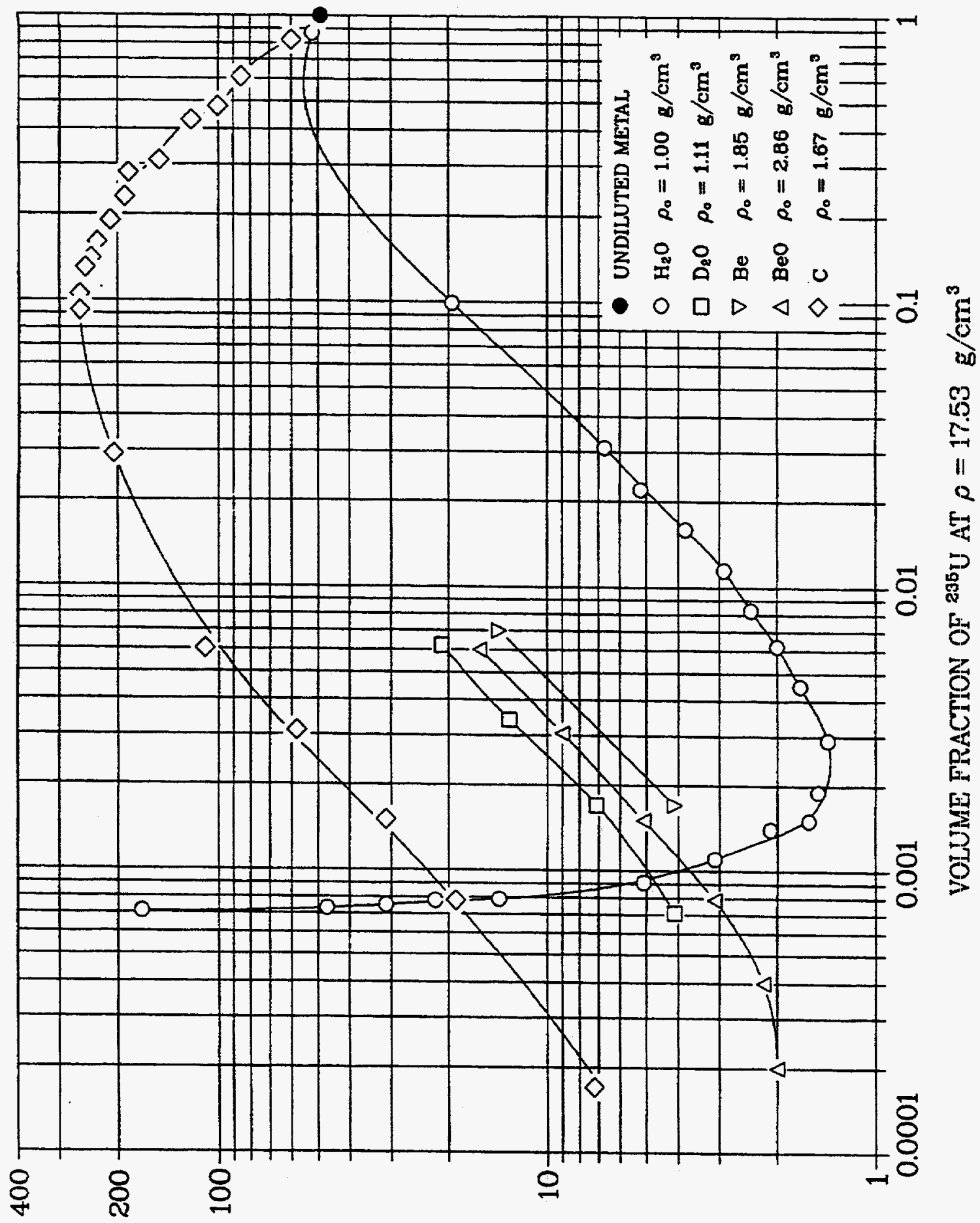


Table F-1 Critical data for U(93) in various materials, assuming limit of $70 \mathrm{~Bq} / \mathrm{g}$ radioactivity $\left(8.75 \times 10^{-4} \mathrm{~g}^{235} \mathrm{U} / \mathrm{g}\right.$ material)

\begin{tabular}{|c|c|c|c|c|c|}
\hline Material, $\mathrm{M}$ & $\begin{array}{c}\text { Material Density } \\
\left(\mathrm{g} / \mathrm{cm}^{3}\right)\end{array}$ & $\begin{array}{c}\text { Volume } \\
\text { Fraction, } \\
{ }^{235} \mathrm{U} / \mathrm{M}\end{array}$ & $\begin{array}{c}\text { Critical Mass } \\
\left(\mathrm{g}^{235} \mathrm{U}\right)\end{array}$ & $\begin{array}{c}\text { Volume for } \\
\text { Critical Mass, } \\
\text { Liters }\end{array}$ & $\begin{array}{c}\text { Critical } \\
\text { concentration } \\
\mathrm{g}^{235} \mathrm{U} / \mathrm{cm}^{3} \mathrm{M}\end{array}$ \\
\hline $\mathrm{BeO}$ & 2.86 & $1.4 \times 10^{-4}$ & 2,000 & 800 & $2.5 \times 10^{-3}$ \\
\hline Beryllium & 1.85 & $9.2 \times 10^{-5}$ & $\begin{array}{c}1,000 \text { to } 1,500 \\
\text { (est.) }\end{array}$ & $\begin{array}{c}620 \text { to } 930 \\
\text { (est.) }\end{array}$ & $1.6 \times 10^{-3}$ \\
\hline $\mathrm{D}_{2} \mathrm{O}$ & 1.11 & $5.5 \times 10^{-5}$ & 2,000 (est.) & 2,060 & $9.7 \times 10^{-4}$ \\
\hline Graphite & 1.67 & $8.3 \times 10^{-5}$ & $\begin{array}{c}5,000 \text { to } 6,000 \\
(\text { est.) }\end{array}$ & 3,420 to 4,100 & $1.46 \times 10^{-3}$ \\
\hline Water & 1.0 & $5 \times 10^{-5}$ & $\mathrm{NA}^{a}$ & $\mathrm{NA}^{a}$ & $\mathrm{NA}^{a}$ \\
\hline
\end{tabular}

${ }^{a} \mathrm{NA}=$ not applicable. 



\section{APPENDIX G}

Recommended New Criteria for Fissile-Material Exemptions 


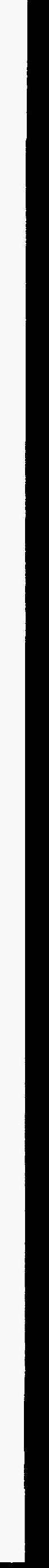




\section{APPENDIX G}

\section{Recommended New Criteria for Fissile-Material Exemptions}

The fissile-material exemptions provided in $\$ 71.53$ (a) currently have a consignment mass limit and a very limiting restriction for selected, low-neutron-absorbing (special) moderators. The assessment of Sect. 4 notes that the consignment mass limit is not sufficient unless conveyance control is also provided. As noted in Sect. 4.0 and recommended in Sect. 5.3, a new criteria specifying allowed ratios of fissile-material mass to nonfissile-material mass would eliminate both the need for conveyance control and the need for a severe restriction on selected special moderators. As indicated in Sect. 5.3 and Table 5-4, the variable mass ratios (fissile to nonfissile) also include complementary criteria: a limiting mass per package; exclusion of $\mathrm{Be}, \mathrm{C}$, or $\mathrm{D}_{2} \mathrm{O}$ as part of the nonfissile mass determination; inclusion of only noncombustible, insoluble-in-water material as part of the nonfissile mass determination; and $\$ 71.43$ packaging standards for one exemption. This appendix discusses each of the three exemption criteria proposed as a replacement for the criteria presently in $\$ 71.53(\mathrm{a})$.

The exemptions of Sect. G.2 and Sect. G.3 were designed to address the practical need for shipping material with low concentrations of fissile material [similar to the existing $\$ 71.53(\mathrm{a})(2)-(3)$ ] but with control provided on a more predictable nonfissile mass rather than a volume (which can contain noncombustible, insoluble-in-water material or no material at all). Again, with this type of criteria specification, it is judged that the restriction on selected special moderators is not needed, except that these moderators cannot be used in the nonfissile mass determination.

\section{G.1 Exemption for Packages with Small Fissile-Material Mass}

This proposed exemption corresponds to $\$ 71.53(\mathrm{a})(1)$ and would enable shippers to transport small quantities of fissile material with sufficient nonfissile mass added to prevent criticality even with large accumulation of similar packages. The new suggested requirement calls for $200 \mathrm{~g}$ of noncombustible, insoluble-in-water material (excluding $\mathrm{Be}, \mathrm{C}$, or $\mathrm{D}_{2} \mathrm{O}$ ) for every $1 \mathrm{~g}$ of fissile material. This specification ensures that large numbers of packages, containing $15 \mathrm{~g}$ of fissile material per package, will remain safely subcritical because of the fissile material density reduction by stable materials which are not special moderators. For example, $1 \mathrm{~g}$ of optimally moderated ${ }^{235} \mathrm{U}$ in a mixture at about $0.05 \mathrm{~g}{ }^{235} \mathrm{U} / \mathrm{cm}^{3}$ occupies a volume of about $20 \mathrm{~cm}^{3}$. Two hundred grams of aluminum metal at about $2.7 \mathrm{~g}$ of aluminum/ $/ \mathrm{cm}^{3}$ occupies a volume of about $74 \mathrm{~cm}^{3}$. As specified therefore, the $15 \mathrm{~g}$ of ${ }^{235} \mathrm{U}$ per package will have a diluted volume of about $1,410 \mathrm{~cm}^{3}$ at a density of about $0.01 \mathrm{~g}^{235} \mathrm{U} / \mathrm{cm}^{3}$-a density reduction by a factor of 5 . Though aluminum is a minor absorber of low-energy neutrons, most other common materials of packaging have moderate neutron-absorbing properties that further ensure safely subcritical accumulations of such packages. The increase in the subcritical mass of $614 \mathrm{~g}$ of optimally moderated ${ }^{235} \mathrm{U}$, permitted by the reduction of fissile material density, is related to the ratio of the densities to the power of 1.8 (see Ref. 17, pp. 19-22). Given the density reduction of 5 in the above example, the adjusted subcritical mass becomes $11,125 \mathrm{~g}$ of ${ }^{235} \mathrm{U}$, requiring in excess of about 741 packages (containing $15 \mathrm{~g}$ of ${ }^{235} \mathrm{U}$ per package) to exceed the determined equivalent quantity of material. The lack of stringent normal conditions of transport and hypothetical accident conditions for packaging requires that noncombustible, insoluble-in-water materials be used to ensure the presence and/or minimize the reconfiguration of the fissile material under such conditions.

\section{G.2 Exemption for Packages not Meeting Standards for NCT}

The second proposed exemption criteria is specified to allow $350 \mathrm{~g}$ of fissile material per package, providing there is no more than $1 \mathrm{~g}$ of fissile material per $2000 \mathrm{~g}$ of noncombustible, insoluble-in-water material in the packaging and contents (excluding $\mathrm{Be}, \mathrm{C}$, and $\mathrm{D}_{2} \mathrm{O}$ ). Thus, a more liberal package mass limit is allowed by ensuring increased dilution with poorly 
moderating materials. As in the example above for the 15 -g per package exemption, $1 \mathrm{~g}$ of optimally moderated ${ }^{235} \mathrm{U}$ in a mixture at about $0.05 \mathrm{~g}{ }^{235} \mathrm{U} / \mathrm{cm}^{3}$ occupies a volume of about $20 \mathrm{~cm}^{3}$. Two thousand grams of aluminum metal at about $2.7 \mathrm{~g}$ of aluminum $/ \mathrm{cm}^{3}$ occupies a volume of about $741 \mathrm{~cm}^{3}$. As specified therefore, the allowable $350 \mathrm{~g}$ of ${ }^{235} \mathrm{U}$ per package will have a diluted volume of about $266,350 \mathrm{~cm}^{3}$ for a density of about $0.0013 \mathrm{~g}^{235} \mathrm{U} / \mathrm{cm}^{3}$-a density reduction by a factor of about 38. Though aluminum is a minor absorber of low-energy neutrons, most other common materials of packaging have moderate neutron-absorbing properties that further ensure safely subcritical accumulations of such packages. As in the example for Sect. G.1, the increase in the subcritical mass of $614 \mathrm{~g}$ of optimally moderated ${ }^{235} \mathrm{U}$, permitted by the reduction of fissile material density, is related to the ratio of the densities to the power of 1.8 (see Ref. 17, pp. 19-22). Civen the density reduction of 38 , the adjusted subcritical mass becomes $428,330 \mathrm{~g}$ of ${ }^{235} \mathrm{U}$, requiring in excess of about 1,224 packages (containing $350 \mathrm{~g}$ of ${ }^{235} \mathrm{U}$ per package) to exceed the determined equivalent quantity of material. Additionally, the effective density of $0.0013 \mathrm{~g} \mathrm{~g}^{235} \mathrm{U} / \mathrm{cm}^{3}$ is about one order of magnitude less than the minimum critical concentration (see Ref. 17). Again, the lack of stringent normal conditions of transport and hypothetical accident conditions for packaging requires that noncombustible, insoluble-in-water materials be used to ensure the presence and/or minimize the reconfiguration of the fissile material under such conditions.

\section{G.3 Exemption for Packages Meeting Standards for NCT}

The final suggested new exemption requirement would permit $350 \mathrm{~g}$ of fissile material, providing there is no more than $1 \mathrm{~g}$ of fissile material per $200 \mathrm{~g}$ of noncombustble, insoluble-in-water material in the packaging and contents (excluding Be, $\mathrm{C}$, and $\mathrm{D}_{2} \mathrm{O}$ ) and the package is designed for integrity under NCT. Thus, the dilution of the fissile material is the same as that specified for the packages with small quantities $(1: 200)$, but the increased fissile mass per package is allowed based on packaging credit for meeting the requirements of $\$ 71.43$. As in the example used previously, $1 \mathrm{~g}$ of optimally moderated ${ }^{235} \mathrm{U}$ in a mixture at about $0.05 \mathrm{~g}{ }^{235} \mathrm{U} / \mathrm{cm}^{3}$ occupies a volume of about $20 \mathrm{~cm}^{3}$. Two hundred grams of aluminum metal at about $2.7 \mathrm{~g}$ of aluminum $/ \mathrm{cm}^{3}$ occupies a volume of about $74 \mathrm{~cm}^{3}$. As specified therefore, the allowable $350 \mathrm{~g}$ of ${ }^{235} \mathrm{U}$ per package will have a diluted volume of about $32,900 \mathrm{~cm}^{3}$ for a density of about $0.01 \mathrm{~g}{ }^{235} \mathrm{U} / \mathrm{cm}^{3}$, a density reduction by a factor of about 5 . Though aluminum is a minor absorber of low-energy neutrons, most other common materials of packaging have moderate neutron-absorbing properties that further ensure safely subcritical accumulations of such packages. As indicated above, the increase in the subcritical mass of $614 \mathrm{~g}$ of optimally moderated ${ }^{235} \mathrm{U}$, permitted by the reduction of fissile material density, is related to the ratio of the densities to the power of 1.8. Given the density reduction of 5 in this example, the adjusted subcritical mass becomes $11,125 \mathrm{~g}$ of ${ }^{235} \mathrm{U}$, requiring in excess of about 31.7 packages (containing $350 \mathrm{~g}$ of ${ }^{235} \mathrm{U}$ per package) to exceed the safely subcritical quantity of material. However, the requirement for packages to withstand normal conditions of transport and the dilution requirement for noncombustible, insoluble-in-water materials to be present in the packages minimizes the reconfiguration of the $0.01-\mathrm{g}$ fissile material $/ \mathrm{cm}^{3}$, which is on the order of the minimum critical concentration of ${ }^{235} \mathrm{U}$ (i.e., $0.0123 \mathrm{~g}^{235} \mathrm{U} / \mathrm{cm}^{3}$ ). 
1. REPORT NUMBER

(Assigned by NRC, Add Vol., Supp., Rev., and Addendum Numbers, if any.)

\section{BIBLIOGRAPHIC DATA SHEET}

(See instructions on the reverse)

\section{TITLE AND SUBTITLE}

Assessment and Recommendations for Fissile-Material Packaging Exemptions and General Licenses Within 10 CFR Part 71

5. AUTHOR(S)

C. V. Parks, C. M. Hopper, and J. L. Lichtenwalter
NUREG/CR-5342

ORNLTM-13607

\begin{tabular}{l|l} 
MONTH & YEAR \\
\hline
\end{tabular}

July 1998

4. FIN OR GRANT NUMBER

B0009

6. TYPE OF REPORT

Technical

7. PERIOD COVERED (Inclusive Dates)
3. DATE REPORT PUBLISHED

8. PERFORMING ORGANIZATION - NAME AND ADDRESS (If NRC, provide Division, Ofice or Region, U.S. Nuclear Regulatory Commission, end meiling address; if contracto, provide name and mailing addross.)

Oak Ridge National Laboratory

Oak Ridge, TN 37831-6370

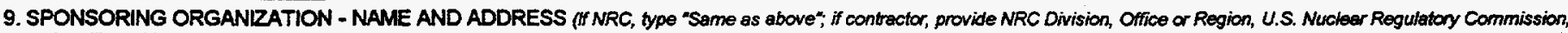
and mailing address.)

\section{Spent Fuel Project Office}

Office of Nuclear Material Safety and Safeguards

U.S. Nuclear Regulatory Commission

Washington, DC 20555-0001

10. SUPPLEMENTARY NOTES

P. G. Brochman, NRC Project Manager

11. ABSTRACT (200 words or less)

This report provides a technical and regulatory assessment of the fissile material general licenses and fissile material exemptions within Title 10 of the Code of Federal Regulations Part 71. The assessment included literature studies and calculational analyses to evaluate the technical criteria; review of current industry practice and concerns; and a detailed evaluation of the regulatory text for clarity, consistency and relevance. Recommendations for potential consideration by the Nuclear Regulatory Commission staff are provided. The recommendations call for a simplification and consolidation of the general licenses and a change in the technical criteria for the first fissle material exemptions.

12. KEY WORDSIDESCRIPTORS (List words or phrases that will assist researchers in locating the report.)

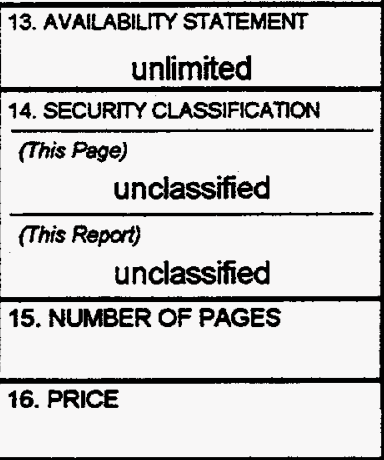

